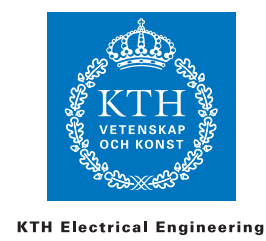

\title{
Wind power integration in power systems with transmission bottlenecks
}

JULIJA MATEVOSYAN

Doctoral Thesis in Electrical Systems

Royal Institute of Technology

School of Electrical Engineering

Electric Power Systems

Stockholm, 2006 
TRITA-ETS 2006:041

ISSN-1650-674X

ISBN-91-7178-445-4
School of Electrical Engineering Electric Power Systems Royal Institute of Technology S-100 44 Stockholm SWEDEN

Akademisk avhandling som med tillstånd av Kungl Tekniska Högskolan fram lägges till offentlig granskning för avläggande av doktors examen torsdagen den 3 oktober $2006 \mathrm{kl} 10.00$ i sal V2, Teknikringen 76, Kungl Tekniska Högskolan, Stockholm.

(C) Julija Matevosyan, 2006

Tryck: Universitetsservice US AB 


\section{Abstract}

During the last two decades, the increase in electricity demand and environmental concern resulted in fast growth of power production from renewable sources. Wind power is one of the most efficient alternatives. Due to the rapid development of wind turbine technology and increasing size of wind farms, wind power plays a significant part in the power production mix of Germany, Spain, Denmark, and some other countries.

The best conditions for the development of wind farms are in remote, open areas with low population density. The transmission system in such areas might not be dimensioned to accommodate additional large-scale power infeed. Furthermore a part of the existing transmission capacity might already be reserved for conventional power plants situated in the same area.

In this thesis four alternatives for large-scale wind power integration in areas with transmission bottlenecks are considered. The first possibility is to revise the methods for calculation of available transmission capacity. The second solution for large-scale integration of wind power in such areas is to reinforce the network. This alternative, however, may be expensive and time consuming. As wind power production depends on the wind speed, the full load hours of wind turbine generator are only 2000-4000 hours per year. Therefore reinforcing a transmission network in order to remove a bottleneck completely is often not economically justified. Wind energy curtailments during congestion situations is then the third solution for large-scale wind power integration with less or no grid reinforcement. The fourth solution is to store excess wind energy. Pumped hydro storage or battery storage for the large-scale wind farms are still rather expensive options, but existing conventional power plants with fast production control capabilities and sufficient storage capacity, e.g., hydro power plants, could be used for this purpose.

As there is a lot of research work on the first two alternatives, the thesis provides a review and summarizes the main conclusions from the existing work. The thesis is then directed towards the development of the methods for estimation of wind energy curtailments, evaluation of wind energy storage possibility in hydro reservoirs and development of short term hydro power production planning methods, considering coordination with wind power.

Additionally in the thesis the strategy that minimizes imbalance costs of a wind power utility, trading wind power on the short term power market is elaborated and analyzed 



\section{Acknowledgements}

This doctoral thesis concludes my work carried out at the School of Electrical Engineering, Royal Institute of Technology (KTH) since November 2001.

First of all, I would like to express my deepest gratitude to my supervisor Prof. Lennart Söder for fruitful discussions, guidance, encouragement throughout this project, as well as valuable comments on this document. I endlessly appreciate understanding and countenance with which he supported me in difficult moments throughout these years.

My sincere gratitude to Hans Auer and Prof. Reinhard Haas for hosting me at Energy Economics group of Vienna Technical University, during the last stage of this project. Thanks to all my new colleges there for creating good working environment, as well as for their great friendship.

Special thanks to my colleagues and friends Valery Knyazkin and Thomas Ackermann for contribution of knowledge, valuable advice and countenance during the work on the project.

Many thanks to all my colleagues in the division of Electric Power Systems for providing stimulating ambience and help with different aspects of this project. Special thanks to Katherine Elkington for invaluable comments on the last paper. My sincere appreciation to Margaretha Surjadi, Eva Pettersson and Lillemor Hyllengren for their help in many practical matters.

I specially wish to thank Bo Wrang, Urban Axelsson and Viktoria Neimane at Vattenfall, Christer Bäck and Stefan Arnborg at Svenska Kraftnät, Hans Bergström at Uppsala University for provision of test data, valuable reference literature, contribution of knowledge and new ideas at different stages of this project.

Financial support of the project from Vindforsk Research Program is gratefully acknowledged.

My deepest respect and gratitude to Prof. Antanas Sauhatas, my undergraduate diploma supervisor at Institute of Power Engineering, Riga 
Technical University for his guidance, encouragement, and valuable ideas throughout my professional life and, particulary, concerning this project.

Finally, my most sincere gratitude to my family and friends for support and understanding. I am endlessly indebted to my husband Norayr for his patience, love, encouragement, and valuable advice concerning the project. 


\section{Contents}

1 Introduction 1

1.1 The outline of the thesis . . . . . . . . . . . . . 4

1.2 Contribution of the thesis . . . . . . . . . . 7

2 Background $\quad 9$

2.1 Wind turbine generator design concepts . . . . . . . . . . . 10

2.2 Current state of wind power in Sweden . . . . . . . . . . 13

2.3 Overview of the Swedish power system . . . . . . . . . 14

2.4 Overview of the Nordic power market . . . . . . . . . . . 16

2.4 Spot market . . . . . . . . . . . . . . 16

2.4 .2 Elbas . . . . . . . . . . . . . . . . . 16

2.4.3 Regulating market . . . . . . . . . . . . . . 17

2.4.4 Balance settlement . . . . . . . . . . . . . . 17

3 Transmission limits $\quad 19$

3.1 Thermal limits . . . . . . . . . . . . . . . . . . . . . . . . 19

3.2 Voltage stability limit . . . . . . . . . . . . . . 20

3.3 Rotor angle stability . . . . . . . . . . . . . . . . . 22

3.4 Determination of cross-border transmission capacity . . . . 23

3.5 Determination of TC within the country . . . . . . . . 25

3.6 Measures to increase TC . . . . . . . . . . . . . . . 25

3.7 Congestion management . . . . . . . . . . . . . . . 27

3.8 Wind power impact on transmission capacity . . . . . . . 28

4 Requirements for connection of wind turbines 33

4.1 Active power control . . . . . . . . . . . . . . . 36

4.2 Frequency range and control . . . . . . . . . . . . . . 37

vii 
4.3 Reactive power control . . . . . . . . . . . . . . . . 39

4.4 Transient fault and voltage operating range . . . . . . . . . . 40

4.5 Power quality . . . . . . . . . . . . . . . . . . . . . . 43

4.6 Discussion of the connection requirements . . . . . . . . 43

5 Wind energy curtailments $\quad 45$

5.1 General assumptions . . . . . . . . . . . . . . . . . 47

5.2 Simplified estimation method . . . . . . . . . . . . 48

5.3 Probabilistic estimation method . . . . . . . . . . . . 49

5.3.1 Discrete probabilistic method . . . . . . . . . 50

5.3 .2 Continuous probabilistic method . . . . . . . . . . 52

5.3 .3 Direct method ................ 56

5.3 .4 Comparison of estimation methods . . . . . . . 58

5.4 Case study, estimation of wind energy curtailments . . . . . 59

5.4 .1 General results . . . . . . . . . . . . 60

5.4 .2 Economical evaluation .............. 61

5.4.3 Impact of the assumptions on calculation results . . . 63

6 Coordination of wind power and hydro power 65

6.1 Overview of previous research . . . . . . . . . 66

6.2 Coordination strategies for wind power and hydro power . . . 68

6.3 Overview of the planning algorithm . . . . . . . . . . . . 69

6.4 Mathematical formulation of the planning algorithm . . . . . 74

6.4.1 Base case hydro power production planning . . . . . . 74

6.4.2 Wind power forecast error scenarios . . . . . . . . 78

6.4.3 Power market price model . . . . . . . . . . . . . 81

6.4.4 Scenario reduction and bundling ... . . . . . 83

6.4.5 Hydro power re-planning coordinated with wind power 84

6.4.6 Evaluation . . . . . . . . . . . . . . . . 92

6.5 Case study . . . . . . . . . . . . . . . . . . . . . . . . 95

6.6 Conclusions . . . . . . . . . . . . . . . . . . . . 96

7 Minimization of imbalance cost $\quad 101$

7.1 Overview of previous research . . . . . . . . . . . . 102

7.2 Overview of the bidding strategy . . . . . . . . . . . . 103

7.3 Mathematical formulation . . . . . . . . . . . . . 105

7.3.1 Imbalance price scenarios . . . . . . . . . . . . . . 105

7.3.2 Optimization problem ............. 106 
7.3.3 Evaluation of bidding strategy . . . . . . . . . . 108

7.4 Case study . . . . . . . . . . . . . . . . . . . . . 108

7.5 Conclusions . . . . . . . . . . . . . . . . . . . 109

$\begin{array}{ll}\text { Bibliography } & 111\end{array}$

A Mathematical definitions 123

A.1 Correlation Coefficient . . . . . . . . . . . . . . . . . . . . 123

A.2 The Weibull distribution . . . . . . . . . . . . . . . . 124

$\begin{array}{ll}\text { B Publications } & 127\end{array}$ 



\section{List of Figures}

1.1 Alternatives for large-scale wind power integration in power systems with transmission bottlenecks . . . . . . . . . . 2

2.1 Technology development of Vestas wind turbines . . . . . . . . . 10

2.2 Wind energy conversion system . . . . . . . . . . . . . . 11

2.3 Power curves of pitch and stall controlled WTGs . . . . . . . . 12

2.4 a. Wind power in Sweden; b. Existing transmission limitations in Nordic power system . . . . . . . . . . . . . . . 13

2.5 Duration curves of power transmission through Cross section 2 . 15

3.1 Dependence of current-carrying capacity on wind speed and ambient temperature for ACSR conductor . . . . . . . . . . 20

3.2 Nose curve for the two-terminal network with different load power factors . . . . . . . . . . . . . . . 21

3.3 Relationship between receiving end voltage, line length, and load of the transmission line . . . . . . . . . . . . . . . 22

3.4 Available transmission capacity determination . . . . . . . . . . . 24

3.5 Power curve for BONUS $600 \mathrm{~kW}$, depending on ambient conditions 28

3.6 Power curve of a modern large-scale wind turbine and smoothed WF power curve . . . . . . . . . . . . . . . . . . . . . . . . . . 29

4.1 Requirements for frequency range and frequency control of WF. . 38

4.2 Comparison of power factor ranges as required by the different grid codes. . . . . . . . . . . . . . . . . 39

4.3 Requirements for voltage operating range of WF. . . . . . . . . . 42

5.1 Power system with hydro and wind power production on the same side of the bottleneck . . . . . . . . . . . . . . . . 46 
5.2 Wind power production, actual transmission, desired transmission duration curves and transmission limit for simplified estimation method . . . . . . . . . . . 48

5.3 Wind power production, actual transmission, desired transmission duration curves and transmission limit for discrete probabilistic estimation method . . . . . . . . . . . 51

5.4 Wind power production, actual transmission, desired transmission duration curves and transmission limit for discrete probabilistic estimation method, considering WTG availability . 52

5.5 Power curve of the WTG with rated power $610 \mathrm{~kW}$ approximated with, smooth, increasing function. . . . . . . . . . 54

5.6 Example of piecewise linear approximation of overall efficiency curve of the WTG with rated power $610 \mathrm{~kW}$. . . . . . . . 56

5.7 Wind power production, actual transmission and desired transmission duration curves for continuous and for discrete probabilistic estimation methods . . . . . . . . . 57

5.8 The percentage of wind energy that has to be spilled at various wind power penetration levels, estimated with simplified method, discrete probabilistic method and direct method . . . . . . . 60

5.9 Wind energy curtailment expressed in MSEK (Mkr) per year, at energy cost of $0.3 \mathrm{SEK} / \mathrm{kWh}$ and $0.4 \mathrm{SEK} / \mathrm{kWh} \ldots \ldots . . . .662$

6.1 Flow chart of the daily hydro power planning coordinated with wind power . . . . . . . . . . . . . 70

6.2 Schematic example of the spot price scenario tree. . . . . . . 71

6.3 Hydropower generation as a function of discharge . . . . . . . . 75

6.4 Standard deviations of the real wind forecast error and standard deviations from ARMA series . . . . . . . . . . . . . 79

6.5 Example of wind power production scenarios for $60 \mathrm{MW}$ wind farm for the planning day (Thursday in this example) and for the rest of the ongoing week included in planning . . . . . . . 80

6.6 Construction of a scenario tree by successive scenario reduction

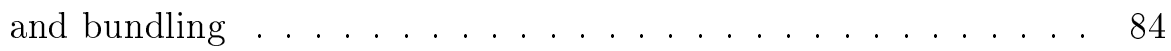

6.7 Schematic structure of the scenario tree . . . . . . . . . . 86

6.8 Evaluation algorithm of the short term hydro power production planning coordinated with wind power (evaluation period 1 year) 93

6.9 Studied HPP system of Ume river . . . . . . . . . . . . . 96 
7.1 Flowchart for the bidding strategy and its evaluation. . . . . . . 104 



\section{List of Tables}

2.1 Wind power capacity in some European countries . . . . . . . 10

5.1 Comparison of estimation methods for wind energy curtailments 58

5.2 The percentage of spilled wind energy at various levels of wind power penetration . . . . . . . . . . . . 61

6.1 Differences between Publications E-F . . . . . . . . . . . 98 



\title{
List of Abbreviations and Definitions
}

Terms that are defined bellow (after the list of abbreviations) are emphasized when they appear in the text for the first time.

\author{
AAC Already Allocated Transmission Capacity \\ ACSR Aluminium Stranded Conductors Steal-Reinforced \\ ARMA Autoregressive Moving Average \\ ARIMA Autoregressive Integrated Moving Average \\ ATC Available Transmission Capacity \\ ct Eurocent \\ EU European Union \\ FACTS Flexible AC Transmission Systems \\ GCR Grid Connection Requirements \\ HE Hour Equivalent, water flow $1 \mathrm{~m}^{3} / \mathrm{s}$ for 1 hour \\ HVAC High Voltage Alternating Current \\ HVDC High Voltage Direct Current \\ HPP Hydropower Plant \\ NPS Negative Phase Sequence \\ NTC Net Transmission Capacity \\ NTNU Norwegian University of Science and Technology \\ RL Reservoir limit \\ RPM Revolution per minute \\ SEK Swedish Krona \\ SvK Svenska Kraftnät, Swedish Transmission System Operator \\ TDC Transmission Duration Curve \\ TC Transmission Capacity
}


xviii

TSO Transmission System Operator

WF Wind Farm

WPDC Wind Power Production Duration Curve

WTG Wind Turbine Generator

transmission bottleneck

or congestion

full load hours

transmission reliability

margin

recourse variable
A situation when it is economically or technically motivated to transfer more power than available transmission capacity allows.

Annual energy production of power plant in MWh divided by rated power of the power plant in MW. A security margin in which numerous sources of uncertainty regarding determination of $\mathrm{TC}$ are summarized. Transmission reliability margin is subtracted from total transmission capacity. In the stochastic optimization problem, a variable introduced in the stochastic constraints which measures the corresponding violation (if any) of these constraints. Since violation depends on the realization of some stochastic parameter, so does the corresponding recourse variable, i.e., the recourse variables are random variables [56]. 


\section{List of Symbols}

$P_{R}, P_{S} \quad$ Active power at the resp. receiving and sending end of two-terminal network [MW];

$Q_{R}, Q_{S} \quad$ Reactive power at the resp. receiving and sending end of two-terminal network [MVAr];

$U_{R}, U_{S} \quad$ Voltage at the resp. receiving and sending end of two-terminal network [V];

$P_{o} \quad$ Natural load $[\mathrm{MW}]$

$f \quad$ Electric frequency $[\mathrm{Hz}]$;

\section{Nomenclature for estimation of wind energy curtailments}

$\begin{array}{ll}v & \text { Wind speed }[\mathrm{m} / \mathrm{s}] ; \\ f_{V}(v) & \text { Probability density function of the wind speed; } \\ \alpha & \text { Scale parameter of the Weibull distribution }[\mathrm{m} / \mathrm{s}] ; \\ \beta & \text { Shape parameter of the Weibull distribution; } \\ A & \text { Swept area of the wind turbine rotor }\left[\mathrm{m}^{2}\right] ; \\ \rho & \text { Air density }\left[\mathrm{kg} / \mathrm{m}^{3}\right] ; \\ c_{p} & \text { Power coefficient; } \\ P_{w} & \text { Power production of wind turbine generator }[\mathrm{W}] ; \\ W_{s p i l l} & \text { Curtailed wind energy [MWh]; } \\ W_{w} & \text { Produced wind energy [MWh]; } \\ t & \text { Number of hours (for the duration curves); } \\ T & \text { Time period [h]; } \\ \eta & \text { Percentage of curtailed wind energy [\%]; } \\ C & \text { Transmission limit [MW]; } \\ F_{X}(x) & \text { Distribution function of variable } X ;\end{array}$

xix 
$f_{X}(x) \quad$ Probability density/mass function of variable $X$;

$m \quad$ Mean value of the Gaussian distribution;

$\sigma \quad$ Standard deviation of the Gaussian distribution;

$\bar{v} \quad$ Mean value of the Weibull wind speed distribution;

$\sigma_{V} \quad$ Standard deviation of the Weibull wind speed distribution;

$M \quad$ Number of wind turbine generators within a wind farm;

$k \quad$ Time step;

$P_{t} \quad$ Power transmission [MW];

$P_{d} \quad$ Desired power transmission [MW];

$P_{\text {spill }} \quad$ Wind energy curtailment per time step [MW];

\section{Nomenclature for wind-hydro coordination}

Indexes and Index sets

$K \quad$ Index set of all hours in the planning period;

$K_{\text {last }}^{\text {day }} \quad$ Last hour in the planning day $K_{\text {last }}^{\text {day }} \in K$;

$K_{\text {last }} \quad$ Last hour in the planning period $K_{\text {last }} \in K$;

$I \quad$ Index set of hydro power plants;

$I_{c} \quad$ Index set of HPPs sharing same transmission; capacity with wind farm;

$S_{i} \quad$ Index set of the segments of the HPP production; curve, plant $i$;

$\Omega_{i} \quad$ Index set of the HPPs directly upstream of plant $i$;

$N \quad$ Index set of nodes of the power price scenario tree;

$M \quad$ Index set of nodes of the wind power production scenario tree;

$K_{c}(n, m) \quad$ Index set of congestion hours, for nodes $n$ and $m, K_{c} \subset K$;

$K_{n c}(n, m)$ Index set of hours without congest., for nodes $n, m, K_{n c} \subset K$;

\section{Parameters}

$\alpha, \beta \quad$ Parameters of the wind speed forecast error model; 
$v(k, m) \quad$ Wind speed, hour $\mathrm{k}$, node $\mathrm{m}[\mathrm{m} / \mathrm{s}]$;

$v^{f}(k) \quad$ Wind speed forecast, hour $\mathrm{k}[\mathrm{m} / \mathrm{s}]$;

$P_{i}^{h}(k) \quad$ Hydro power production in stations $I_{c}$ without coordination, historical data;

$D(k) \quad$ Hourly load [MW];

$\bar{P}_{w}(k, m) \quad$ Maximum power production of the WF, hour $k$, node $m$ [MW];

$\bar{P}_{w}^{h}(k) \quad$ Maximum power production of the WF, hour $k$, historical data $[\mathrm{MW}]$;

$\bar{P}_{12} \quad$ Maximum transmission capacity [MW];

$\bar{u}_{i s} \quad$ Maximum discharge in plant $i$, segment $s[\mathrm{HE}]$;

$\mu_{i s} \quad$ Prod. equiv. in plant $i$, segment $s[\mathrm{MWh} / \mathrm{HE}]$;

$\nu_{i} \quad$ Prod. equiv. of future generation in plant $i[\mathrm{MWh} / \mathrm{HE}]$;

$\bar{x}_{i} \quad$ Maximum reservoir content [HE];

$x_{i}^{o} \quad$ Initial reservoir content [HE];

$x_{i}^{\text {last }} \quad$ Reservoir content at the end of the period [HE];

$w_{i}(k) \quad$ Water inflow to the reservoir $i$, hour $k$ [HE];

$\tau_{i j} \quad$ Water delay time between reservoir $i$ and the next downstream reservoir $j$;

$H_{i} \quad$ Number of whole hours between reservoir $i$ and the next reservoir downstream;

$M_{i} \quad$ Number of minutes additional to the whole hours between reservoir $i$ and the next reservoir downstream;

$p^{n}(n) \quad$ Probability of the node $n$ in power price scenario tree;

$p^{m}(m) \quad$ Probability of the node $m$ in wind power prod. scenario tree;

$c^{s}(k, n) \quad$ Spot price, hour $k$, node $n$ [SEK/MW];

$c \quad$ Price for coordination with WF $[\mathrm{SEK} / \mathrm{MW}]$;

$c^{f} \quad$ Estimated price for future generation [SEK/MW];

$c^{r}(k) \quad$ Regulating power price, hour $k$;

$c^{d}(k, n) \quad$ Downward regulating power price, hour $k$, node $n$;

$c^{u p}(k, n) \quad$ Upward regulating power price, hour $k$, node $n$;

Variables

$\Delta V(k) \quad$ Random wind speed forecast err. in $k$-hour forecast;

$Z(k) \quad$ Random Gaussian variable, standard deviation $\sigma_{Z}$;

$u_{i s}(k, n) \quad$ Water discharge from plant $i$, hour $k$, node $n$ [HE];

$\Delta u_{i s}(k, n)$ Increase in discharge of hydro plant $i$, segment $s$, hour $k$, 
node $n[\mathrm{MW}]$

$\Delta P_{i s}(k, n)$ Power saved in plant $i$, segment $s$, hour $k$, node $n$ [MW];

$P_{i s}^{u p}(k, n, m)$ Upward power adjustment at plant $i$, segment $s$, hour $k$, nodes $n$ and $m$ [MW];

$P_{i s}^{d}(k, n, m)$ Downward power adjustment at plant $i$, segment $s$, hour $k$, nodes $n$ and $m[\mathrm{MW}]$

$u_{i s}^{t o t}(k, n, m)$ Total discharge in plant $i$, segment $s$, hour $k$, nodes $n, m$, includes base case discharge and the discharge changes due to coordination [HE];

$y_{i}(k, n) \quad$ Water spillage from plant $i$, hour $k$, node $n[\mathrm{HE}]$

$x_{i}(k, n, m)$ Reservoir content at the hydro plant $i$, hour $k$, nodes $n, m$ [HE];

$q^{s}(k, n) \quad$ HPPs bid to the spot market, hour $k$, node $n$ [MW];

$q^{u p}(k, n, m)$ HPPs upward regulation bid to the regulating market, hour $k$, nodes $n$ and $m$ [MW];

$q^{d}(k, n, m)$ HPPs downward regulation bid to the regulating market, hour $k$, nodes $n$ and $m$ [MW];

$z^{b} \quad$ Expected HPPs income from trading on the spot market, base case planning [SEK];

$z^{c} \quad$ Expected HPPs income from trading on the spot market and coord. with wind power [SEK];

$z^{d} \quad$ Expected HPPs recourse costs from trading downward regulation on the regulating market [SEK];

$z^{u p} \quad$ Expected HPPs recourse income from trading upward regulation on the regulating market [SEK];

$z^{\text {tot }} \quad$ Total expected HPPs income [SEK];

$z_{n c}^{w} \quad$ Income of the wind power utility (hours without cong.) [SEK];

$z_{c}^{w} \quad$ Income of the wind power utility (hours with cong.) [SEK];

Operators

$\diamond^{a v} \quad$ Average value of $\diamond$;

$B \quad$ Backshift operator, i.e., $B x(k)=x(k-1)$;

Nomenclature for minimization of imbalance costs

Indexes and Index sets 
$K \quad$ Index set of all hours in the planning period;

$J \quad$ Index set of all imbalance price scenarios;

I Index set of all wind power production scenarios;

$I_{r} \quad$ Index set of all preserved wind power production scenarios after scenario reduction, $I_{r} \subset I$;

\section{Parameters}

$c^{s} \quad$ Spot price $[\mathrm{SEK} / \mathrm{MW}]$

$c_{j}^{d} \quad$ Downward regulating power price, scenario $j[\mathrm{SEK} / \mathrm{MW}]$;

$c_{j}^{u p} \quad$ Upward regulating power price, scenario $j[\mathrm{SEK} / \mathrm{MW}]$;

$c_{i m b, p, j} \quad$ Positive imbalance price, scenario $j[\mathrm{SEK} / \mathrm{MW}]$;

$c_{i m b, n, j} \quad$ Negative imbalance price, scenario $j$ [SEK/MW];

$c_{i m b, p, r e a l}$ Actual positive imbalance price [SEK/MW];

$c_{i m b, n, \text { real }}$ Actual negative imbalance price $[\mathrm{SEK} / \mathrm{MW}]$;

$q_{j} \quad$ Probability of price scenario $j$;

$p_{i} \quad$ Probability of wind power production scenario $i$;

$P_{W F} \quad$ Total installed capacity of the wind farm [MW];

$P_{i} \quad$ Wind power production, scenario $i[\mathrm{MW}]$;

$P_{\text {real }} \quad$ Actual wind power production $[\mathrm{MW}]$;

$M \quad$ Large positive number, $M>>P_{W F}$;

\section{Variables}

$P_{b} \quad$ Bid of the wind farm operator to the spot market [MW];

$b_{i} \quad$ Binary variable ;

$z \quad$ Expected imbalance costs [SEK];

$z_{i m b} \quad$ Actual imbalance costs [SEK]; 



\section{Chapter 1}

\section{Introduction}

During the last two decades, the increase in electricity demand and environmental concern resulted in a fast growth of power production from renewable sources. Wind power is one of the most efficient alternatives. Due to the rapid development of wind turbine technology and increasing size of wind farms, wind power plays a significant part in the power production mix of Germany, Spain, Denmark, and some other countries.

Similarly to hydropower, wind power has to be build in an immediate proximity to the resource - wind. The best conditions for installation of wind power are in open, remote areas, with low population density. The transmission system in such areas might not be dimensioned to accommodate additional large-scale power infeed. Furthermore, a part of the transmission capacity (TC) might already be reserved for conventional power plants located in the same area.

It should, however, be pointed out that insufficient export capability problem would emerge for any type of new generation, planned in similar conditions, although wind power has some special features that should be considered when solving this problem. Wind power is an intermittent, variable power output technology, which cannot be easily predicted and controlled. The wind farm full load hours are only 2000-4000 hours per year. Wind speed usually follows seasonal variations [13] and the real-time wind speed measurements (and sometimes even temperature measurements) are available from the wind farm.

Large scale integration of wind power in power systems with transmission bottlenecks is a relatively new problem for the wind power field. Therefore, 
there is not much research in this area, although the methods elaborated for other purposes, e.g., grid expansion, generation expansion planning, generating capacity adequacy assessment, production planning, etc. could be revised and applied in this area.

In this thesis four alternatives for large-scale wind power integration in power systems with transmission bottlenecks are considered, Figure 1.1.

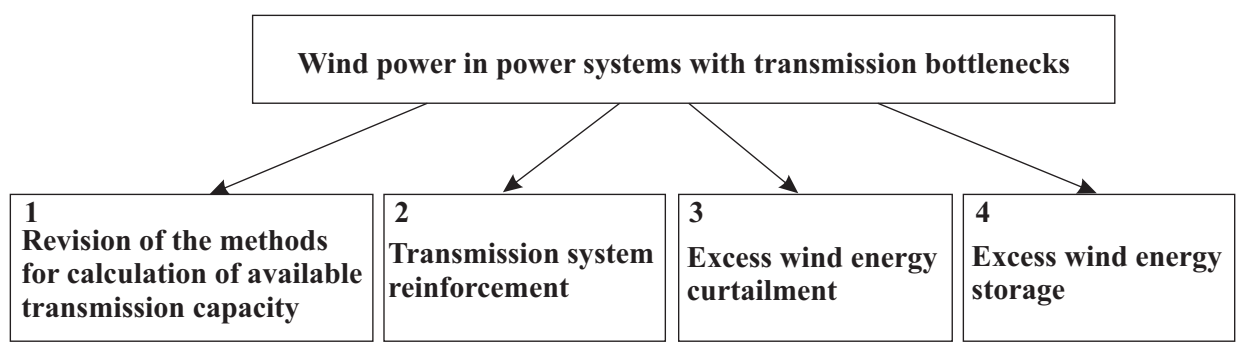

Figure 1.1: Alternatives for large-scale wind power integration in power systems with transmission bottlenecks

One possibility is to revise the methods for calculation of available transmission capacity. For example to use dynamic estimation of the TC, thus, higher transmission could be allowed in some periods, see [100], [18], [28], which is particulary advantageous for wind power integration, as wind speed measurements from the wind farm (WF) can be used for estimation of the TC of short transmission lines. In [49] it is shown that methods and assumptions for calculation of available transmission capacity differ between transmission system operators (TSOs) and even harmonization of these methods could result in an increase of cross boarder TC. Wind power integration itself may impact the TC and also affect the methods for determination of TC. However, in the recent years the requirements for connection of wind farms to the grid have been elaborated by system operators. If these requirements are fulfilled the impact of wind power on available transmission capacity can be minimized.

Another solution for large-scale integration of wind power in such areas is the network reinforcement (e.g., new transmission lines, shunt reactive power compensation, series compensation, etc.). Since this measure is widely used to improve operation of power system in general (not only in case of large scale wind power integration) there exist well developed methods that can be readily applied to find the best solution in each particular project, see, 
e.g., [80]. This alternative, however, may be expensive and time consuming. Wind power production depends on the wind speed, moreover, wind power production peaks do not necessarily occur during the periods with insufficient transmission capacity. Therefore reinforcing a transmission network in order to remove a bottleneck completely is often not economically justified.

Wind energy curtailments during congestion situations is then one of the solutions for large-scale wind power integration with less of nil grid reinforcement. This solution has been suggested in, e.g., [42] and some grid connection requirements for wind turbine generators (WTGs), although the methods for assessment of this alternative were not provided. Therefore there is a need for development of new methods that would help to evaluate this alternative for new-coming projects.

Instead of energy curtailment, the storage of excess wind energy during the periods with insufficient transmission capacity should also be considered. Pumped hydro storage or battery storage for large scale wind farms is rather expensive, on the other hand existing conventional power plants capable of fast production control (e.g., hydro power plants or gas fired power plants) situated in the same area may be used for this purpose. The coordination of wind power and hydro power has been studied earlier in connection with several different problems. In [62] this option is considered in generation expansion planning, where two investment possibilities are compared: new hydro power plant (HPP) vs new wind farm. In [103], [104] it is analyzed how wind power would affect the market price. The research in [103], [104] is directed towards assisting hydro power utilities considering investments in wind power. In [61] coordinated operation of several geographically spread wind parks and aggregated hydro power plant sharing the same transmission capacity, is simulated for several years, considering the wind and water inflow uncertainty. None of these papers, however, treats hydro power production planning for daily operation, considering the coordination with wind power.

The purpose of this thesis is to study the causes of transmission limitations and methods to calculate available transmission capacity and to look into the possibilities for large-scale wind power integration in power systems with transmission bottlenecks. As mentioned above, four possibilities were considered, Figure 1.1, although it is not excluded that there may exist some other options. Since there is a lot of research regarding the first two possibilities, the thesis provides a review and summarizes conclusions from the existing work. The thesis then further concentrates on the development of the methods for estimation of wind energy curtailments, 
evaluation of wind energy storage possibility in hydro reservoirs and the development of short term hydro power production planning methods, considering coordination with wind power.

The present short term power markets are designed for trading conventional (dispatchable) generation. The time span after the market clearing until the delivery hour can be up to 36 hours (Scandinavia) and up to 38 hours (Spain), any deviations from the submitted production plan are penalized. As wind speed forecast error increases with increasing prediction horizon, with forecast being needed 36 or 38 hours ahead of time, wind generators may be subjected to substantial imbalance costs. Additionally, in this thesis, the strategy that minimizes imbalance costs of wind power utility, trading wind power on the short term power market is elaborated, analyzed and applied to a case study.

The next section provides a more extensive outline of the thesis.

\subsection{The outline of the thesis}

The thesis is structured as follows. Chapter 2 provides the reader with some background information of interest for the research topics of this thesis. The chapter gives a short summary on the wind power development and the current state in Europe and Sweden in particular, followed by a brief overview of the Swedish power system and Nordic power market.

The thesis summarizes eight publications.

- Publication A, J. Matevosyan, Chapter 20: Wind Power in Areas with limited Transmission Capacity, in the book Wind Power in Power Systems, edited by T. Ackermann, published by John Wiley\&Sons, ISBN 0470012676, January 2005

- Publication B, J. Matevosyan, C. Jauch, T. Ackermann, S. M. Bolik, International Comparison of Requirements for Connection of Wind Turbines to Power Systems, Wind Energy Journal, John Wiley\&Sons, Ltd, vol.8, Issue 3, pp 295-306, 2005

- Publication C, J. Matevosyan, T. Ackermann, S. Bolik, Chapter 7: Technical Regulations for the Interconnection of Wind Farms to the Power System, in the book Wind Energy in Power Systems, edited by T. Ackermann, published by John Wiley\&Sons, ISBN 0470012676, January 2005. 
- Publication D, J. Matevosyan, L. Söder, Estimation of Potential Wind Energy Curtailment for Wind Power Plants in Power Systems with bottleneck problems, in the proceedings of EPE-PEMC'2004, 11th International Power Electronics and Motion Control Conference, 2-4 September 2004, Riga, Latvia.

- Publication E, A. Jäderström, J. Matevosyan, L. Söder, Coordinated regulation of wind power and hydro power with separate ownership, in the proceeding of the 4th International Conference in Energy Economics, IEWT'5, February 2005, Vienna, Austria Revised version of the paper was also presented at the conference Hydropower'05, May 2005, Stavanger, Norway.

- Publication F, J. Matevosyan, L. Söder, Short Term Hydro Power Planning Coordinated with Wind Power in Areas with Congestion Problems, in Proceedings of PMAPS 2006, revised version submitted to Wind Energy Journal, John Wiley \&Sons

- Publication G, J. Matevosyan, M. Olsson, L. Söder, Hydro Power Planning Coordinated with Wind Power in Areas with Congestion Problems for Trading on the Spot and the Regulating Market, submitted to Electric Power Systems Research, Elsevier

- Publication H, J. Matevosyan, L. Söder, Minimization of Imbalance Costs Trading Wind Power on the Short Term Power Market, in Proceedings of IEEE Power Tech Conference, 27-30 June 2005, St. Petersburg, Russia, recommended for publication in IEEE PES Transactions, revised and published in IEEE Transactions on Power Systems, vol. 21, Issue 3, pp 1396 - 1404, August 2006

These publications are thematically divided into five groups. Chapters 3-7 of the thesis, summarize respectively each group of the publications. As these five subjects are only partly interconnected summary of all conclusions in a separate chapter is omitted. The conclusions are instead provided at the end of each chapter.

Chapter 3 is a summary of Publication A. The chapter starts with the definitions of transmission limits. It also gives an overview of the methods applied by European transmission system operators to determine available transmission capacity. This overview is mainly based on references [49] and [37]. The aim of the overview is to demonstrate and explain the 
reasons for the difference between the physical transmission capacity and the available transmission capacity defined by a TSO. Some possible measures to increase transmission capacity are also discussed. The measures concern not only transmission system reinforcement (alternative 2 in Figure 1.1) but also possibilities to improve the methods for determination of available capacity (alternative 1 in Figure 1.1) that in turn may result in transmission capacity increase. Congestion management is an alternative to transmission capacity increase, therefore a short summary on congestion management is also presented. The impact of wind power on transmission limits is then discussed.

To insure the secure operation of the power system with significant level of wind power penetration there arose a necessity for connection requirements for WTGs. These connection requirements, among other issues, lead to reduced impact of wind power on the transmission limits (alternative 1 in Figure 1.1). Some countries have chosen to create separate requirements just for wind power, others try to apply existing grid codes to the WF. The main aspects of such requirements from Germany, Denmark, Sweden, Scotland and Ireland and some other countries ${ }^{1}$ are compared in Publications $\mathrm{B}$ and $\mathrm{C}$. Chapter 4, based on these publications, attempts to answer the following questions: Why grid connection requirements for wind turbines emerged and what is the purpose? Why the comparison of the requirements from different countries is necessary? What are the main aspects defined in the requirements and why these aspects are important? At the end of the chapter the main conclusions of the comparison are summarized.

Transmission system reinforcement may be costly and time consuming. In Chapter 5 wind energy curtailments are considered as an alternative to transmission system reinforcement (alternative 3 in Figure 1.1), integrating large-scale wind power into the system with congestion problems. The chapter starts with a brief introduction and an overview of previous research, then estimation methods for wind energy curtailments, developed in this thesis (Publications A and D), are discussed in details. Finally a case study, concerning large scale integration of wind power in Northern Sweden, is presented and the main conclusions are summarized.

Publications E-G are summarized in Chapter 6. In this chapter the possibility to coordinate wind power and hydro power in power systems

${ }^{1}$ The choice of the countries is dictated by availability of the source rather than by installed wind power capacity. 
with transmission bottlenecks is considered (alternative 4 in Figure 1.1). First, the comprehensive overview of the previous research on this subject is provided, followed by a brief summary of the pre-feasibility study conducted in Publication E. Then a planning algorithm for a hydro power system coordinated with a wind farm in area with limited power export capability is presented in detail. An evaluation algorithm is also developed to study the impact of the coordinated planning on both wind power and hydro power utilities in the long term. The developed methods are applied to the case study. The short summary of the case study and its main findings conclude the chapter.

Chapter 7, summarizes Publication H. In this chapter the strategy for minimization of imbalance costs of the wind power utility, trading wind power on the short term power market is presented. First, some background and an overview of the previous research on this subject is provided. Then the main principles of the bidding strategy is briefly presented, followed by modelling details. The developed bidding strategy is applied to the case study. The short summary of the case study and its main findings conclude the chapter.

\subsection{Contribution of the thesis}

The main contributions of the thesis are listed bellow:

- An overview of the methods applied by different TSOs determining available transmission capacity and measures to increase transmission capacity are presented. Difference between the physical transmission limits and the available transmission capacity defined by TSO is clarified.

- The impact of wind power on available transmission capacity is discussed.

- The main aspects of the requirements for the grid connection of large-scale wind farms in Germany, Denmark, Sweden, Scotland and Ireland are summarized and compared.

- Wind energy curtailments are considered as one of the alternatives to grid reinforcement, when integrating large scale wind power in power 
systems with transmission bottlenecks. New methods are developed for the evaluation of this possibility.

- Another alternative to grid reinforcement is coordination of wind power with local hydro power. First, the pre-feasibility study for this alternative is conducted in the thesis. Then the planning algorithm is also developed for a multi-reservoir hydro power system in coordination with a wind farm considering the uncertainty of the wind speed forecast and the power market prices. The evaluation algorithm is also developed to study the impact of the coordinated planning on both wind power and hydro power utilities in the long term.

- Finally, an imbalance cost minimizing bidding strategy for a wind power utility is developed, considering the uncertainty of the wind power forecast and the imbalance prices.

- The developed methods are applied in the case studies concerning large-scale wind power integration in mountainous areas in northern Sweden. The results are discussed in the thesis. 


\section{Chapter 2}

\section{Background}

This chapter will provide the reader with some background information of interest for the research topics of this thesis. The chapter will give a short summary on the wind power development and the current state in Europe and Sweden in particular. Then a brief overview of the Swedish power system and Nordic power market will be provided.

During the last two decades, increase in electricity demand and environmental concern resulted in fast growth of power production from renewable energy sources. Wind power is one of the most cost efficient alternatives. In the 90's world wide wind capacity doubled approximately every third year. The cost of electricity from wind power has fallen to one sixth of the cost in the early 1980's [2]. This trend continues and, presently, wind power already plays a significant role in the power production mix of Germany, Spain, Denmark and some other countries (see Table 2.1).

Wind energy technology itself is also rapidly developing, see Figure 2.1. This leads to increased size of individual wind turbines (3-5 MW) and, in turn, to the development of larger wind farms with installed capacity of more than $100 \mathrm{MW}$, typically offshore. In the following section a brief overview of the main wind turbine generator design concepts is provided. 
Table 2.1: Wind power capacity installed during the last 10 years in some European countries, [38]

\begin{tabular}{|l|l|l|l|l|l|l|l|}
\hline Country & 1995 & 1999 & 2001 & 2002 & 2003 (June) & 2004 & 2005 \\
\hline Germany & 1136 & 4445 & 8734 & 12001 & 12836 & 16629 & 18428 \\
Spain & 145 & 1530 & 3550 & 4830 & 5060 & 8263 & 10027 \\
Denmark & 619 & 1742 & 2456 & 2881 & 2916 & 3118 & 3122 \\
Italy & 25 & 211 & 700 & 788 & 800 & 1265 & 1717 \\
UK & 200 & 356 & 525 & 552 & 586 & 907 & 1353 \\
Netherlands & 236 & 410 & 523 & 678 & 803 & 1079 & 1219 \\
Sweden & 67 & 220 & 318 & 328 & 364 & 442 & 500 \\
\hline
\end{tabular}

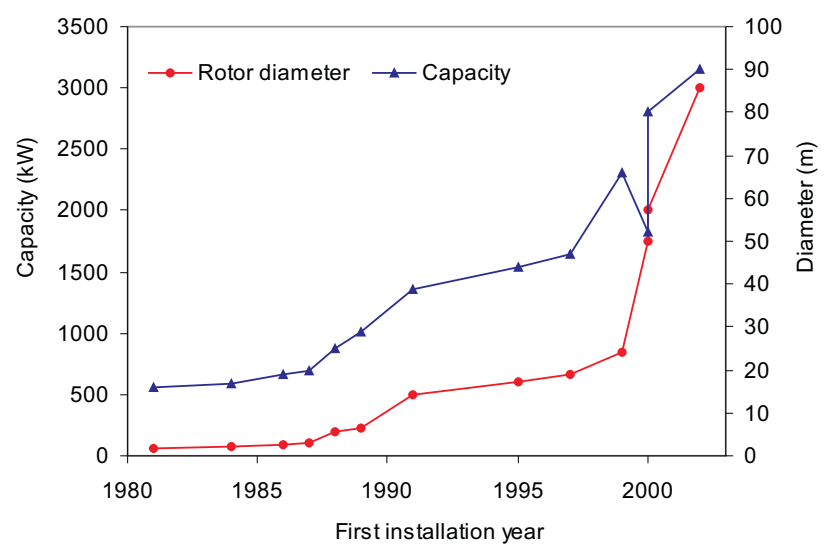

Figure 2.1: Technology development of Vestas wind turbines

\subsection{Wind turbine generator design concepts}

In the generator of WTG mechanical energy is converted to electrical energy.

The conversion system is schematically shown in Figure 2.2, [87].

Present WTGs can be divided into 3 main types [86]:

1. Fixed speed with squirrel cage induction generator,

2. Variable speed with doubly fed induction generator,

3. Variable speed based on direct drive synchronous generator. 


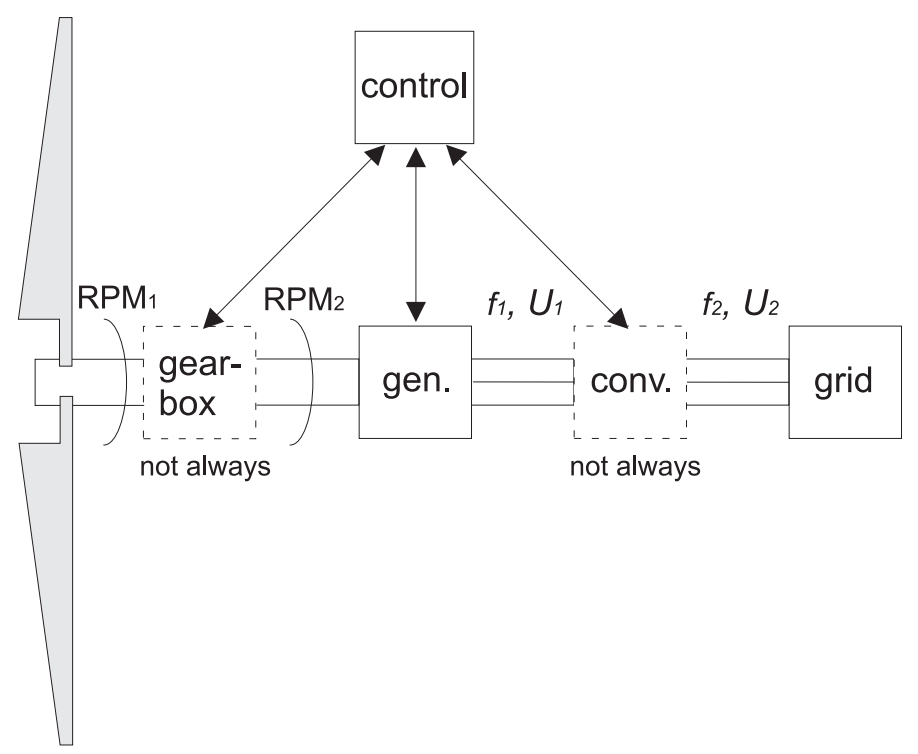

Figure 2.2: Wind energy conversion system

In the fixed speed concept wind turbine rotor and squirrel cage induction generator are coupled via a gearbox. The stator windings are connected directly to the grid. The variation of rotor speed is very small. The squirrel cage induction generator consumes reactive power from the grid. This reactive power demand is compensated locally by shunt capacitors or SVC.

In the variable speed concept, the wind turbine rotor and the doubly fed induction generator are connected via a gearbox. The stator windings are connected directly to the grid. The excitation is provided from the grid through $\mathrm{AC} / \mathrm{DC} / \mathrm{AC}$ converter. As the rotational speed of the rotor varies, the electrical frequency of the rotor current can be adjusted by converter control to keep the frequency of the rotor current close to $50 \mathrm{~Hz}$. In this concept the nominal power of the converter is often only $1 / 3$ of the generator rating.

In the last concept, turbine rotor and synchronous generator are connected directly, without gearbox. The synchronous generator is connected to the grid via full rating AC/DC/AC converter. Thus, mechanical speed of the rotor is decoupled from grid frequency, which makes variable 
speed operation possible.

WTG reaches the highest efficiency (highest power coefficient $c_{p}$ ) at the rated wind speeds, which is usually between $12-16 \mathrm{~m} / \mathrm{s}$. At this wind speed the rated capacity of the generator is reached. Above this wind speed the mechanical power has to be controlled in order to prevent the generator operation above its rated capacity. There are two main principles of such control: stall regulation and pitch control.

For the fixed speed concept the stall regulation is often applied. Due to airfoil profile the air stream creates turbulence in high wind speed conditions on the other side of the rotor blade. This so-called stall effect results in reduction of aerodynamic forces and subsequently power output of the rotor [1]. The advantage of this concept is that it does not require investments in additional control equipment. The disadvantages are that stall effect is difficult to calculate exactly and rated power output is achieved only at one wind speed, Figure 2.3. Stall controlled turbines have to be shut down once a specific wind speed is reached (cut-out wind speed).

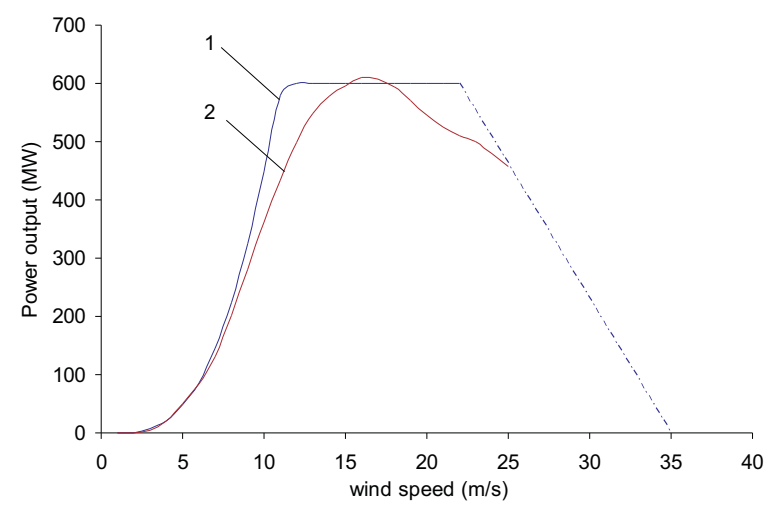

Figure 2.3: Power curves of pitch controlled (curve 1) and stall controlled (curve 2) WTGs

Pitch control is achieved by pitching the turbine rotor blades around their longitudinal axis, thus, the relative wind conditions and subsequently aerodynamic forces are affected so that the power output remains constant after rated power is reached [43], Figure 2.3. At high wind speeds some pitch controlled turbines can gradually change to no-load mode (pitch angle approx. 70 degrees), dash-dotted part of curve 1 in Figure 2.3. This feature is 
applied in order to provide gradual power reduction at high wind speeds. The requirements to gradual WF power output reduction are stated in connection rules of some TSOs, see Chapter 4.

\subsection{Current state of wind power in Sweden}

The Swedish government proposed a bill [45] on planning objectives for wind power. According to this bill the planning objective for $10 \mathrm{TWh}$ of annual wind power production should be achieved up to 2015 . The bill was approved in 2002. However, the development of wind power in Sweden is much slower compared to, e.g., Denmark, Germany and Spain. The installed capacity of wind power amounts to $506 \mathrm{MW}$ (May 2006) that corresponds to 771 WTGs, annual energy production in 2005 was about $870 \mathrm{GWh}$ [79]. The WFs and WTGs are mostly spread along the southern coast, on and near shore of Gotland and Öland islands, Figure 2.4a.
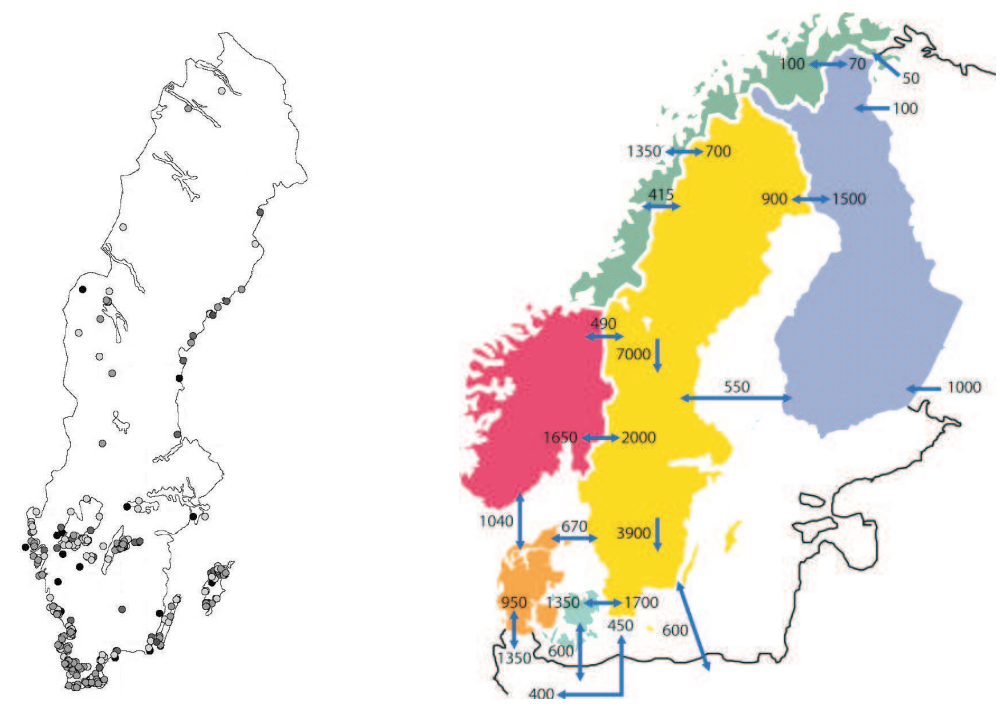

Figure 2.4: a. Wind power in Sweden; b. Existing transmission limitations in Nordic power system, [71]

One of the causes of such slow development is that about $50 \%$ of power is already produced by a renewable source - hydropower. Another reason was the absence of public subsidies for wind power. In the beginning 
of 2003 so-called transitional subsidies were introduced. The transitional subsidies are given for a five-year transitional period in which the bonus is gradually phased out from $1.63 \mathrm{ct} / \mathrm{kWh}$ to $0.33 \mathrm{ct} / \mathrm{kWh}$ [81]. In May 2003 the electricity certificate system was also introduced. Producers of electricity from renewable energy sources receive an electricity certificate for every MWh of produced electricity. This makes it profitable to invest in new renewable electricity production. To create a demand for electricity certificates, there is an annual quota obligation on the part of electricity suppliers to hold electricity certificates corresponding to their sale and use of electricity during the year. By selling these certificates, the producer receives an extra income in addition to the sale of electricity [68]. The third barrier for the faster wind power development in Sweden are the existing bottlenecks in the transmission system, Figure 2.4b.

There are, however, extensive plans for development of large scale offshore wind farms in Sweden in the near future. The construction of the wind farm Lillgrunden offshore in the south-east of Sweden has already been started. The WF will consist of 48 turbines, with total installed capacity of 110 MW, and is expected to produce annually about $330 \mathrm{GWh}$. The WF is scheduled for operation by the end of 2007. Another large scale offshore wind farm is planned on Krigers flack in the Baltic Sea between Germany and Sweden about $30 \mathrm{~km}$ south off the Swedish cost. The WF would consist of 128 turbines, with total installed capacity of $640 \mathrm{MW}$ and is expected to produce annually about $2.1 \mathrm{TWh}$. It is planned to be constructed in stages between 2009-2014.

\subsection{Overview of the Swedish power system}

The Swedish transmission system was built up to use hydropower as efficiently as possible following the expected increase in electricity consumption. The total installed capacity of generating units is about $33551 \mathrm{MW}$ of which $48 \%$ is hydropower, $28 \%$ is nuclear power, $22 \%$ thermal power and $1.3 \%$ is wind power (end of 2004) [91].

About $85 \%$ of all hydropower is concentrated in the northern part of the country. The electricity consumption in this area is rather low, around $20 \%$ of total consumption in Sweden. As a result the strong transmission system was built between northern and southern Sweden [8]. Eight long (500-1000 $\mathrm{km}) 400 \mathrm{kV}$ transmission lines connect the northern part of the transmission 
system with central and southern parts, where the main load is concentrated.

Power transmission in Sweden varies from year to year depending on water inflow in the river systems: increasing during wet years and decreasing during dry years. Within a year power transmission depends on seasonal changes (snow melting, temperature variations), within a day power transmission varies with load variations. It also depends on market prices. Generally the highest transmission is often but not solely during the spring flood, late autumn and winter and it reaches its peaks during the daytime [8]. During these periods power transmission between North and Central part of Sweden (so called Cross section 2) is almost at the limit, which is determined by Swedish TSO as 7000 MW, Figure 2.4b. However during about 4000 hours of the year power transmission is lower than $60 \%$ of total transmission capacity, Figure 2.5. There are also other bottlenecks within Swedish power systems and with neighboring countries, Figure 2.4b.

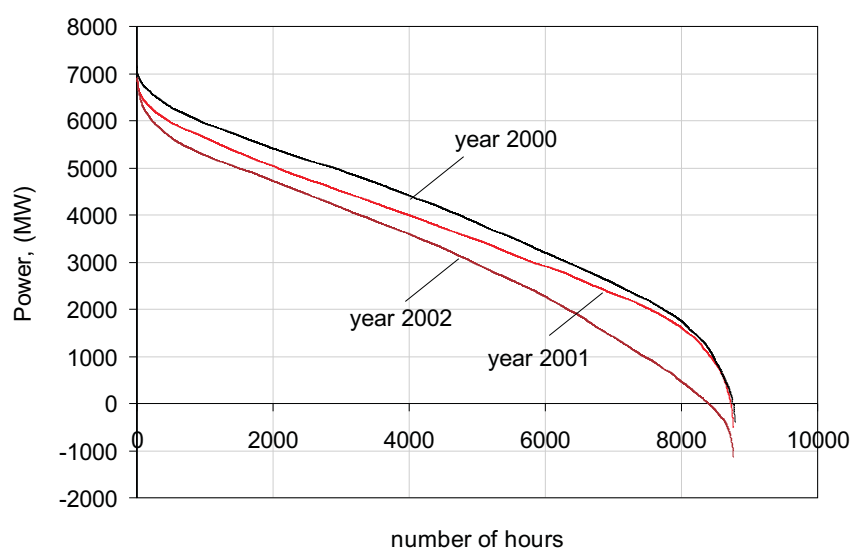

Figure 2.5: Duration curves of power transmission through Cross section 2 [10]

As already mentioned above, the existing bottlenecks in the Swedish transmission system may be one of the barriers to further development of wind power in Sweden. In 2002 the Swedish government commissioned TSO Svenska Kraftnät (SvK) to draw up overall prerequisites for integration of large-scale wind power (10 TWh) in mountainous (in the North) and offshore areas. In the resulting report the case with $4000 \mathrm{MW}$ (assumed full load hours - 2500) of wind power penetration in northern Sweden was considered [8]. According to the report, 5 new $400 \mathrm{kV}$ - transmission lines with the total 
cost of 20000 MSEK would be necessary to make electricity transmission available during $100 \%$ of the year.

Currently, each particular project receives the permission to be connected to the transmission network only if available transmission capacity of the concerned lines is more or equal to rated power of the wind farm. For example in 2003 three wind power utilities were interested to install successively 30, 60 or $90 \mathrm{MW}$ wind power in the mountains of northern Sweden near to Norwegian border [74]. The preliminary power production (for 30, $1 \mathrm{MW}$ turbines) would be about $100 \mathrm{GWh}$ a year. SvK's $220 \mathrm{kV}$ power line AL7 between Grundfors and the Norwegian border has a total available capacity of $350 \mathrm{MW}$. On the Swedish side, $250 \mathrm{MW}$ is reserved for hydro power production and the rest, $100 \mathrm{MW}$, is reserved for power exchange with Norway (transit through Sweden). The power lines are seldom 100 percent utilized, but still a connection for wind power plants has been rejected. This example is used later in this thesis for the case studies .

\subsection{Overview of the Nordic power market}

\subsubsection{Spot market}

On the Nordic power market Norwegian, Finnish, Swedish and Danish actors trade in hourly contracts for the 24 hours of the coming day. The spot market is closing at 12:00 the preceding day. Purchasing and selling curves are constructed and the point where they cross determines the spot market price and the volumes being traded during each hour the coming day [94]. With such market structure wind power forecast length should be 12-36 hours to trade on the spot market.

\subsubsection{Elbas}

Elbas is an adjustment market for the power exchange players in Sweden, Finland and East Denmark. The market opens for trade for the coming power exchange day at 15:00 each day, i.e., after the spot market closure.

Trading in hourly contracts is conducted electronically and can take place up until one hour prior to delivery. In this way, the players get the opportunity to carry out a final balance of their contracts in order to compensate themselves for unexpected events occurring after the spot market has closed. 
Trading on Elbas is more beneficial for wind power because more precise forecasts can be made for the shorter time horizon. However currently Elbas is not very active and only small amounts of energy are traded there.

\subsubsection{Regulating market}

The transmission system operator is responsible for physical balance between production and consumption. Prior delivery hour actors with power reserves are placing bids for quick (up to $10 \mathrm{~min}$ ) production increase or decrease to the so-called regulating market. The bids are arranged in order of price and form a staircase for each delivery hour. At the end of each hour, the regulation price is determined in accordance with the most expensive upward regulation measure that was taken by TSO, or the cheapest down regulation measure that was taken by TSO [94].

Since Western Denmark was integrated into the joint regulating collaboration in January 2006, the regulating market is now common for Nordic countries.

Wind farm operators could also place bids for upward regulation if a certain production margin is kept on the WF for this purpose, e.g., [23]. The participation in downwards regulation means unnecessary energy curtailments at the wind farm (excess wind energy cannot be stored to the next hour). This option is, thus, not economically efficient.

\subsubsection{Balance settlement}

In the Nordic countries, all bulk electricity production must be traded through a balance responsible player. Via balance settlement, TSO distributes the costs of regulation among balance responsible actors on the power market. All actors pay or are getting paid for their unplanned deviations from the balance. The procedures and pricing for balance settlement differs between Nordic countries. The description of balance settlement in Sweden follows bellow.

If upward regulation alone was activated the upward regulation price is paid by players with negative imbalance, while players with positive imbalance are paid a spot price.

If downward regulation alone was activated the downward regulation price is paid to players with positive imbalance, while players with negative imbalance pay a spot price. 
If no regulation took place all actors are settled at spot price.

If both up and downward regulation have been ordered depending on which regulation had higher volume up or downward regulation price is applied. If volumes for ordered up and downward regulation are equal the spot market price is used [94].

For wind power producers there are currently three alternatives [52]:

- To become balance responsible player;

- To trade wind power and have a contract with balance responsible player for balancing any mismatches;

- To sell all wind power to a balance responsible player. It is easier for balance responsible player to keep the balance if there is a flexibility in the production or consumption portfolio. 


\section{Chapter 3}

\section{Transmission limits}

\section{Publication A}

The chapter summarizes Publication A. First, this chapter will define the factors that limit transmission capability of AC power lines, i.e., thermal limits, voltage and rotor angle stability considerations. Then an overview of the methods used by different TSOs to determine available transmission capacity will be given along with some methods to increase transmission capacity. A brief section on congestion management will be also provided. Finally the impact of wind power on transmission limits will be discussed.

Power transmission in a system may be subjected to the thermal limits of the conductors and associated equipment as well as to limits defined by voltage and rotor angle stability considerations. Thermal limits are assigned to each separate transmission line and the respective equipment. Limits arising from voltage and rotor angle stability considerations are always studied by taking into account the operation of the entire interconnected power system or a part of it.

\subsection{Thermal limits}

The thermal limit of an overhead transmission line is reached when the electric current flow heats the conductor material up to a temperature above which the conductor material gradually loses mechanical strength and sags 
due to conductor expansion, thus clearance to ground is decreased.

The maximum allowable conductor temperatures based on annealing considerations are $127^{\circ} \mathrm{C}$ for conductors with high aluminium content and $150{ }^{\circ} \mathrm{C}$ for other conductors [63]. However the maximum permissible conductor temperature is further limited by conductor age, geometry, the heights of the towers and the security standards regarding clearance to ground. Therefore, the maximum allowed continuous conductor temperature varies from $50{ }^{\circ} \mathrm{C}$ to $100{ }^{\circ} \mathrm{C}[49]$.

The maximum allowable current (or so-called current-carrying capacity) depends on the ambient temperature, wind velocity, solar radiation, surface conditions of the conductor, and altitude above the sea level [53]. Figure 3.1 illustrates the dependence of the conductor current-carrying capacity on wind speed and ambient temperature [96].

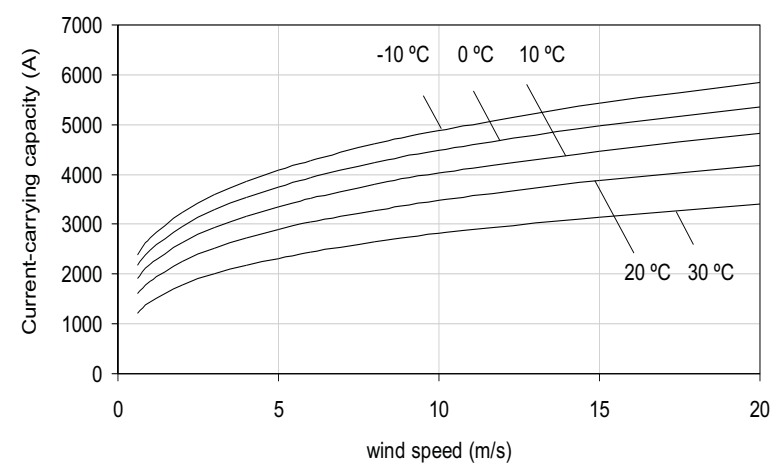

Figure 3.1: Dependence of current-carrying capacity on wind speed and temperature for ACSR conductor, Curlew, 2 Al-wires, $593 \mathrm{~mm}^{2}$

Other network elements such as breakers, voltage and current transformers and power transformers could further restrict the transmission capacity of some network branches. The thermal limit of the transmission line is then given by the lowest rating of the associated equipment.

\subsection{Voltage stability limit}

Voltage stability is the ability of the system to maintain steady acceptable voltages at all buses in the system under normal conditions and after being subjected to a disturbance [63]. Instability occurs in the form of a progressive 
fall or rise of voltages in some buses. A possible outcome of voltage instability is loss of load in an area or generation outages. Furthermore, loss of synchronism may result from these outages or from operation under field current limit [101].

The relationship between transferred power and the voltage can be illustrated by so-called nose curve. Figure 3.2 shows nose curves for two-terminal network (consisting of constant voltage source on the sending end, transmission line with certain impedance and load on the receiving end) for different values of load power factor. The locus of critical operation points is shown by dotted line in the figure. Only the operating points above the critical points represent satisfactory operation conditions; a sudden change of the power factor can cause the system to go from stable operating conditions to an unacceptable or unstable, operating conditions [63].

Improving power factor at the receiving end of the line by local reactive power compensation (unity or leading load power factor) higher maximum active power transfer can be permitted. Transmission of the large amounts of reactive power (lagging load power factor at the receiving end) results in lower maximum active power transfer. Local reactive power compensation also results in voltage increase at the receiving end. The amount of compensation should, thus, be chosen to keep the voltage at the receiving end within the acceptable limits.

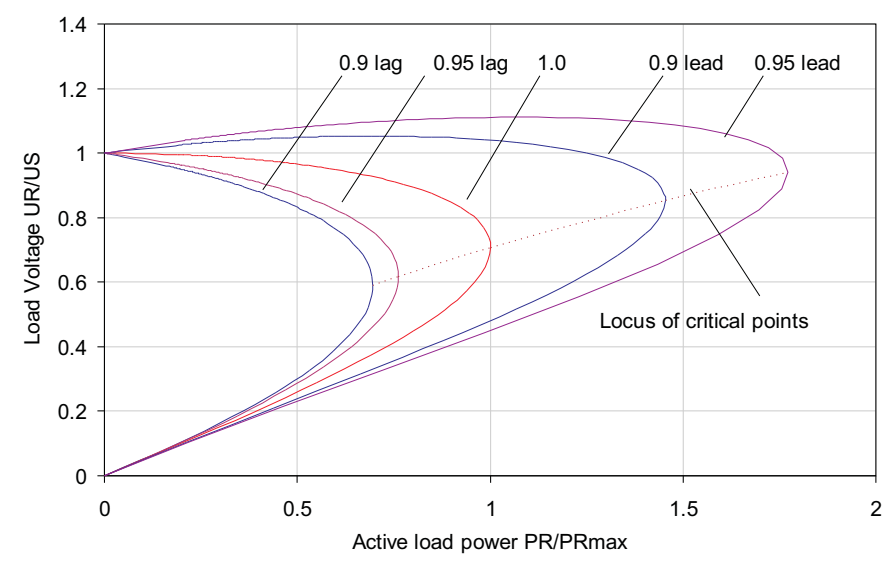

Figure 3.2: Nose curve for the two-terminal network with different load power factors 
The line length has a significant impact on the voltage stability. A line reactance increases with the line length and reactive power consumption of the transmission line at heavy loading causes a decrease of maximum power transfer. Figure 3.3 illustrates the performance of the lines with different length, assuming unity load power factor.

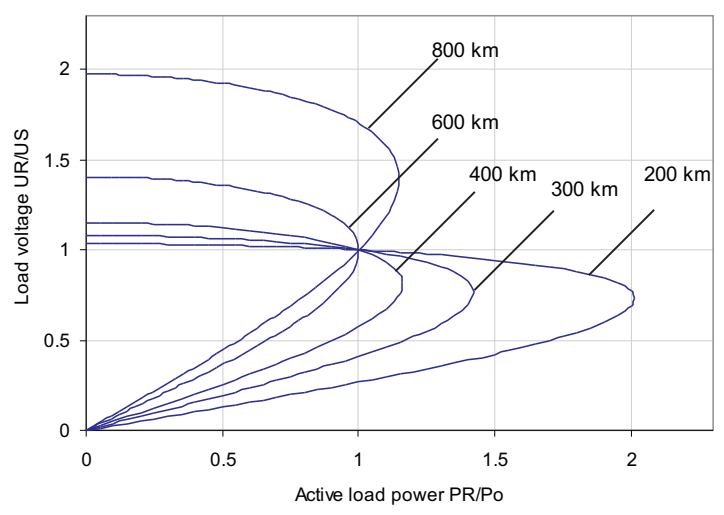

Figure 3.3: Relationship between receiving end voltage, line length, and load of the transmission line

For the line length above $400 \mathrm{~km}$ capacitance of the transmission line partly compensates the reactive power consumption of the line but result in high voltage at the receiving end especially at the light loading when reactive power consumption of the line is lower. For the lines longer than $600 \mathrm{~km}$, series reactive power compensation is used to reduce the reactance of the line and thus consumption of the reactive power [63].

\subsection{Rotor angle stability}

The rotor angle stability phenomenon is separated into two categories: small-signal stability and transient stability. Small-signal stability is ability of the power system to remain in synchronism after small disturbances, e.g., small load or generation changes.

Transient stability is the ability of the power system to maintain synchronism, when subjected to severe transient disturbances. Stability depends on both initial operating state and the severity of the disturbance [63]. The disturbances, which are usually considered in transient stability 
studies are phase-to-ground, phase-to-phase-to-ground or three-phase short circuits. They are usually assumed to occur on the transmission lines. The fault is cleared by the opening of the appropriate breakers to isolate the faulted element.

In reality it is difficult to separate pure voltage stability phenomenon and pure rotor angle stability phenomenon, since they can interact with each other, especially during and after the disturbance in the system. Dynamic simulations of the whole system or a part of it are necessary to investigate voltage and rotor angle stability and their impact on maximum power transfer. The role these simulations play in determination of available transmission capacity is discussed in the next section.

\subsection{Determination of cross-border transmission capacity}

To provide consistent capacity values, European TSOs are publishing net transmission capacities (NTC) twice a year. For each border or set of borders, the NTC is determined individually by all adjacent countries and, in case of different results, negotiated among involved TSOs.

In [49] the approaches of TSOs to determine the transmission capacity between EU member states, Norway and Switzerland were studied. According to this study the methods applied by TSOs follow the same general pattern (summarized in Publication A). The interpretations and definitions are, however different for different TSOs. For example NTC depends on assumptions of the base case load flow. The base scenario may change in next calculation cycle and influence NTC even if technical parameters remain constant. Modelling of generation increase/decrease, with regard to base case load flow, also differs among TSOs.

When determining limits of feasible network operation, some TSOs consider a differentiation of thermal limits throughout the year and throughout their areas of responsibility (e.g., SvK, Finngrid, Elkraft, Statnet). Others apply probabilistic model based on meteorological statistics (e.g., TSOs in Belgium and Great Britain). Some TSOs assume constant ambient conditions throughout the entire year (e.g., Eltra, German TSOs).

The maximum allowed continuous conductor temperature differs largely from one TSO to the other with values from $50^{\circ} \mathrm{C}$ to $100^{\circ} \mathrm{C}$. Some TSOs allow higher continuous current limits in $(n-1)$ contingency situations, i.e., 
outage of a single network element. However, the percentage of accepted overloads is different for different TSOs. Many TSOs tolerate higher current limits in contingency situations only when the loading can be decreased by means of TSO actions bellow normal limits within short time (10-30 min).

Voltage stability and rotor angle stability are assessed for normal system operation as well as operation after $(n-1)$ contingencies that are considered relevant for security assessment. Some TSOs investigate not only single failures, but also certain failure combinations. Nordic TSOs (Fingrid, Stanett, Svenska Kraftnät) consider busbar failures as the severity of possible consequences endangers the security of the system.

The methods for uncertainty assessment as well as sources of uncertainties considered are also different between TSOs.

Apart from determination of NTC twice a year, available transmission capacity (ATC) is determined on weekly or daily basis. Available transmission capacity is calculated as a difference between NTC and already allocated transmission capacity (AAC) due to bilateral contracts [37], Figure 3.4. The pattern for NTC determination is the same as before, although base case is now reflecting a load flow forecast based on day-before snapshot and sometimes also weather forecast. System models are updated according to known changes in topology and switching status. Weather forecasts are used by some TSOs to allow higher thermal transmission limits. As there are also less uncertainties in short term horizon, the actual net transmission capacity can vary substantially from the NTC values calculated twice a year.

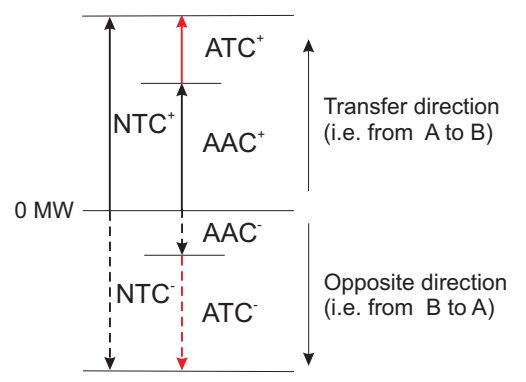

Figure 3.4: Available transmission capacity determination 


\subsection{Determination of TC within the country}

For the area of responsibility of each TSO complete system models are used for assessment of the available transmission capacity. The methods are similar for all TSOs but again the security standards and base scenario assumptions may differ.

Thermal limits are evaluated for each particular line depending on material, age, geometry, the heights of the towers, the security standards imposing limitations on clearance to ground etc. There can be different policies regarding tolerance of overloads during the contingencies.

Different scenarios are elaborated for load flow calculations that are used for voltage stability assessment at normal operation and after most frequent and severe contingencies. The selection of failures to be assessed is based on implicit distinction between "frequent" and "rare" failure and between "severe" and "minor" consequences [49]. As discussed in the previous subsection the types of considered contingencies are different.

Rotor angle stability is investigated by performing dynamic simulations of the system during and after the fault. The transmission limits for the power lines are defined by the most severe set of conditions.

Inner transmission limits are taken into account in security assessment for cross-border capacity allocation. The inner transmission limits can put additional limitations on cross border transmission capacity.

Inner transmission limits are also taken into account during system operation (to provide corrective measures in case of congestion: re-dispatch of the generators, switching, load shedding); to prepare technical prerequisites for connection of new generation to the grid, etc.

\subsection{Measures to increase TC}

The measures to increase transmission capacity can be summarized in two groups: the "soft" measures and reinforcement measures.

The "soft" measures concern the improvements for the methods of transmission capacity determination and, thus, may result in increase of transmission capacity at relatively low costs. The list of some "soft" measures is provided in Publication A. These measures mostly concern cross border transmission capacity however some of them may be applied to increase the TC within the country. 
Extensive use of system protection schemes, especially automatic control actions following critical line outages, can also be used to relax transmission congestion without substantial investments. The main purpose of these schemes would be primarily to enable increased transmission limits not only to reduce consequences of disturbance or interruptions [18].

The reinforcement measures to increase transmission capacity are discussed bellow.

If thermal current limit is the critical factor, reinforcement measures (apart from the construction of new lines) can either be aimed to increase of the current limits of individual lines and/or associated equipment (e.g., breakers, voltage and current transformers, etc.) or to optimize the distribution of load flows to decrease loading of the critical lines. The list of the possible measures is also provided in Publication A.

In case of voltage limits or when voltage stability is the determining factor for transmission capacity, additional sources of reactive power (shunt capacitors, shunt reactors or FACTS elements) can be installed at critical locations to smoothen the steady state voltage profile and to increase reserves to mitigate voltage stability problems. If voltage instability is caused by power transfer at long distances, series capacitors can be installed to decrease the impedance of the lines. The applicability of the suggested reinforcement measures depends on individual network topology.

One way to increase TC is to convert power lines from HVAC to HVDC. This allows to increase power transmission rating 2-3 times and reduce transmission losses [50]. Depending on the condition of the existing system the cost for conversion from HVAC to HVDC can be from $30 \%$ to $50 \%$ lower compared to construction of a new transmission line. However the construction of the two converter stations is not included in this figure.

The obvious and effective measure to increase transmission capacity is to build a new transmission line. However this is time consuming (about 5 years) and expensive option. The cost of one new transmission line is approx. $4 \mathrm{MSEK} / \mathrm{km}$ [8]. During the last years due to environmental concern, it is difficult to receive a permission for building new overhead transmission lines. 


\subsection{Congestion management}

In order to handle the bottlenecks congestion management methods are applied. The congestion management methods should deal with short-term congestion in an economically efficient way and provide incentives for network and generation investment in the right locations [36]. An overview of the existing congestion methods is provided in [73] and [105]. In this section two methods applied in Nordpool are briefly described.

Every day prior the spot market opening the system operators define ATC for the market. When the system price is calculated, the desired flows are checked against these ATC values. If transmission lines are not congested, the cross point between supply and demand is set without constraints. This is the case for the Nordpool market during approx. $40 \%$ of the year [66]. If a bottleneck occurs, the market is split into two separate bidding areas on each side of the bottleneck in order to maintain power transfer limit. Thus a higher price is established in the receiving end area than in the sending end area; power is then bought from the sending end area until the ATC reaches the limit. The income from buying power in the low price area and selling power in the high price area is divided between involved TSOs. This method is called market splitting and is applied in the Nordic power market.

In order to manage the bottlenecks during the actual operation hour TSO runs frequently updated load flow simulations for normal operation of the network to check correspondence for thermal and voltage stability margins. The same load flows are performed for operation after $(n-1)$ or sometimes even a sequence of contingencies. The transmission limit is defined by the most severe conditions. In fact this limit can be exceeded but with a great risk for equipment failure or even voltage collapse. The calculated limits are compared with actual load flow ${ }^{1}$. If the bottleneck occurs in actual operation hour, the corrective measures are taken by TSO in terms of re-dispatch of selected power plants on each side of the bottleneck or through disconnection of interruptible loads. The price for re-dispatching in each area is given by bid curve in the regulating market. The purchase will be made by TSO at price that is equal or higher than the unconstrained upward regulation price and the sale at price that is equal or lower than unconstrained downward regulation price [95]. The system operator will take additional costs for congestion. This method is called counter-trading and is used, e.g., within

\footnotetext{
${ }^{1}$ The voltage stability can be assessed base on the load flow only, see [99]
} 
Sweden and within each price area in Norway.

\subsection{Wind power impact on transmission capacity}

When a WF is planned in an area with limited transmission capacity, there exist several important factors that have to be considered in evaluation of WF's power output:

- Wind power production curve provided by manufacturer is applicable for the standard conditions of $15^{\circ} \mathrm{C}$ air temperature, $1013 \mathrm{mBar}$ air pressure $\left(0 \mathrm{~m}\right.$ above the see level) and $1.225 \mathrm{~kg} / \mathrm{m}^{3}$ air density ${ }^{2}$.

In Figure 3.5, power curve for BONUS $600 \mathrm{~kW}$ stall regulated turbine is shown. The first power curve is given for standard conditions. At the air density conditions other than standard the power curve 1 is not valid anymore, Figure 3.5, curve 2 and 3. This is because air density is a function of ambient temperature and pressure.

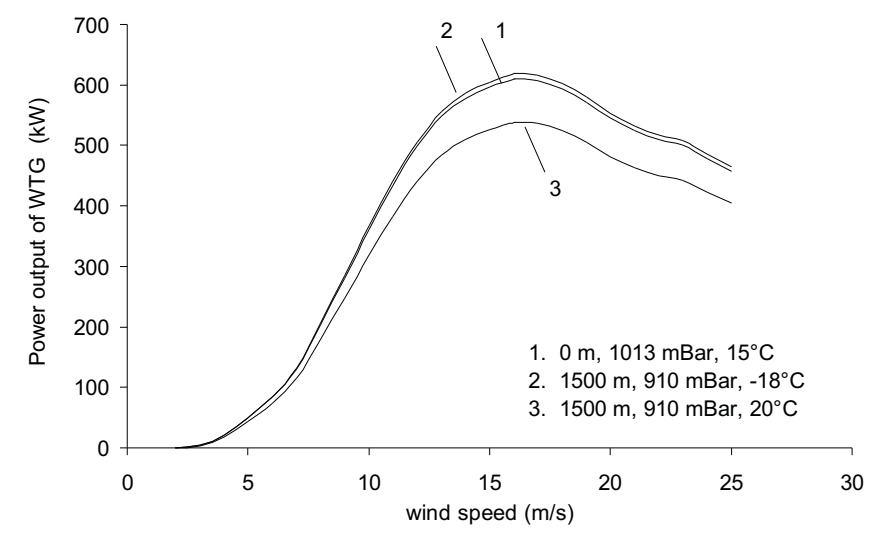

Figure 3.5: Power curve for BONUS $600 \mathrm{~kW}$, depending on ambient conditions

In pitch controlled wind turbines this effect is less significant. The wind turbine still reaches the rated power production but at higher

\footnotetext{
${ }^{2}$ These standard conditions do not apply for offshore wind turbines. There is no agreement between manufacturers at the moment, since waves are influencing the behavior of wind.
} 
wind speed than in the standard conditions. Therefore there will be fewer hours with rated wind power production than in the standard conditions.

- WTGs have low full load hours and the hours with rated power production do not necessarily coincide with peak power transmission in the considered transmission line. Furthermore, not all WTGs within a WF meet same wind speed, thus maximum power production of the WF is less often equal to the sum of rated power productions of each WTG, Figure 3.6, [75]. Due to these reasons there could be just some hours per year, when transmission limit is exceeded because of wind power. The question arises whether it is economic to increase TC to cover all possible situations? As it will be shown further in the thesis sometimes it is more economic to curtail or store excess wind energy during transmission congestion periods.

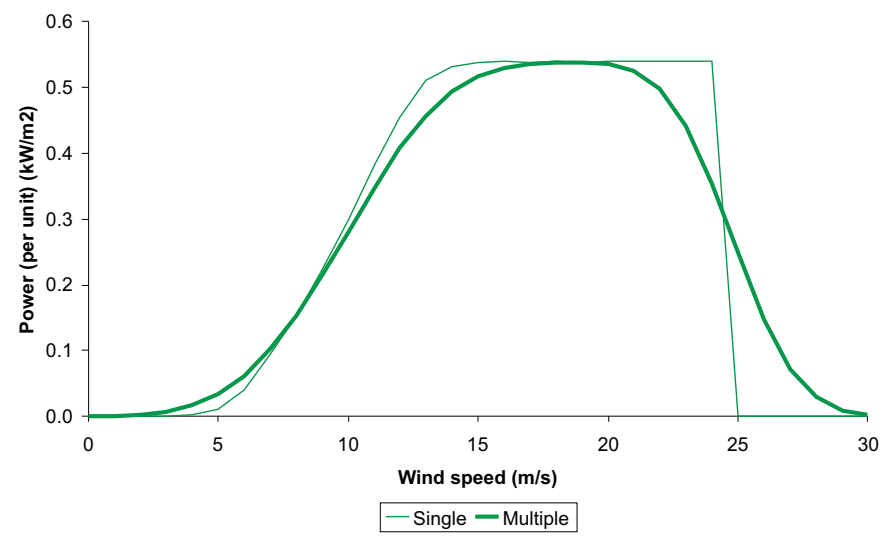

Figure 3.6: Power curve of a modern large-scale wind turbine and smoothed WF power curve, normalized by number of turbines in WF, [75]

After wind power production is carefully evaluated considering aspects described above, wind power can be treated as any conventional generation in evaluation of thermal limits. Moreover, the wind speed measurements from WF can be used for on-line estimation of current-carrying capacity of the short transmission lines as current-carrying capacity is increasing at high wind speeds. In some areas, where wind speeds are high in winter, the low temperatures also contribute to the increase of current-carrying 
capacity. This will allow an increase of power transmission. However, the on-line estimation becomes difficult for longer transmission lines. Wind speed and temperature changes considerably with the distance and it would be necessary to have wind speed and temperature measuring equipment in many places along the transmission line. This option would, thus, become expensive.

The induction generators, mainly used in wind power application, consume reactive power. If no reactive power compensation is provided, this results in lagging power factor at WF connection point. This may decrease the maximum power transfer from WF to the network, set by voltage stability consideration.

Reactive power compensation of WTG is usually provided by shunt capacitor banks, SVC or by controlling AC/DC/AC converter of WTG. Reactive power compensation provided by shunt capacitor banks depends on voltage at the connection point and, therefore, may not be sufficient at lower voltage, which is typical for systems recovering from a fault. However, if continuous reactive power compensation is used (by, e.g., SVC or control of $\mathrm{AC} / \mathrm{DC} / \mathrm{AC}$ converter), wind power does not have an impact on maximum power transfer, set by voltage stability considerations. Moreover, if leading power factor at WF connection point is provided, the maximum power transfer over the considered line could be increased [80].

During and after the faults in the system, the behavior of wind turbines is different from conventional power plants. Conventional power plants use synchronous generators that are able to continue to operate during severe voltage transients produced by transmission system faults. Earlier, variable speed WTGs were allowed or in some countries even required to disconnect from the grid during a fault in order to protect the converter. If a large amount of wind generation is tripped because of the fault, the negative effects of that fault could be magnified [42]. This may in turn affect transmission capacity in areas with significant amounts of wind power, as a sequence of contingencies would be considered in security assessment instead of one contingency. Fixed speed WTG may, during a fault, consume large amounts of reactive power from the system. This may make a recovery from the fault much slower [85]. This fact could also affect transmission capacity.

In order to ensure the secure operation of power system, the grid codes are elaborated by TSOs. In the grid codes the requirements to, e.g., active power and frequency control, power quality, protection etc. are stated. In the recent years the requirements particulary for WTGs were also created 
in some countries. If WTGs can comply with these requirements, especially, regarding reactive power compensation, active power reduction and voltage operating range during and after the fault, the impact on transmission limits may be decreased or eliminated. The grid codes of some European countries are further discussed in the next chapter.

Integration of large-scale wind power may also have special impact on determination methods of available transmission capacity due to the following reasons:

- The power output of the WF depends on wind speeds, therefore wind forecasts should be used by TSOs to prepare base case for day-ahead NTC calculation and wind speed statistics to prepare base case for determination of NTC twice a year. This could result in higher uncertainties associated with errors in prediction of generation distribution and therefore increase of transmission reliability margin, in other words decrease of net transmission capacity.

- WFs have less developed models of generator characteristics compared to conventional generation. This would make simulation results less reliable, i.e., some TSOs would choose to increase a transmission reliability margin to account for that.

Apart from impact on TC determination methods, wind power integration also requires higher investments for some of the measures for increase of TC, e.g., it could be significantly more expensive to provide sophisticated protection schemes for WFs distributed over an area than for conventional generation of equivalent capacity [42]. WF are built in remote areas where necessity for grid reinforcement is higher and more expensive than in areas close to industrial loads, where conventional generation is usually built. 



\section{Chapter 4}

\section{Requirements for connection of wind turbines to power systems}

\section{Publications $B$ and $C$}

The chapter summarizes Publications $B$ and $C$. This chapter will discuss grid connection requirements $(G C R)$ for wind turbines. The chapter will try to answer the following questions: Why GCRs for wind turbines emerged and what is the purpose? Why a comparison of GCRs from different countries is necessary? What are the main aspects defined in GCRs and why these aspects are important? At the end of the chapter the main conclusions of the comparison will be summarized.

The relationship of transmission system operator with all users of the transmission system (generators, customers, etc.) is set out in grid codes. The objectives of the grid codes are to secure efficiency and reliability of power generation and transmission, to regulate the rights and responsibilities of the entities acting in the electricity sector.

In the past there were usually no wind power connected to power system or the percentage of wind power penetration was extremely small compared to total power production. Therefore connection requirements for the wind farms were originally not included in the grid codes. As wind power technology started to develop more actively in the end of 1980 's, each network company that was facing the increasing amount of WFs developed its own 
connection rules.

The reason why the established requirements for connection of conventional generation could not apply to WTG is a difference in design concepts and, consequently, operation principles. In wind power application induction generators are mainly used, wind power production is variable and difficult to dispatch and control, etc., see Chapter 4 in [2] for a detailed description of different wind turbine design concepts. These factors result in different behavior of WTGs during normal operation and faults in the system.

During the 1990s, the connection rules were harmonized on a national level, e.g., in Germany and Denmark. This harmonization process involved national network associations as well as national wind energy associations, which represented the interests of wind farm developers and owners.

Increasing share of wind power in overall production mix of the countries, development of wind turbine technology and connection of larger wind farm directly to the high voltage grids have resulted in continuous reformulation of the requirements for WTGs even on transmission level. It was already mentioned in the previous chapter that if WF can comply with these requirements the impact of wind power on transmission limits may be decreased or eliminated. That is why the comparison of the GCRs in different countries is also of interest for this thesis.

Some TSOs still have unified requirements for all production units, which makes it very difficult for WTG producers and WF developers to fulfil. Other TSOs have defined special requirements for WTGs based on the existing requirements for conventional production units.

Unfortunately, the continuously changing network rules as well as the liberalization of the power marked make a comparison or evaluation of the already very complex connection rules very difficult and only a small amount of literature exists on this topic [15], [24], [34]. The comparison is however important and useful due to the following reasons:

- Analysis and comparison of connection requirements may help to reduce controversies between WF developer and network operator. This also concerns wind power impact on the transmission limits.

- The fulfilment of new connection requirements is a challenge for WTG producers. New hardware and control strategies have to be developed. The comparison of connection requirements in different countries might help WTG producers to get a better overview of the existing rules. 
- Provide a better understanding of relevant issues for those countries, regions, or utilities that are in the process for developing connection requirements for WFs.

In Publication B the most important aspects of connection requirements of TSOs in western Denmark (Eltra), [32], E.ON Netz, one of five German TSO's (E.ON), [33], Electricity Supply Board National Grid in Ireland (ESBNG),[35], TSO in Sweden (SvK), [93] and guidance note of Scottish Power Transmission \& Distribution and Scottish Hydro-Electric (Scottish), [82], for WTGs are discussed and compared. These documents generally contain minimum requirements by TSO to the WF owner (or generally power producer) to ensure the properties essential for power system operation, regarding security of supply, reliability and power quality.

In Publication $\mathrm{C}$ additionally the recommendations for connection of wind turbines to medium and low voltage networks of Denmark [26], [27], Sweden [92], Germany [102], UK [30], [31] and Norway [84] are compared. In contrast to transmission grid connection requirements, these recommendations are usually not obligatory and directed towards distribution network companies, wind turbine manufacturers and WF operators as well as others that are interested in connecting wind farms to the low or medium voltage network. The objective is to establish guidelines for wind turbines and networks in compliance with applicable standards for power quality and reliability of supply. The guidelines also deal with the technical data needed to assess the impact of wind turbines on power quality and discuss the requirements to be met by networks to which wind turbines are to be connected (power quality on the customer side).

Most of the considered grid codes and the connection recommendations include requirements to active power control, frequency range and frequency control, and reactive power control, fault tolerance and wind farm control in order to insure secure system operation during and after faults. The importance of these aspects is briefly explained in the subsequent subsections.

Since connection requirements, especially those newly and specifically developed for wind farms, are subject to frequent revision it is difficult to make comparison that is always up to date. Thus in this thesis (Publications $\mathrm{B}$ and $\mathrm{C}$ ) the requirements in force, or published as proposals, at the end 2003 - beginning 2004 are considered. 


\subsection{Active power control}

From a power system operator's point of view the ability to control active power is important for two reasons: during normal operation, to avoid frequency excursions; during transient fault situations to guarantee transient and voltage stability.

To secure stable power system operation the power production and power consumption in the grid has to be in balance. Changes in power supply or demand can lead to a temporary imbalance in the system and thereby affect operating conditions of power plants as well as consumers. To avoid long-term unbalanced conditions the power demand is forecasted and power plants are adjusting their power production respectively. The requirements for active power control are thus stated in order to ensure stable frequency in the system, prevent overloading of transmission lines, insure that power quality standards are fulfilled, avoid large voltage steps and inrush currents at start-up and shut down of WTGs.

Power control is also important for transient and voltage stability during faults. When a 3 -phase short circuit fault occurs in the system the voltage at the generator terminals drops to a level depending on the location of the fault, and the WTG might not be able to export as much power as is input by the wind. This leads to imbalance between input mechanical power and output electrical power and the wind turbine and therefore acceleration of the turbine. This in turn implies higher reactive power demand of the generator after the fault is cleared and thus much more difficult for the voltage recovery at the WF terminals, see section 4.4 for further details. If the mechanical power can be reduced efficiently as soon as a fault occurs, the turbine can be prevented from going into over speed [3]. Considering turbines with directly grid connected induction generators, the reactive power demand is then less after the fault is cleared, which helps re-establishing the grid voltage [4]. Another concern from the viewpoint of the power system operator is the rate with which power is ramped up after a fault is cleared. The requirement for ramp rates is made to avoid power surges on the one hand, and to avoid that generation is missing because generators ramp up too slowly on the other hand. Both cases would mean power imbalance, which could lead to instability although the initial fault is cleared.

Power control is required in all considered connection requirements for WTG. The requirements vary greatly and depend among other factors mainly on the short circuit capacity of the system considered. The lower the 
short circuit capacity the more demanding is the power control necessary for keeping the system stable during and after a fault.

\subsection{Frequency range and control}

Frequency in the power system is an indicator of the balance between production and consumption. For the normal power system operation the frequency should be stable and close to its rated value. In Europe the frequency is usually between $50 \pm 0.1 \mathrm{~Hz}$ and falls out of 49-50.3 Hz range very seldom.

The imbalance has to be catered for by the generation, since load is usually not controllable. For this purpose primary and secondary frequency control is used (e.g., Nordic power system). The primary control units increase or decrease their generation until the balance between production and consumption is restored and the frequency has stabilized. The frequency is then not necessarily stabilized on its rated value and primary control reserves are partly engaged. The time span for this control is 1-30 seconds. In order to restore the frequency to its rated value, and to release engaged primary reserves, the secondary control is employed with a time span of 10-15 min. In some countries automatic generation control is used, in other countries the secondary control is accomplished manually by request from the system operator.

At normal operation the power output of a WF can vary 10-15\% of installed capacity within 15 minutes [64]. This could lead to additional imbalances between production and consumption in the system. Considerably larger variations of power production may occur during and after extreme wind conditions. When comparing the frequency operating ranges the stiffness of the grids considered has to be borne in mind. Small systems are more prone to deviate from rated frequency in case of unbalance between load and generation than large systems. The Danish system and the Scottish system for example become small when their few connections to their neighboring systems are lost. In addition the Danish system is weakened due to the many small, dispersed generators; and the Scottish system is embedded in the British system, which is inherently small, compared to the system on the European continent. Figure 4.1 illustrates the requirements for frequency range tolerance and frequency control in the considered countries, see Publication B for further details. 


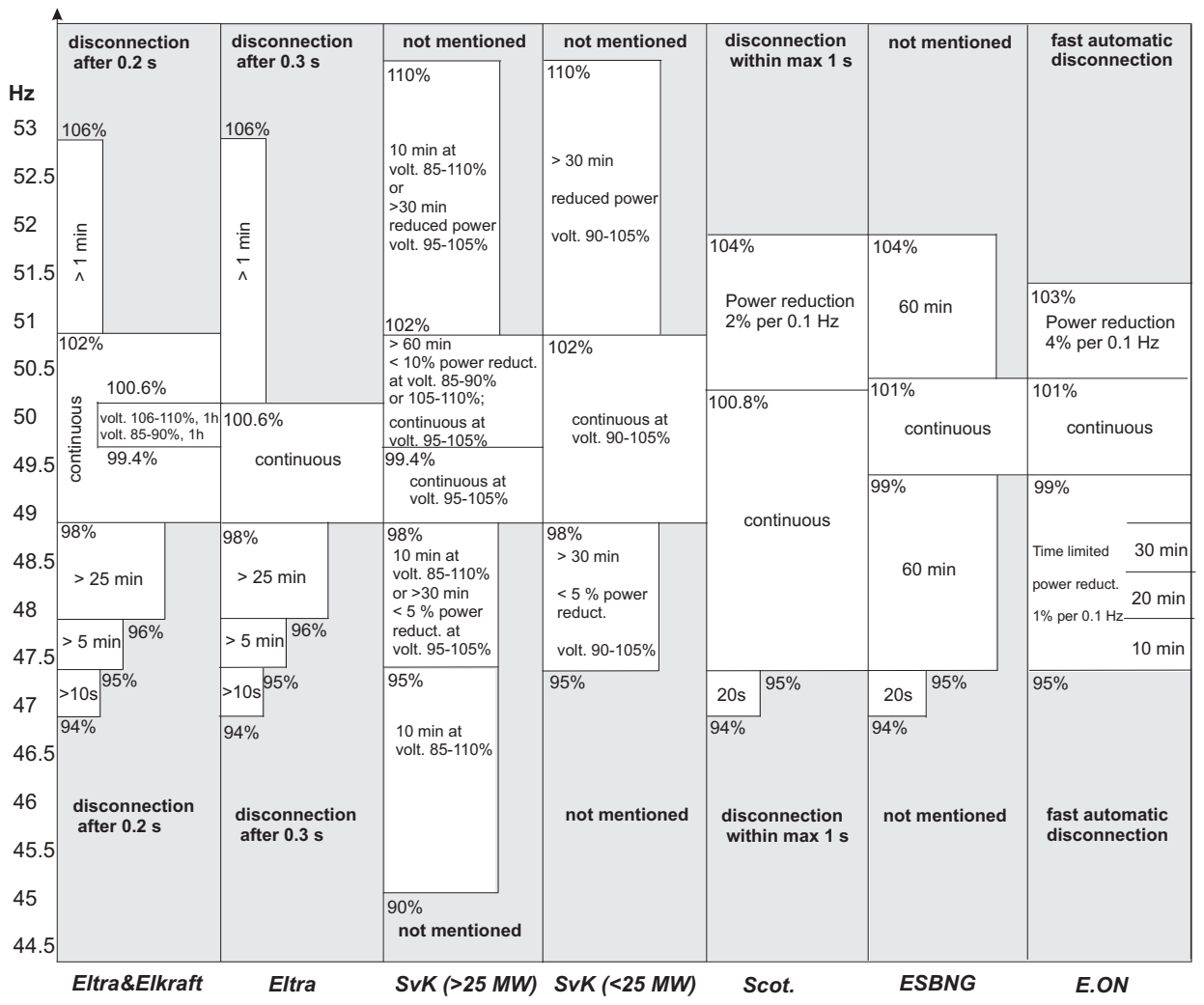

Figure 4.1: Requirements for frequency range and frequency control of WF.

A transient fault in an interconnected power system can lead to swings in the system frequency. It is desirable that the frequency tolerance of generators is as wide as possible, to avoid that under such post fault conditions the situation gets worse because generation gets disconnected.

Extensive frequency operating ranges have effects on the operation of turbines. The speed of constant speed WTGs depends directly on the grid frequency. The aerodynamic properties of the WTG's blades is nonlinearly depending on the tip speed ratio, and hence on the speed of the turbine [48]. In case of the Scottish system constant speed stall WTGs are practically 
ruled out by the new requirements. The power of constant speed stall controlled turbines, in higher wind speeds, drops more than pro rata with frequency [90], which is not allowed according to the Scottish requirements. Variable speed turbines, on the other hand, can run at the desired speed irrespective of the grid frequency.

\subsection{Reactive power control}

Utility and customers' equipment is designed to operate at certain voltage rating. Voltage regulators and control of reactive power at the generators' and consumers' connection points are used in order to keep the voltage within the required limits, and to avoid voltage stability problems, see section 3.2. WTGs are also required to contribute to voltage control in the power system.

In Figure 4.2 the reactive power requirements are compared in terms of power factor. Note that the notation "lagging" on this figure refers to production of reactive power and "leading" to absorption of reactive power. In generator sign convention the current lags the voltage when reactive and active current are positive. In Figure 4.2 only the operating limits are considered, i.e., it is not taken into account under which voltage conditions the respective amount of reactive power is demanded.

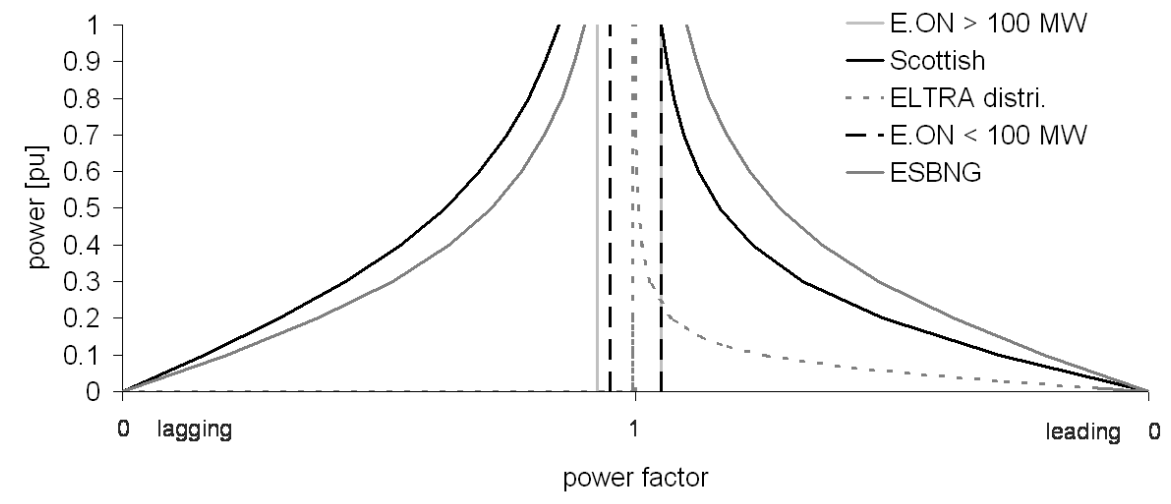

Figure 4.2: Comparison of power factor ranges as required by the different grid codes. 
Reactive power is in the first instance required to compensate for the reactive power demand of the generator, transformer and other inductive equipment, so that the wind power installation does not burden the power

system with reactive power demand. If the wind power installation absorbs reactive power, the thermal capacity of the conductors, connecting the installation with the power system, is to a lesser extend available for active power transfer. In addition the voltage at the generator terminals is suppressed due to the voltage drop caused by the reactive current flowing into the wind power installation, see sections 3.2 and 3.8 .

The second reason for reactive power requirements is that generators can actively control the voltage at their terminals by controlling reactive power exchange with the grid. Especially during transient faults, the voltage has to be supported since the reactive power demand of induction generators increases when the voltage drops [65], [5]. The requirement to the voltage operating range are discussed in the next section. Generators with voltage source inverters can support the system voltage at their terminals by exporting reactive power [6], in order to boost their active power export during the fault and hence mitigate the problem of acceleration.

The reason why generators are also required to absorb reactive power (leading power factor), as illustrated in Figure 4.2, is operating conditions like lightly loaded system conductors, see section 3.2.

Comparing the reactive power requirements for connection of WFs to the high voltage networks [32], [33], [35], [93] and [82] with recommendation for connection of WTGs to medium and low voltage networks [26], [27], [92], [102], [30] and [84] it becomes clear that the more WFs get similar to conventional power plants (big capacity and connected to a high voltage level), the wider the power factor range demanded, see Publications B and C for details.

\subsection{Transient fault and voltage operating range}

The response of the power system to a disturbance (frequency changes due to generator trips or load changes; voltage drops due to a short circuit, etc.) is determined mainly by the generators.

Previously, almost all power has been generated by conventional synchronous generators connected directly to the grid. The response of such generators under various disturbances has been studied for decades. Wind 
turbines use different types of generators (squirrel cage induction generators or generators that are connected to the grid via power electronic converter). The interaction of this generator types with the grid is different from that of conventional synchronous generators [2].

In the early 90's wind turbines were allowed to disconnect from the network during the fault to protect itself against damage. However, as wind power penetration continues increase, the additional loss of significant amount of generation during the fault may put the stability of the power system at risk. Thus, in connection requirements is stated that wind farms are now required to "ride through" the fault for a certain time without disconnection.

When a 3-phase short circuit fault occurs in the system the voltage at the generator terminals drops to a level depending on the location of the fault, and the WTG might not be able to export as much power as is input by the wind [65]. If a WF is connected by a radial feeder only, and a 3-phase short circuit occurs on this feeder, the WF can only export as much power as is dissipated in the resistances of the generators, transformers, lines and the fault. Only in Eltra WFs are exempted from having to attempt to ride through transient faults that open circuit the WF terminals. The amount of power dissipated during such a fault is, depending on the operation point of the WF, often only a fraction of the mechanical input power. As soon as the circuit breakers open, to isolate and clear the fault, the WF is isolated and cannot export any power. Hence during the fault, and even more during the clearance of the fault, the WTGs can only store the mechanical energy by accelerating. As long as the WTGs are freely accelerating the slip in the generators (assuming induction generators) is zero. But acceleration implies that the slip after the clearance of the fault is bigger than prior the fault. The bigger the slip, the bigger the reactive power demand of the generator, and this implies that it is much more difficult for the voltage at the WF terminals to recover after the fault is cleared. The longer it takes for the voltage to recover, the longer the period during which the WT is in unbalance between mechanical input power and electrical output power, i.e., the WT accelerates, or at least draws more reactive power [4], [59], [85].

In case of a 2-phase fault, the unbalance between input and output power, as well as the speed and reactive power demand problem, as described above, are less severe. But with this type of fault the voltage becomes unbalanced and this implies that the current becomes unproportionately more unbalanced, again assuming induction generators. This can be 
explained by means of the equivalent circuit of induction machines where the rotor resistance is divided by slip. Under normal operation slip is small $(<0.1)$, i.e., the rotor resistance is big. If the voltage at the generator is unbalanced it contains a negative sequence (NPS) component. This NPS voltage rotates in opposite direction of the grid voltage; hence considering this NPS voltage, slip is very big (approximately 2), i.e., the rotor has a small resistance. This implies that the NPS component of the grid voltage drives a large NPS current, which might trip the protection equipment and hence prevents the turbine from riding through the fault.

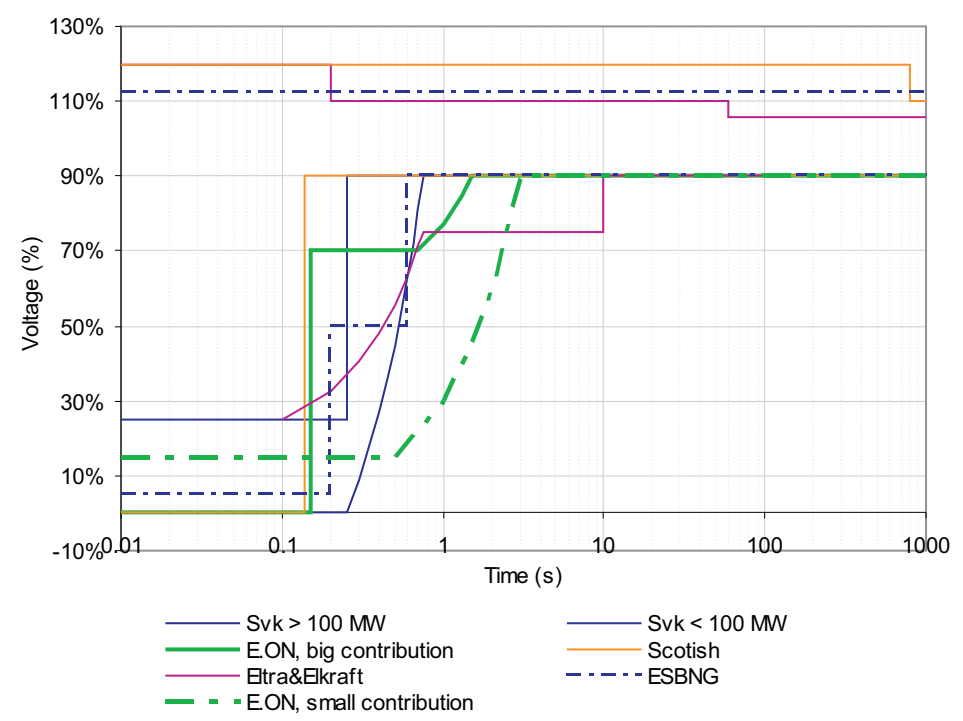

Figure 4.3: Requirements for voltage operating range of WF.

In Publications $\mathrm{A}$ and $\mathrm{B}$ the voltage operating ranges and the corresponding trip times are compared. The comparison considers the requirements in terms of "WTGs have to stay connected to the grid". Requirements stating delay times after which WTGs have to disconnect once they no longer need to stay connected are not deemed important. This is done so because, from the viewpoint of WTGs, the time during which severe operating conditions have to be tolerated is most relevant. The comparison of the different voltage operating ranges and their corresponding trip times in Figure 4.3 shows merely outermost operating limits. This means that 
no correlation to active or reactive power, as specified in the connection requirements, is considered here.

\subsection{Power quality}

Power quality is related to factors that describe the variability of voltage levels as well as distortion of voltage and current waveforms [64]. Depending on the time scale of the phenomena the various power quality parameters fall into different categories, such as harmonics, voltage flicker, rapid voltage variations, inrush currents, etc. Voltage variations and harmonics can damage and shorten the lifetime of the utility and customer equipment. Voltage flicker causes visible variations of the light intensity in bulb lamps. Inrush current may cause nuisance tripping of the equipment by its protection.

Individual wind turbines might cause power quality problems at start up of the wind turbine, as well as, due to rapid wind speed variations, pitching rotor blades, connection/disconnection of reactive power compensation. However, these problems do not occur simultaneously at all wind turbines and therefore they are mainly cancelled out within larger wind farms. On the other hand power quality problems cause more concern in the distribution networks due to the direct impact on the customers. Therefore, more attention is paid to power quality aspects in the recommendations for connection of wind turbines to medium and low voltage levels, see Publication $\mathrm{C}$ for details.

\subsection{Discussion of the connection requirements}

The brief overview of the interconnection regulations presented in Publications A and B and summarized above shows that the regulations vary considerably and that it is often difficult to find a general technical justification for the different technical regulations that are currently in use world-wide. This applies particularly to power quality regulations such as flicker and harmonics limits.

Many of the differences in the technical regulations are caused by different wind power penetration levels (percentage of wind power installed capacity in the production mix of the concerned power system) in the national power systems and different power system robustness. For instance, countries with 
a rather weak power system such as Scotland or Ireland have to consider the impact of wind power on network stability issues, which means that they require fault-ride-through capabilities of WTGs already at a lower wind power penetration level compared to countries which have very robust systems.

Discussions with wind turbine manufacturers showed that they would prefer a greater harmonization whenever possible, but they generally also say that they are able to comply with the different technical regulations. They are, however, much more concerned about the continuous changes in the technical standards world-wide, the very short notice for updates and changes and the little influence WTG manufacturers have on these aspects. Large WTG manufacturers, for instance, employ 4 to 5 or even more experts to keep track of the ongoing changes in technical regulations and to document the technical capabilities of their wind turbines. Smaller wind turbine manufacturers, which cannot employ as many experts in this area, often stay out of certain national markets because they cannot follow the changes in regulations and the corresponding required technical documentation and validation of the technical capabilities of their product.

In addition, new network interconnection regulations increase the costs of wind turbines. According to wind turbine manufacturers, allowing wind turbines with doubly-fed induction generators to "ride through a fault", as defined in many European regulations for wind turbines, increases the total costs of a wind turbine by up to $5 \%$.

Hence, it can be summarized that interconnection regulations should be harmonized in areas that have little impact on the overall costs of wind turbines, i.e., power quality regulations. In other areas, interconnection regulations should take into account the specific power system robustness, the penetration level and/or the generation technology. Therefore, interconnection standards of different countries may also vary in the future between. It is important that national regulations should aim at an overall economically efficient solution, i.e., costly technical requirements such as a "fault-ride-through" capabilities of wind turbines should only be included if they are technically required for a reliable and stable power system operation. 


\title{
Chapter 5
}

\section{Wind energy curtailments in areas with limited transmission capacity}

\author{
Publications $A$ and $D$
}

The chapter is based on Publication A (subsection 20.6.2.) and Publication $D$, but contains more details regarding modelling and results of the case study. In this chapter wind energy curtailments are considered as an alternative to costly and time-consuming transmission system reinforcement, integrating large-scale wind power into the system with transmission bottlenecks. The chapter will start with a brief introduction and an overview of previous research, then estimation methods for wind energy curtailments, developed in this thesis, will be discussed in detail. Finally the case study, concerning large scale integration of wind power in Northern Sweden, will be presented and main conclusions will be summarized.

The transmission system reinforcement in order to increase transmission capacity may be time-consuming and expensive. Furthermore, under deregulated market conditions it is also not clear how the investments for a new transmission capacity should be divided between TSO, production utilities and distribution companies. Different policies for distribution of wind farm grid connection costs and grid reinforcement costs apply in 
different countries, see Chapter 18 in [2] for an overview and the examples from Denmark, Sweden, Germany and UK. Some of these policies are ambiguous and it might take additional time to solve the controversies.

Additionally, transmission capacity should not be increased at any cost. The optimal balance should be found between extra benefit and costs for additional transmission capacity. It is obvious that it normally will not be optimal to remove a bottleneck completely. Thus, some other alternatives are necessary to handle the congestion problems and make large-scale integration of wind power possible. One possibility is curtailment of excess wind energy, when transmission is congested.

Wind energy curtailments were previously evaluated as an alternative to grid reinforcement, e.g., in [97], where this alternative was considered for a particular network during one year in order to show how much automatic generation control for avoiding transmission line overloading can influence annual wind energy output ${ }^{1}$. In [42] as well as in some grid connection requirements, e.g., [32], [93], the possibility of wind energy curtailments, particulary in case of congestion problems is mentioned.

In this thesis the estimation methods for wind energy curtailments are developed for the basic system shown in Figure 5.12.

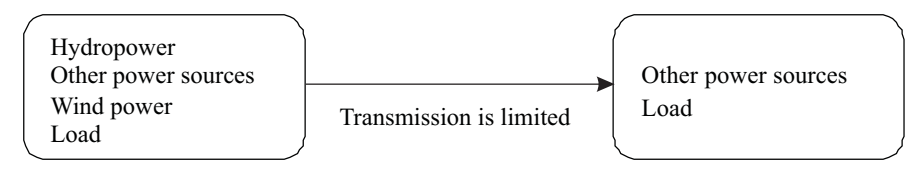

Figure 5.1: Power system with hydro and wind power production on the same side of the bottleneck

The estimation methods are based on analysis of statistical data for power transmission through the studied transmission line and wind speed measurements from the actual site. These methods can be used by WF developers at the early stage of pre-feasibility study for the project but when the wind speed measurements are already available or wind speed probability

\footnotetext{
${ }^{1}$ The calculation method applied in that paper is called "direct method" later in this chapter and used for comparison with the other estimation methods developed in the thesis.

${ }^{2}$ This figure is further used in the next chapter, where coordination between wind farm and hydro power system is discussed, that is why hydro power is also mentioned on the figure.
} 
distribution can be estimated, by TSO preparing technical prerequisites for connection of WF to the network or by authorities for evaluation of large-scale wind power integration projects.

\subsection{General assumptions}

The following assumptions and approximations are made for the estimation method:

- Statistical data (wind speed and power transmission measurements) are assumed representative for the studied site.

- The power production of the WTG is calculated using its power curve, provided by manufacturer. WTG is assumed to be pitch controlled.

- All wind turbine generators are assumed to be of the same type.

- All WTGs within one WF are assumed to meet the same wind speed simultaneously. This assumption can be relaxed using the a wake effect model developed in [57] ${ }^{3}$, however this model require statistical data on wind direction and data about the WF layout. The wake effect can be considered when evaluating particular projects.

- All WFs within the area with limited export capacity are also assumed to meet the same wind speed simultaneously. The models for so called smoothing effect due to geographically spread wind farms are developed in, e.g., [75] and [9]. These models require data about wind direction and location of the wind farms. Thus this effect can be included when evaluating particular projects.

- Available transmission capacity for the studied lines is assumed to be determined by TSO and is constant during the studied period.

- Only active power flows are considered in the estimation methods.

- It is assumed that all produced wind power may be consumed on the other side of the bottleneck.

\footnotetext{
${ }^{3}$ The wake effect model from [57] is also briefly summarized in subsection III.B of Publication $\mathrm{H}$.
} 


\subsection{Simplified estimation method}

The simplified method for estimation of wind energy curtailment in area with limited TC is based on the simplified assumption that wind power production and power transmission through the studied transmission line have correlation coefficient 1 . This means that maximum power transmission will occur at the same time as expected maximum wind power production, see also Appendix A.1. This assumption may not necessarily be realistic for the studied site but it represents the most extreme situation that can occur.

To analyze the transmission and wind power production data over the long time period, it is convenient to use duration curves. Transmission duration curve (TDC) shows for each given transmission level the number of hours, when this transmission level was exceeded, Figure 5.2. Wind power production duration curve (WPDC) shows for each given production level the number of hours, when this level was exceeded, Figure 5.2. As wind power production and power transmission are assumed to be correlated with correlation coefficient 1, TDC and WPDC can be summed to represent new duration curve for desired power transmission, including power production of the studied WFs, Figure 5.2.

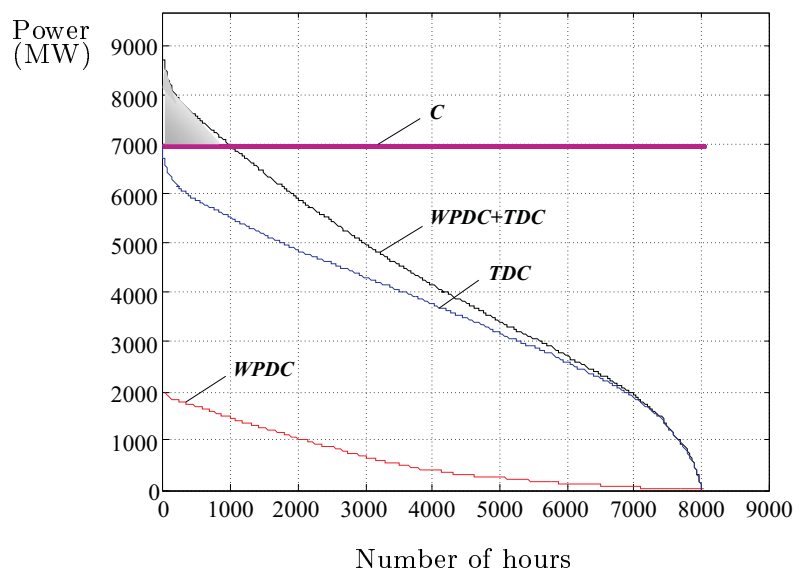

Figure 5.2: Wind power production, actual transmission, desired transmission duration curves TDC, WPDC, TDC + WPDC and transmission limit $C$ for simplified estimation method. The shaded area corresponds to the amount of wind energy that should be curtailed. 
When wind power production is too high, it could be impossible to transfer all generated power because transmission capacity is limited. If excess wind energy cannot be stored it has to be curtailed. With the assumptions listed above wind energy curtailment can be estimated as follows:

$$
W_{\text {spill }}=\int_{0}^{t_{C}}(T D C(t)+W P D C(t)-C) d t
$$

where $C$ is the transmission limit in $\mathrm{MW}$, and $t_{C}$ is number of hours when $T D C(t)+W P D C(t) \geq C$, i.e., $T D C\left(t_{C}\right)+W P D C\left(t_{C}\right)=C$. The percentage of spilled wind energy can now be expressed as follows:

$$
\eta=\frac{W_{\text {spill }}}{W_{w}} \cdot 100 \%
$$

where $W_{w}$ is energy generated by WF during the studied period $T$ :

$$
W_{w}=\int_{0}^{T} W P D C(t) d t
$$

Figure 5.2 illustrates the example of the results of the estimation method. The shaded area corresponds to the total necessary wind energy curtailment.

\subsection{Probabilistic estimation method}

This method is close to probabilistic production cost simulation [14 $]^{4}$. Applying the probabilistic estimation method, it is possible to calculate probability that transmission limit is exceeded, similarly to loss of load expectation in probabilistic production cost simulation. It is also possible to estimate necessary wind energy curtailments, similarly to expected energy not served. For this estimation method wind power production and power transmission are assumed to be independent stochastic variables.

Depending on the amount of available data, the probabilistic method can be split into discrete probabilistic method and continuous probabilistic method.

\footnotetext{
${ }^{4}$ The original reference [11] is in French
} 


\subsubsection{Discrete probabilistic method}

In the majority of cases, when plans for new wind farms are assessed, long-term wind speed measurements are available from the site. If a power transmission data series (not necessarily for the same period as wind speed measurements) is also available, the discrete probabilistic method can be used for estimation of possible wind energy curtailments.

For simplicity, let $X$ be the amount of power in MW transmitted through the bottleneck before wind power is installed. Let $Y$ correspond to expected wind power production in MW. As mentioned above $X$ and $Y$ are assumed to be discrete independent variables ${ }^{5}$.

The distribution function for transmitted power and corresponding probability mass function are $F_{X}(x)=P(X \leq x), f_{X}(x)=P(X=x)$, where $P(X \leq x)$ is the probability that transmission $X$ is less than or equal to a level $x$ and $P(X=x)$ is the probability that power transmission $X$ is exactly $x$. For the discrete case:

$$
f_{X}(x)=P(X=x)=\operatorname{freq}_{X}(x) / N
$$

where $f r e q_{X}(x)$ is frequency of level $x$ MW, $N$ is number of measurements per year;

$$
F_{X}(x)=P(X \leq x)=\sum_{i: x_{i} \leq x} f_{X}\left(x_{i}\right)
$$

Similarly, distribution function and probability mass function is expressed for wind power output $Y, F_{Y}(y)=P(Y \leq y), f_{Y}(y)=P(Y=y)$. Using long-term wind speed measurements, the power output $Y$ of the planned WF can be obtained from the power curve of the WTG. Then distribution and probability mass functions of $Y$ are calculated. Now we introduce the discrete variable $Z$, such that $Z=X+Y$. $Z$ is the desired transmission after wind power is installed in the area with the bottleneck problems. Its probability mass function $f_{Z}(z)$ is obtained from the convolution expression as follows [46]:

$$
f_{Z}(z)=\sum_{x} f_{X}(x) f_{Y}(z-x)=\sum_{y} f_{X}(z-y) f_{Y}(y)
$$

\footnotetext{
${ }^{5}$ Here the notation $X, Y, Z$, is chosen for wind power production and power transmission in order to make equations more understandable
} 
The distribution function of the discrete variable $\mathrm{Z}$ is:

$$
F_{Z}(z)=\sum_{i: z_{i} \leq z} f_{Z}\left(z_{i}\right)
$$

Figure 5.3 illustrates the results of the discrete probabilistic estimation for the same case as in Figure 5.2. As $F_{Z}(z)=P(Z \leq z)$, the value $1-F_{Z}(C)$ in Figure 5.3 corresponds to the probability that the transmission limit $C$ is exceeded.

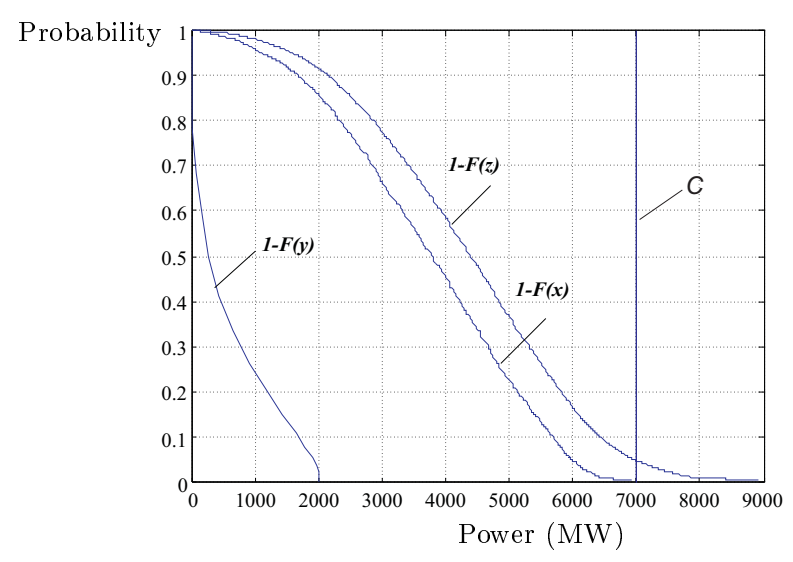

Figure 5.3: Wind power production, actual transmission, desired transmission duration curves $1-F_{X}(x), 1-F_{Y}(y), 1-F_{Z}(z)$ and transmission limit $C$ for discrete probabilistic estimation method

According to [79] availability of the WTG varies between approx. 95\% and $100 \%$ on yearly basis depending on weather conditions, age of the WTG etc. The method for deriving probability distribution function of WF production considering availability of WTGs is developed in [44], [106] and [83] and is shortly summarized in Publication D. Figure 5.4 illustrates the results of the discrete probabilistic method considering $95 \%$ availability of the wind turbines within WF. For comparison the results form Figure 5.3 where $100 \%$ availability of WTG was assumed are also placed on the same plot. The difference between results is not so significant but still might give some refinement to the estimation method. 


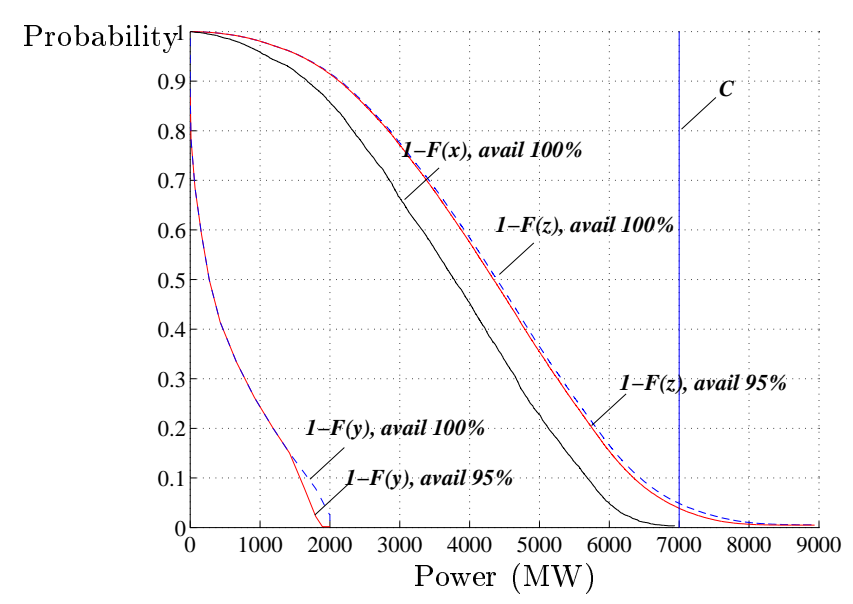

Figure 5.4: Wind power production, actual transmission, desired transmission duration curves $1-F_{X}(x), 1-F_{Y}(y), 1-F_{Z}(z)$ and transmission limit $C$ for discrete probabilistic estimation method; WTG availability $=95 \%$, solid curves; WTG availability $=100 \%$, dashed curves

\subsubsection{Continuous probabilistic method}

Continuous probabilistic method is a generalization of discrete probabilistic method and can be applied when long-term measurements are not available. Variables X, Y, Z can then be assumed continuous ${ }^{6}$ with known probability distribution. Power transmission distribution function is closely related to load distribution. In some cases Gaussian distribution function is representative for the load. Thus, for power transmission variable $\mathrm{X}$, the Gaussian function with known mean $m$ and standard deviation $\sigma$ is assumed here. The probability density function for the Gaussian distributed variable is expressed as follows:

$$
f_{X}(x)=\frac{1}{\sigma \sqrt{2 \pi}} e^{\frac{-(x-m)^{2}}{2 \sigma^{2}}}
$$

The corresponding distribution function is:

$$
F_{X}(x)=\int_{-\infty}^{x} f_{X}(u) d u=\frac{1}{\sigma \sqrt{2 \pi}} \int_{-\infty}^{x} e^{\frac{-(u-m)^{2}}{2 \sigma^{2}}} d u
$$

\footnotetext{
${ }^{6}$ Note that for continuous variable, e.g., $\mathrm{X}$, probability density is $f_{X}(x)=P\left(x_{1}<\right.$ $\left.X<x_{2}\right)$, for the finite interval $\left(x_{1}, x_{2}\right)$, where $x_{1}<x_{2}$
} 
For wind power application Rayleigh or Weibull distribution is used [43]. For the Weibull distribution the shape parameter $\beta$ can be adjusted to achieve better fit to the discrete data. The probability density function is:

$$
f_{V}(v)=\frac{\beta}{\alpha}\left(\frac{v}{\alpha}\right)^{\beta-1} e^{-\left(\frac{v}{\alpha}\right)^{\beta}}
$$

The corresponding distribution function is

$$
F_{V}(v)=\int_{0}^{v} f_{V}(u) d u=\frac{\beta}{\alpha^{\beta}} \int_{0}^{v} u^{\beta-1} e^{-\left(\frac{u}{\alpha}\right)^{\beta}} d u
$$

where $v$ is a wind speed in $\mathrm{m} / \mathrm{s}, \beta$ and $\alpha$ are the shape and scale parameters of Weibull distribution.

The mean value $\bar{v}$ and the variance $\sigma_{V}^{2}$ of the Weibull distribution are given by the following expressions, see Appendix A.2 for derivation:

$$
\begin{gathered}
\bar{v}=\alpha \Gamma\left(1+\frac{1}{\beta}\right) \\
\sigma_{V}^{2}=\alpha^{2} \Gamma\left(1+\frac{2}{\beta}\right)-\bar{v}^{2}
\end{gathered}
$$

If the mean and variance of the wind speed for the studied site are known, the equations (5.12) and (5.13) can be solved directly for $\alpha$ and $\beta$. An approximation for $\beta$ is provided in [55]:

$$
\beta=\left(\frac{\sigma_{V}}{\bar{v}}\right)^{-1.086}
$$

When $\beta$ is determined (5.12) is solved for $\alpha$

$$
\alpha=\frac{\bar{v}}{\Gamma(1+1 / \beta)}
$$

Now from the wind speed distribution it is necessary to define wind power production distribution function. Power production as a function of wind speed, or power curve, is expressed as follows, using simplified notation:

$$
y=\frac{1}{2} c_{p}(v) A \rho v^{3} \cdot 10^{-6}
$$

where $y$ is wind farm power output in MW, $A$ is swept area in $\mathrm{m}^{2}, c_{p}(v)$ is overall efficiency of turbine, $\rho$ is air density in $\mathrm{kg} / \mathrm{m}^{3}$. 
If wind speed is expressed as a function of power $v(y)$ from (5.16) and substituted to (5.10) and (5.11), the probability density function $f_{Y}(y)$ and distribution function $F_{Y}(y)$ for wind power production can be obtained. In order to express $v(y)$, the power curve needs to be inverted, however, on the intervals $0<v<v_{\text {cut-in }}$ and $v_{\text {rated }}<v<v_{\text {cut-out }}$ it is not invertible that is several values of $v$ correspond to one value of $y$. To solve this problem, the power curve on these intervals can be approximated by a smooth, increasing function, Figure $5.5^{7}$. The probability of each production level then becomes equal to probability of the respective wind speed.

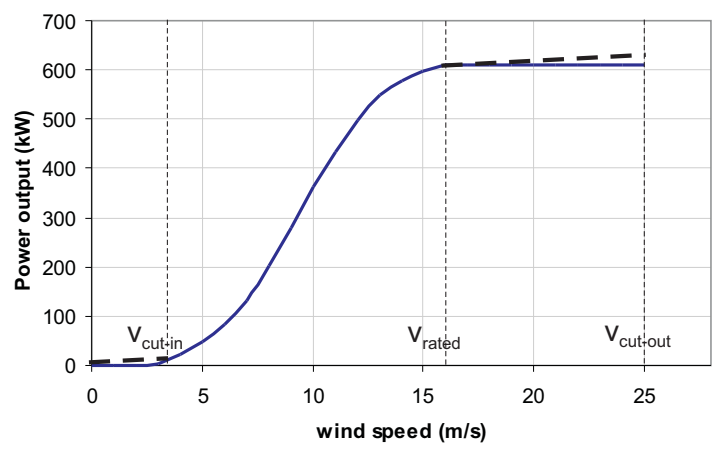

Figure 5.5: Powe curve of the WTG with rated power $610 \mathrm{~kW}$ [16], on the intervals $0<v<v_{\text {cut-in }}$ and $v_{\text {rated }}<v<v_{\text {cut-out }}$ approximated by a smooth, increasing function (dashed line).

Assuming $M$ wind turbine generators within a studied WF, the inverted power production function is obtained as follows:

$$
v(y)=\sqrt[3]{\frac{2 y \cdot 10^{6}}{A c_{p}(y) \rho M}}
$$

Substituting (5.17) to (5.10), and (5.11) probability density and distribution functions for wind power output of the WF are obtained:

$$
f_{Y}(y)=\frac{\beta}{\alpha^{\beta}}\left(\sqrt[3]{\frac{2 y \cdot 10^{6}}{A c_{p}(y) \rho M}}\right)^{\beta-1} e^{-\left(\sqrt[3]{\frac{2 y \cdot 10^{6}}{A c_{p}(y) \rho M \alpha^{3}}}\right)^{\beta}}
$$

\footnotetext{
${ }^{7}$ For illustrative purposes the deviation of the approximated power curve from the real one is somewhat exaggerated on the figure.
} 


$$
\begin{aligned}
F_{Y}(y) & =\int_{0}^{y} f_{Y}(u) d u \\
& =\frac{\beta}{\alpha^{\beta}} n^{\beta-1} \int_{0}^{y}\left(\sqrt[3]{\frac{y}{c_{p}(y)}}\right)^{\beta-1} e^{-\left(n \sqrt[3]{\frac{y}{c_{p}(y) \alpha^{3}}}\right)^{\beta}} d y
\end{aligned}
$$

where $n=\left(\sqrt[3]{\frac{2 \cdot 10^{6}}{A \rho M}}\right)$

The probability density function for the desired transmission $f_{Z}(z)$ is obtained from the convolution expression [46]:

$$
f_{Z}(z)=\int_{0}^{y_{\max }} f_{X}(z-y) f_{Y}(y) d y
$$

Substituting $f_{X}$ from (5.8) and $f_{Y}$ from (5.18) to (5.20) and after some simplifications:

$$
f_{Z}(z)=\frac{1}{\sigma \sqrt{2 \pi}} \frac{\beta}{\alpha^{\beta}} n^{\beta-1} \int_{0}^{y_{\max }} e^{-\frac{(z-m-y)^{2}}{2 \sigma^{2}}}\left(\sqrt[3]{\frac{y}{c_{p}(y)}}\right)^{\beta-1} e^{\left(n \sqrt[3]{\frac{y}{c_{p}(y) \alpha^{3}}}\right)^{\beta}} d y
$$

It is difficult to simplify (5.21) further because of overall efficiency $c_{p}(y)$, which is not a continuous function, but a set of experimentally obtained values. $c_{p}(y)$ can be calculated from the power curve of the WTG provided by manufacturer that is a set of discrete values obtained from test measurements. The overall efficiency $c_{p}(y)$ depends on aerodynamic performance, internal mechanical transmission system type and generator design of the WTG. Due to the choice of measured points we take $c_{p}(y)$ by piecewise monotone function and approximate it by piecewise linear function, Figure 5.6.

Equation (5.21) is then modified as follows:

$f_{Z}(z)=\frac{\beta n^{\beta-1}}{\alpha^{\beta} \sigma \sqrt{2 \pi}} \sum_{i=1: S}\left[\int_{y_{i}}^{y_{i+1}} e^{-\frac{(z-m-y)^{2}}{2 \sigma^{2}}}\left(\sqrt[3]{\frac{y}{a_{i} y+b_{i}}}\right)^{\beta-1} e^{\left(n \sqrt[3]{\frac{y}{\left(a_{i} y+b_{i}\right) \alpha^{3}}}\right)^{\beta}} d y\right]$

where $\mathrm{S}$ is the number of linear segments of overall efficiency curve $c_{p}(y)$; $a_{i} y+b_{i}$ is equation of a linearized segment $i ; i$ is integer number:

$$
\begin{aligned}
a_{i} & =\frac{c_{p}\left(y_{i+1}\right)-c_{p}\left(y_{i}\right)}{y_{i+1}-y_{i}} \\
b_{i} & =c_{p}\left(y_{i}\right)-a_{i} y_{i}=c_{p}\left(y_{i+1}\right)-a_{i} y_{i+1} \quad \forall i \in[1,(S-1)]
\end{aligned}
$$




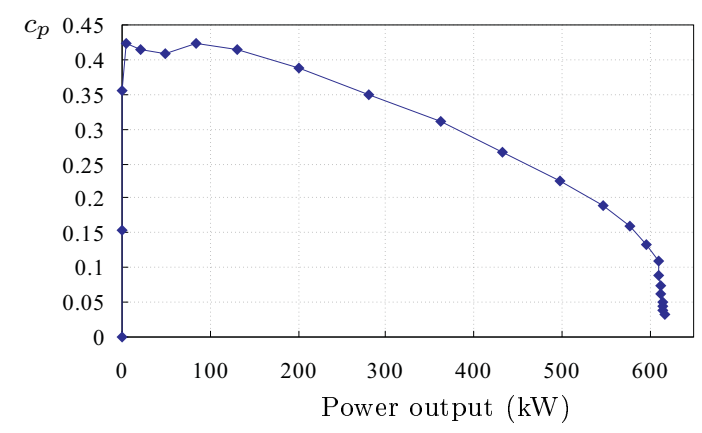

Figure 5.6: Example of piecewise linear approximation of overall efficiency curve $c_{p}(y)$ of the WTG with rated power $610 \mathrm{~kW}$.

Finally the distribution function of desired power transmission is calculated:

$$
F_{Z}(z)=\int_{0}^{z} f_{Z}(z) d z
$$

$1-F_{Z}(C)$ corresponds to the probability that the transmission limit $C$ is exceeded. The area under $1-F_{Z}(C \leq z<\infty)$ is equal to wind energy that should be spilled.

Figure 5.7 illustrates the results of continuous probabilistic estimation method using known distribution functions for the same case as the other methods. In Figure 5.7 duration curves for wind power production, transmission before wind power is installed and desired transmission are shown. For comparison the results of discrete probabilistic method, Figure 5.3 are placed on the same figure. The chosen continuous distribution functions for wind power production and power transmission approximate quite good the discrete distribution functions obtained from statistical data.

\subsubsection{Direct method}

Since wind power is only being planned, it is not possible to compare the results of the estimation methods, presented above, with any actual measurements. However, wind speed measurements $v(k)$ from a site and power transmission measurements $P_{t}(k)$ for its associated transmission line (see Figure 5.1) for the same time period with the same time resolution may be used for this purpose. For each time step $k$ the wind speed 


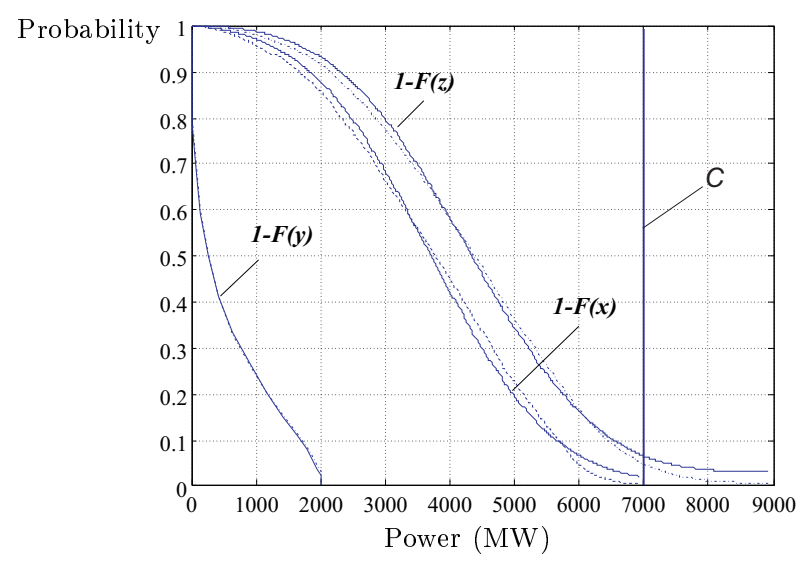

Figure 5.7: Wind power production, actual transmission and desired transmission duration curves $1-F_{X}(x), 1-F_{Y}(y), 1-F_{Z}(z)$ for continuous (solid lines) and for discrete (dash-dotted lines) probabilistic estimation methods

measurement $v(k)$ should be converted to expected wind power output $P_{w}(k)$ using power curve, as before. The desired power transmission (with wind power) is then calculated as $P_{d}(k)=P_{w}(k)+P_{t}(k)$ for each time step $k$, thus, actual correlation between power transmission and wind speed during the considered period is taken into account. If transmission limit $C$ is assumed constant, wind energy curtailment for each time step where transmission limit is exceeded, i.e., where $P_{d}(k)>C$, can be calculated as $P_{\text {spill }}(k)=P_{d}(k)-C$. Total wind energy curtailment at certain level of wind power penetration is:

$$
W_{\text {spill }}=\sum_{k} P_{\text {spill }}(k)
$$

The percentage of spilled wind energy can be expressed in accordance with (5.2), where $W_{w}$ can be calculated by (5.3) or as follows:

$$
W_{w}=\sum_{k} P_{w}(k)
$$

The resultant wind energy curtailment at each level of wind power penetration is considered as the actual case. In this thesis the results of 
Table 5.1: Comparison of estimation methods for wind energy curtailments

\begin{tabular}{|l|l|l|l|}
\hline Method & Data requirement & Advantages & Disadvantages \\
\hline Simplified & statistical data & $\begin{array}{l}\text { easy to calcul. } \\
\text { no need for synch. } \\
\text { input data series }\end{array}$ & $\begin{array}{l}\text { assumption of corr=1 may } \\
\text { not be representative }\end{array}$ \\
\hline $\begin{array}{l}\text { Probabilistic } \\
\text { discrete }\end{array}$ & statistical data & $\begin{array}{l}\text { no need for synch. } \\
\text { input data series }\end{array}$ & $\begin{array}{l}\text { assumption of corr=0 may } \\
\text { not be representative }\end{array}$ \\
\hline $\begin{array}{l}\text { Probabilistic } \\
\text { continuous }\end{array}$ & $\begin{array}{l}\text { parameters of Weibull } \\
\text { and Gaussian distrib. }\end{array}$ & $\begin{array}{l}\text { no need for long } \\
\text { input data series }\end{array}$ & $\begin{array}{l}\text { assumption of corr=0 may } \\
\text { not be representative } \\
\text { tangled for different } \\
\text { WTG types }\end{array}$ \\
\hline Direct & synch. data series & $\begin{array}{l}\text { considers actual } \\
\text { correlation }\end{array}$ & $\begin{array}{l}\text { input data difficult to } \\
\text { obtain }\end{array}$ \\
\hline
\end{tabular}

the simplified and probabilistic estimation methods presented above are compared with the direct method in order to illustrate the impact of different assumptions on the results.

\subsubsection{Comparison of estimation methods for wind energy curtailments}

The application of the suggested methods depends on available time and data as well as necessary accuracy, see Table 5.1.

The simplified and discrete probabilistic methods require wind speed measurements from the studied site as well as power transmission measurements (or estimated duration curve) for the studied line. However, as the assumption about the correlation between power transmission and expected wind power production is made (correlation is 1 or 0 ) there is no need for synchronous data series ${ }^{8}$.

If only the mean value and the variance of the Weibull distribution for the wind speed and Gaussian distribution for power transmission are available the continuous probabilistic method may be used.

The simplified method is straight forward and may be applied in areas, where wind speed and power transmission are strongly correlated. For the areas where correlation between wind speed and power transmission is lower than 1, the simplified method gives the worst case approximation of wind energy curtailments. If there is low or no correlation between wind speed and power transmission, the probabilistic methods (discrete or continuous) give more accurate results. This is shown in a case study in the next subsection.

\footnotetext{
${ }^{8}$ Data series for the same time period
} 
For the estimation methods it is assumed that all WTGs within one WF are of the same type, which is not always true. This complication can be easily treated in simplified and discrete probabilistic production method, but the continuous method becomes rather tangled because of it.

\subsection{Case study, estimation of wind energy curtailments}

The developed estimation methods for wind energy curtailments are tested on the Swedish power system. The case with up to $4000 \mathrm{MW}(\approx 10 \mathrm{TWh})$ wind power in northern Sweden is studied in order to compare economical losses due to wind energy curtailments with investments necessary for the grid reinforcement suggested in [8], this study is also briefly mentioned in section 2.2 .

To adopt the model for the case study to the two area model in Figure 5.1, Sweden is divided into two parts, North and South of Cross section 2 (in Figure 2.4b). Thus, we have a two-area model with mainly hydropower production and load on one side of the bottleneck, where also up to 4000 MW wind power are tested, and thermal power production and load on the other side of the bottleneck.

Power transmission through the bottleneck is assumed constantly limited to $7000 \mathrm{MW}$. The power flow on the other transmission lines are for simplicity assumed unaffected by wind power integration. This assumption is not realistic as there exist transmission possibilities to Norway and Finland, see Figure 2.4.b, but represents the worst case scenario for the Cross section 2.

Data from January-November 2001 are used for the case study. Hourly loads in northern Sweden including export/import to the neighboring countries and hourly production in northern Sweden are used to calculate hourly power transmission in 2001 (see also Figure 2.5). Wind power production is calculated using 10-minute average wind speed measurements from the site Sourva in northern Sweden (additional information about this site is available in [13] and [21]). From these wind speed measurements hourly average wind speeds are calculated and converted to power using the power curve for a $600 \mathrm{~kW}$ pitch controlled with turbine. Then, calculated power output is scaled to represent different levels of wind power penetration in northern Sweden. 


\subsubsection{General results}

Some of the results for simplified, discrete probabilistic and continuous probabilistic methods were already presented above in Figures 5.2, 5.3 and 5.7 respectively. These figures illustrated the results with $2000 \mathrm{MW}$ wind power integrated in northern Sweden. Each figure indicates number of hours (simplified estimation), or probability (probabilistic estimation), when transmission limit is exceeded as well as potential energy curtailments. Figure 5.7 also shows that both probabilistic methods (discrete and continuous) give quite close results. This can be explained by our choice of parameters $\alpha, \beta$ and $m$ for Weibull and Gaussian distributions in the continuous estimation. In this case study, the parameters were calculated from the same statistical data as used in discrete estimation. Also the Gaussian and the Weibull distribution functions itself have proved to be quite good approximation. Since the results of continuous and discrete probabilistic methods are so close, only discrete probabilistic method is considered in the proceeding analysis.

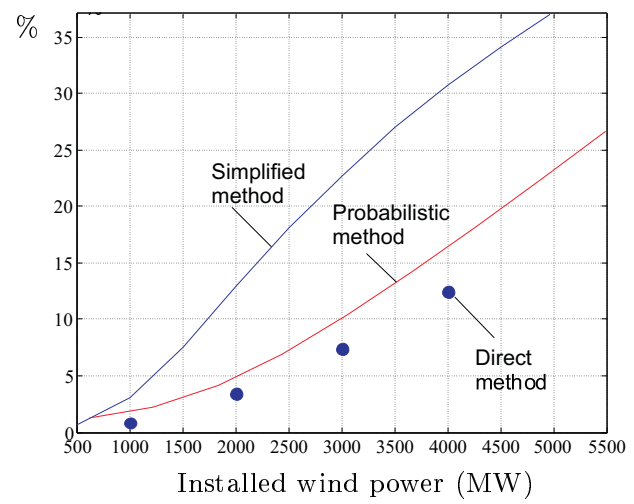

Figure 5.8: The percentage of wind energy that has to be spilled at various wind power penetration levels, estimated with simplified method, discrete probabilistic method and direct method

For other wind power penetration levels similar calculations were made. Figure 5.8 illustrates the percentage of wind energy that has to be curtailed at various wind power penetration levels. The results from simplified estimation, discrete probabilistic and direct method are placed on the same 
figure. For the direct method 4 various penetration levels of wind power are tested.

Direct method is used in this thesis to illustrate how the results of estimation method agree with "reality". Since in a direct method the synchronous data series for wind speed and power transmission are used, the actual correlation between these two data series is included in the results. The actual correlation coefficient during 2001 between wind speed in Sourva and power transmission, calculated from these data series is -0.06, i.e., during that year the tendency was that the highest wind speeds in northern Sweden were during the time when transmission was somewhat lower than the maximum. Therefore, the resulting wind energy curtailment points from direct method are lower than the curtailment curve calculated by probabilistic method. As mentioned in the previous chapter the synchronous data series may not be available. Furthermore, more extensive analysis of data series is necessary to make the conclusion about actual dependency between wind speed and power transmission. In the following analysis the results of probabilistic methods are used to insure that wind energy curtailment is not underestimated.

Table 5.2: The percentage of spilled wind energy at various levels of wind power penetration

\begin{tabular}{|c|c|c|c|}
\hline $\begin{array}{c}\text { Installed } \\
\text { wind power [MW] }\end{array}$ & $\begin{array}{c}\text { Transm. limit } \\
\text { exceeded [h] }\end{array}$ & $\begin{array}{c}\text { Spill, \% } \\
\text { (discrete probabilistic method) }\end{array}$ & $\begin{array}{c}\text { Spill, \% } \\
\text { (direct method) }\end{array}$ \\
\hline 1000 & 94 & 1.9 & 0.8 \\
2000 & 453 & 5 & 3.4 \\
3000 & 750 & 10.1 & 7.4 \\
4000 & 1019 & 16.7 & 12.4 \\
\hline
\end{tabular}

\subsubsection{Economical evaluation}

Transmission grid reinforcement is economically motivated only if the costs for the wind energy curtailment exceed the costs for new transmission lines. The following economic evaluation is made in order to compare these costs. According to [8] $4000 \mathrm{MW}$ of additional transmission capacity costs 20000 MSEK, which at 10\% interest rate and 40 years lifetime gives 2000 MSEK/year. This corresponds to five new $400 \mathrm{kV}$ transmission lines with transmission capacity of approximately $800 \mathrm{MW} /$ line. Therefore, if a new 
lines were build, it should reduce wind energy curtailment with at least 400 MSEK/year.

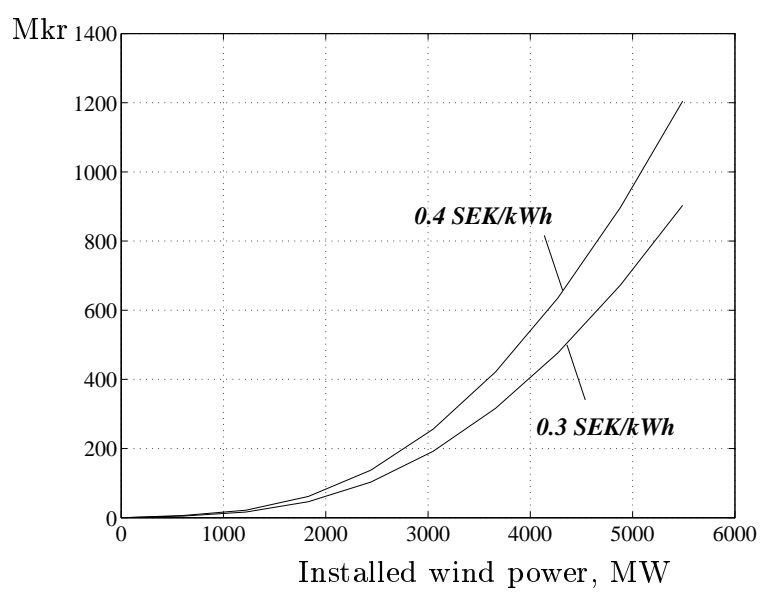

Figure 5.9: Wind energy curtailment expressed in MSEK (Mkr) per year, at energy cost of $0.3 \mathrm{SEK} / \mathrm{kWh}$ and $0.4 \mathrm{SEK} / \mathrm{kWh}$

In Figure 5.9 spillage of wind energy from Figure 5.8 is expressed in MSEK/year, assuming that curtailed wind energy costs $0.3 \mathrm{SEK} / \mathrm{kWh}$. According to Figure 5.8 and Figure 5.9 at 4000 MW penetration of wind power, $15.4 \%$ of wind energy will be curtailed with cost of approximately $410 \mathrm{MSEK} /$ year.

If the new line is built, $800 \mathrm{MW}$ of wind power can be transmitted without curtailment and the residual $3200 \mathrm{MW}$ will be subject to a spill of $10.5 \%$ of wind energy, see Figure 5.8. The cost of wind energy curtailment is then $220 \mathrm{MSEK} /$ year, Figure 5.9. This means that the new transmission line will decrease costs for spill to 410-220=190 MSEK/year. According to [8], the cost for this line is $400 \mathrm{MSEK} /$ year. Therefore it is not economically motivated to build a new line under the assumptions made.

Now let us assume that wind energy curtailment costs $0.4 \mathrm{SEK} / \mathrm{kWh}$ and analyze spillage costs versus grid reinforcement costs the same way as before, Figure 5.9. The total cost for curtailed wind energy at $4000 \mathrm{MW}$ wind power penetration is $540 \mathrm{MSEK} /$ year in this case; for $3200 \mathrm{MW}$ it is 
$300 \mathrm{MSEK} /$ year. Consequently, a new transmission line decreases costs for energy spillage to $540-300=240 \mathrm{MSEK} /$ year. The conclusion is that even in this case it is not economically motivated to build a new line.

\subsubsection{Impact of the assumptions on calculation results}

It is important to point out that the preceding analysis provides answers two questions:

- How much wind energy is curtailed?

- Is it economically motivated to build a new line?

The estimated wind energy curtailment may change with the assumptions. However, as the assumptions are the same for each level, the relative difference in the results for each level of wind power penetration will still be the same. Therefore the answer to the second question will not change, unless the costs for the transmission line are estimated differently (e.g., with lower interest rate). A new transmission line may also decrease a risk for capacity deficit, the cost for a new line could then be split between TSO and WF developer. This corresponds to lower costs for the transmission line in the analysis above.

The following explains how the changes of assumptions may influence estimated wind energy curtailment:

- In the preceding analysis wind data from one site and the power curve of one turbine were used and scaled to represent various wind power penetration levels. In reality, however, the wind power turbines will be of various types and spread around a wide area. Wind energy curtailments are likely to occur at high wind speeds. With large spatial distribution of wind turbines it will be more unusual for all turbines in the studied area to face the same high wind speed simultaneously. The studies on spatial smoothing effect are provided, e.g., in [9], [40], [75].

- It was assumed in the analysis that all WTGs are of the same type. This is not always true and may have different impact on wind energy curtailment. Assume for example that turbines designed for low wind speed sites, i.e., with lower rated wind speed and lower rated power, are 
used at high wind speed sites. Thus, wind power production peaks will be reduced, but annual energy yield may still be the same. Depending on annual power transmission variations this may help to reduce wind energy curtailment.

- Transmission limit assumed in this case study is defined by TSO is constant. However, as it was described in sections 3.4 and 3.5, it is possible to define the transmission limits as, e.g., a function of weather conditions, power prices and other factors affecting the grid operating costs. Then the transmission limit becomes variable and the spillage of wind energy could be affected. The impact will generally depend on correlation between wind power production and transmission limit.

- It was assumed that there is no wind power production coordination with power production at local conventional power plants, local flexible load or any kind of storage. If this is used, the wind energy spillage can be substantially reduced. This will be further discussed in the next chapter.

The estimation is based on the assumption that wind power can be consumed in southern Sweden. If the congestion problem occur more often, the consumption variations would need to be balanced by power plants south of Cross section 2. It is possible that it is less expensive to build new line so that consumption variations could be balanced by northern hydropower. If transmission to Norway and Finland can be used to balance this variations, the problem will be less significant. This could be further studied in the future. 


\title{
Chapter 6
}

\section{Coordination of wind power and hydro power in power systems with transmission bottlenecks}

\author{
Publications E, F, G
}

In this chapter the possibility to coordinate wind power and hydro power in power systems with transmission bottlenecks will be discussed. First, the comprehensive overview of the previous research on this subject will be provided, followed by a brief summary of the pre-feasibility study conducted in Publication E. Then a planning algorithm for a hydro power utility coordinated with wind power utility in area with limited power export capability developed in Publications $G$ and $F$ will be presented in details. An evaluation algorithm developed to study the impact of the coordinated planning on both utilities in the long term will also be given in details. The developed methods are applied to the case study. The short summary of the case study and its main findings will conclude this chapter.

In the preceding chapter the possibility of wind energy curtailment in power system with transmission bottlenecks was considered as one of the alternatives to transmission grid reinforcement. Another alternative would 
be to store excess wind energy during the congestion situations and use it later, when congestion is relaxed. A battery storage or pumped hydro storage for large scale wind power is still very expensive. On the other hand existing conventional power plants with possibility of fast production control and sufficient storage capacity (e.g., hydro power plants or gas fired power plants) situated in the same area may be used for this purpose.

\subsection{Overview of previous research}

The interest for coordination of wind power and hydro power has increased during the last couple of years. It is studied by utilities (e.g. Vattenfall [69], Hydro-Quebec [62]) as well as by research organizations (e.g. SINTEF in Norway [97], [98], [61], NTNU in Norway and VTT in Finland [103], [104], Universidad Carlos III de Madrid in Spain, [7]),

The coordination of wind power and hydro power has been studied in connection with several different problems. The research can be divided into two main categories:

1. "Pre-feasibility" studies, where coordination possibility is evaluated for different purposes, using available tools [103], [104], [69], [97], [98] or developing new evaluation methods [62], [61], Publication E;

2. Planning methods that is development of new planning methods for hydro power utility considering coordination with wind power [60], [22], [7], Publication F and G.

In [62] the coordination option is considered in generation expansion planning, where two investment possibilities are compared: new hydro power plant vs new wind farm. In [103], [104] the effect of wind power on the market price is analyzed. The research in [103], [104] is directed towards assisting hydro power utilities considering investments in wind power.

In [97] and [98] wind energy storage in hydro reservoirs is considered in connection with bottleneck problems in the network. The paper shows to what extent automatic generation control of WF and and HPP for avoiding line overloading may influence the annual energy output of each of these production sources. [61] offers further in-depth evaluation of the coordination possibility. The coordinated operation of several geographically spread wind farms and aggregated hydro power plant ${ }^{1}$ sharing same transmission

\footnotetext{
${ }^{1}$ Equivalent of the HPP system, modeled as one HPP
} 
capacity, is simulated over a period of several years, considering wind and water inflow uncertainty. The simulation uses coordination strategy that maximizes wind power penetration. The paper shows that due to coordination, significantly more wind power can be developed in the studied area.

In Publication E several coordination strategies are elaborated which consider separate ownership of wind power and hydropower. The coordination strategies are then evaluated using historical data of water inflow and wind speed measurements from the studied site. The evaluation method is rather close to the latter reference, [97], although there are some differences in modeling and input data. Also in contrast to [97], in Publication E, several coordination strategies are suggested, modeled and evaluated.

None of the papers above, however, treats hydro power production planning for daily operation, considering the coordination with wind power.

In [60] the dynamic programming algorithm is presented for a daily planning of coordinated operation of wind parks and generic energy storage in area with limited export capability. In [22] the optimization problem is formulated for daily production planning of wind park and pumped storage hydro power plant, though transmission bottlenecks are not considered. Also, in [60] and in [22] the storage is owned by the wind power utility, wind power production is assumed to be deterministic and multi-reservoir hydro power systems are not considered. These limitations are overcome in planning algorithms developed in this thesis in Publications F and G.

One of the most recent publications on coordinated planning of wind and hydro power plants is [7]. In that paper the coordination is applied in order to minimize WF imbalance costs, section 2.4. Thus, the coordination with HPPs is employed only on the intra-day market. Actual wind power production is considered known, spot market prices and imbalance penalties are treated as deterministic. The transmission constraints are not considered in the planning. 


\subsection{Coordination strategies for wind power and hydro power with separate ownership}

In this thesis also the "pre-feasibility" study of wind-hydro coordination in areas with limited export capacity has been conducted first ${ }^{2}$.

The coordination of wind power and hydro power production may take many different forms. Some of the possible strategies are elaborated in this thesis in Publication E:

1. Business as usual-"uncoordinated case"; The HPPs system is managed as if there was no wind power. Both wind power and hydro power are produced if transmission capacity is not exceeded. If the congestion occurs, wind power is curtailed. An advantage of this strategy is that no coordination is necessary, but the amount of curtailed wind energy can be large.

2. Buy wind power production; In this strategy the HPP owner buys the whole wind power production every hour and then manages the operation as if he owned the WF too. Wind or water are spilled, or stored if possible, when the total production exceeds maximum transmission capacity.

3. Store hydro power and sell later on the spot market; During congestion in the transmission line, the hydro power owner can decrease the hydro power production, if it is possible to store water. The WF can then use available transmission capacity. Stored power at the HPPs is sold later at the spot market. It is assumed that wind power owner is paying hydro power owner for each MW of transmission capacity that is made available due to coordination with HPPs.

It is important to note that the hydro power producer can reduce the production only at hours with congestion. HPP production can only be increased (compared to the production plan for the uncoordinated case) when there is no congestion in the transmission lines.

4. Forced regulation; During congestion in the transmission lines, the hydro power owner must decrease the hydro power production

\footnotetext{
${ }^{2}$ This study was conducted by A. Jäderström as a thesis for M.Sc. degree, under supervision of J. Matevosyan
} 
(compared to the production plan for the uncoordinated case), if it is possible to store water. The WF can use available transmission capacity. Stored power at the HPPs is sold later at the spot market. Economical losses due to the forced reduction of hydro power production are assumed compensated by the system operator, who in turn benefits from grid tariffs due to more intensive utilization of the transmission lines. This strategy can be put into effect, e.g., by special agreement between involved parts or by applying counter-trading to the transmission line in question, see section 3.7.

The strategies are modeled for a particular case study. Wind speed measurements from the studied site are used to simulate WF operation. Linear programming is applied in order to simulate HPP production for each strategy based on deterministic loads, wind speeds, water inflows, and electricity prices. Uncertainties with regard to water inflow, wind speeds and market prices as well as HPP participation in regulating market are not considered. This evaluations still provides a sufficient basis to quantify relative impact of the transmission bottlenecks and coordinated operation of wind and hydro power plants. The results of coordinated operation (strategies 2-4) are compared to the uncoordinated strategy. As this study was conducted just as a pre-feasibility study the modeling details are not discussed here and the reader is suggested to consult Publication E for details. The results of the case study are summarized in section 6.5.

In Publication $\mathrm{F}$ and $\mathrm{G}$ the planning algorithm for hydro power in coordination with wind power according to strategy 3 is developed. The planning algorithm is presented in detail in the following sections.

\subsection{Overview of the planning algorithm}

In this thesis the daily planning algorithm is developed for a conventional multi-reservoir hydro power system coordinated with a wind farm. It considers the uncertainty of the wind power forecast (Publications F and G) and the uncertainty of the spot and regulating market prices (Publication G).

Wind power and hydro power are assumed to be owned by different utilities. It is assumed that the wind farm and the HPP system share the same transmission lines, but that the hydro power utility has priority to use the transmission capacity. Consequently, coordination is necessary in 
order to minimize wind energy curtailments during congestion situations on the transmission lines. The wind power utility is assumed to be paying the hydro power utility for the coordination service.

A hydro power system is assumed to be coordinated with a WF in the following way: for each hour of the coming day, if transmission congestion is expected, the hydro power utility decreases its planned production depending on constraints of the hydro reservoirs. Energy is then retained in the hydro reservoirs and the wind farm can use available transmission capacity. Each MW of stored hydro power corresponds to $1 \mathrm{MW}$ of transmission capacity that is made available for excess wind energy. Stored hydro power can then be used in the hours without congestion. This corresponds to coordination strategy 3 in the preceding section.

The hydro power utility and the wind power utility are assumed to be price takers. Cooperative behavior of the hydro power utility is also assumed.

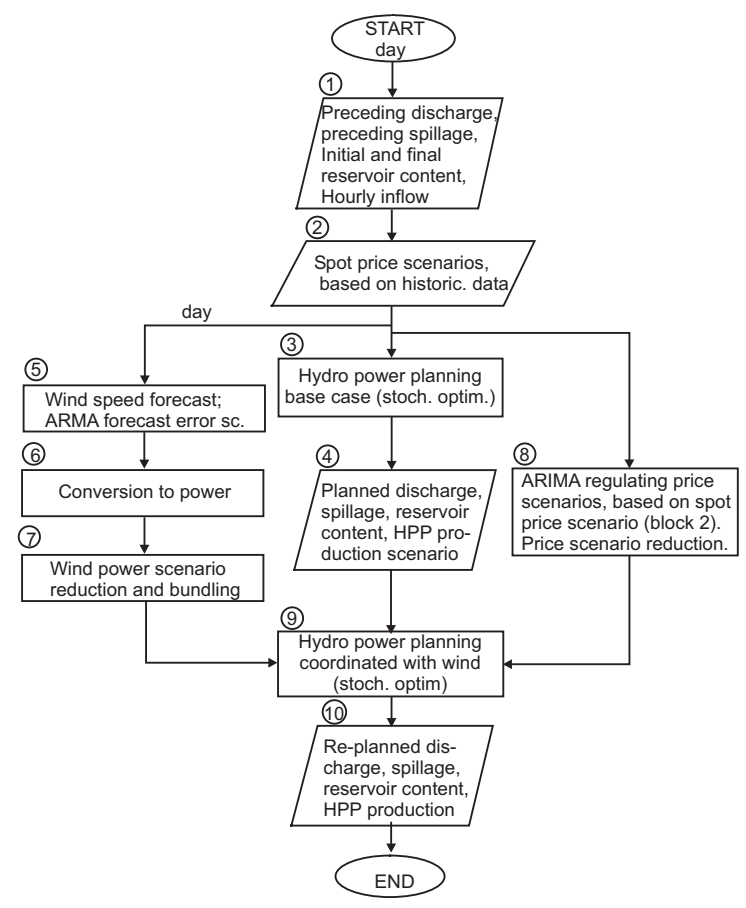

Figure 6.1: Flow chart of the daily hydro power planning coordinated with wind power 
The planning algorithm developed in this thesis (Publications $\mathrm{F}$ and $\mathrm{G}$ ) is shown on the Figure 6.1. In this section a brief overview of the planning algorithm is provided. The modeling details are explained in the following sections.

The hydro power planning for the coming day is assumed to be conducted at 11:00 the day before, in order to place the bids on the spot market that closes at 12:00, section 2.4. For the day to which the planning refers (the planning day) input data are loaded (blocks 1-2): the water inflow, the initial reservoir content at the beginning of the planning day and the final reservoir content at the end of the current week, the spillage and the discharge in the preceding hours to account for the water delay time between the reservoirs and the spot prices.

In order to deal with uncertainty of the spot prices a set of the spot price scenarios is used. Each spot price scenario corresponds to a particular realization of the stochastic process. Here, to generate a set of spot price scenarios, sampling from historical spot price time series is employed. Equal probability is assigned to each spot price scenario.

The set of spot price scenarios form a scenario tree. The root node of the tree corresponds to a known spot price at the time of planning. The tree then branches into the nodes of the subsequent hours. Each node has a unique predecessor node but possibly several successors. The branching continues to the nodes of the last hour of the planning day [51]. The number of the nodes for the last hour of the planning day corresponds to the total number of spot price scenarios. The schematic structure of the spot price scenario tree is shown in Figure 6.2.

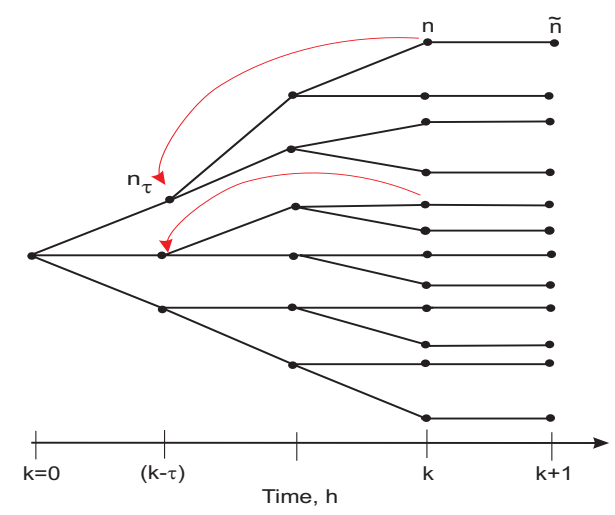

Figure 6.2: Schematic example of the spot price scenario tree. 
The wind power utility is assumed to pay to the hydro power utility for the coordination service. Therefore it is important in the coordinated planning to keep track of the exact amount of hydro power production changes due to wind power and congestions on the transmission lines. For this purpose the planning is divided into two parts:

1. Base case hydro power planning for the spot market without consideration of wind power (blocks 3-4);

2. Re-planning of hydro power production for the spot market and regulating market, considering coordination with wind power (blocks 9-10).

The results of the base case planning - water discharge, hydro power production, water spillage are passed to the re-planning part of the planning algorithm as parameters.

The re-planning part of the algorithm requires wind power production scenarios as an input data. Wind speed forecast is assumed available for the planning day. Wind speed forecast error is a stochastic process. In this thesis the wind speed forecast error model is based on Auto Regressive Moving Average series (ARMA), (block 5). By sampling from ARMA series wind speed forecast error scenarios can be generated. The sum of the wind speed forecast and the forecast error scenario represents wind speed scenario for the coming day with hourly resolution. Wind speed scenarios are converted to wind power production scenarios (block 6). A special scenario reduction technique is then used to reduce the number of wind power production scenarios.

The re-planning part of the planning algorithm also require the regulating market prices as an input data. For each spot price scenario (from block 2), a pair of regulating price scenarios (upwards and downwards regulation prices) is generated. The regulating prices are modeled with Auto Regressive Integrated Moving Average (ARIMA) series (block 8). The scenario reduction technique is used to reduce number of scenarios.

In addition to the coming day the rest of the current week is also included in the planning (block 3 and block 9 ) for two reasons:

- To account for the wind power that might be produced during the following days in the re-planning part of the planning algorithm.

- Hydro reservoir content at the end of the week is fixed in accordance with the mid-term planning, [41];. 
It is possible to use a more flexible representation of the end conditions for hydro reservoirs. In the short term hydro planning the so-called water value function is often used. The water value function shows the expected future income of the hydro power utility as a function of hydro reservoir content [41]. However, in a discussion with hydro producers, it was pointed out that by using the water value function the effect on operation of the hydro power system from coordination with the wind farm would extend to longer periods. Operation of the hydro power system would then be strongly affected by coordination with wind power. By fixing reservoir content at the end of the week to a certain value, the effect of coordination does not extend beyond that week, although it might negatively affect wind energy curtailments.

In Publication $\mathrm{F}$ only the planning for the spot market is considered, spot prices are assumed deterministic. The base case planning part (block 3 ) is formulated as deterministic linear optimization program. In the re-planning part also only the planning for the spot market is considered, block 8 is thus excluded from the flow chart in Figure 6.1. The re-planning problem (block 9) is formulated as a stochastic optimization program - many wind power production scenarios are considered simultaneously. However, once the hydropower production bid is placed on the market it cannot be changed. The solution of the stochastic optimization problem should, therefore, fulfill the transmission constraints for all wind power production scenarios, so-called "fat solution", [56].

In Publication $\mathrm{G}$ the planning algorithm from Publication $\mathrm{F}$ is further improved $^{3}$. The base case part of the planning algorithm is optimization under spot price uncertainty. This part is formulated as a stochastic program. In the re-planning part the planning for the spot market is conducted considering coordination with wind power and, as wind power production is uncertain, hydro power production adjustments are also planned for each wind power production scenario. Bids for these adjustments can be made as upward or downward regulation bids to the regulating market during the day when wind power production forecast would become more precise. The optimization problem is then formulated as a two-stage stochastic program with recourse [56] and hydro power

\footnotetext{
${ }^{3}$ Since Publication G gives further improvement to the algorithm developed in Publication F, in the following section the modeling details for the planning algorithm from Publication $\mathrm{G}$ are presented.
} 
production adjustments are recourse variables. The uncertainty of power market prices is also considered.

In addition to the planning algorithm discussed above, an evaluation algorithm has also been developed to quantify the impact from the coordinated daily planning on the operation of the HPP system and the WF in the long term. The purpose of this algorithm is to run the coordinated daily planning successively day by day over a certain period of time (e.g., one year). For evaluation it is convenient to choose some period in the past, so that actual power market prices and wind speeds would be available. The coordinated and uncoordinated operation could then be compared.

\subsection{Mathematical formulation of the planning algorithm}

\subsubsection{Base case hydro power production planning}

This subsection discusses modeling details of the base case hydro power planning part, without consideration of wind power, (block 3), Figure6.1.

Generally, hydropower production is planned differently by different utilities. There is a large variation in modeling for example the degree of details and representation of uncertainties. Furthermore, actual operation is not always in accordance with production plan because of unexpected events, for example generator outages or participation in the regulating market etc.

The hydro power production characteristic of each unit in a hydro power plant is a family of nonlinear functions of the respective reservoir head, efficiency of the turbine/generator set and water discharge. The generation functions of all production units form a family of nonlinear and nonconcave production curves each for a specified value of the water head [25].

In most short-term planning methods the head dependence is neglected to avoid nonlinearities, which allows to use a single production curve. Furthermore this single production curve is usually approximated by either:

- modeling just the best local efficiency points, Figure 6.3, which leads to linear mixed-integer optimization problem, [70], or

- modeling production curve without head dependance, by a concave piecewise linear function, e.g., one of the linear functions in Figure 6.3. This leads to linear optimization problem, [47]. 
A more detailed method is presented for example in [25], where head dependence is considered and production characteristic is represented as a family of nonconcave piecewise linear functions each for specified value of the head, Figure 6.3.

Linear stochastic optimization problems can be solved in reasonably short time, in contrast to linear mixed-integer or nonlinear stochastic optimization problems. Also, the main focus in this thesis is not on hydro power planning itself but on coordination with wind power in hydro power planning. Therefore, the hydro power production characteristic is approximated by one concave piecewise linear function. The local best efficiency of the actual generation function and the point of maximum discharge are used as breakpoints. The slope of each linear segment is called production equivalent, $\mu_{i s}$.

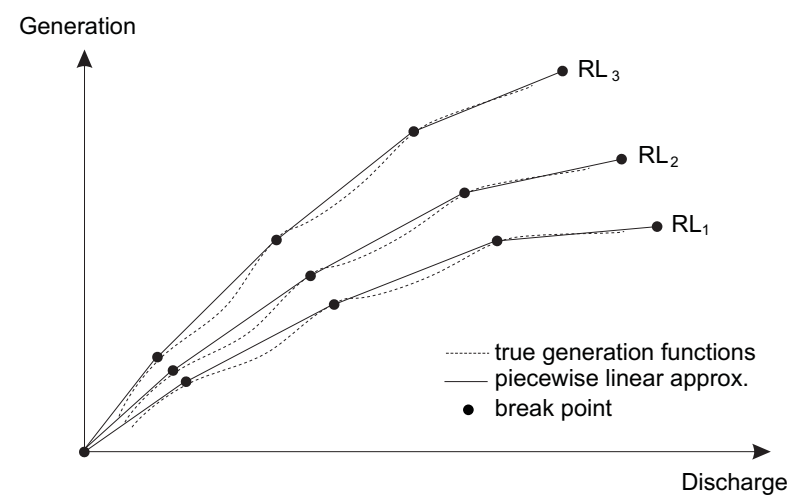

Figure 6.3: Hydropower generation as a function of discharge. Generation functions are shown for three different reservoir levels (RL), $R L_{1}<R L_{2}<$ $R L_{3}$

Water inflow uncertainty is neglected in the most short term planning methods in order to shorten computational time, e.g., in [25], [70]. Water inflow uncertainty is also less significant in the short term compared to, e.g., uncertainty associated with power market prices. Therefore water inflow uncertainty is usually considered in the mid-term or long term planning [41].

The stochastic optimization (block 3) finds an optimal decision, i.e., hydro power production bids to the spot market for each spot price scenario. 
The stochastic decision process then has the same tree structure as the spot price scenario tree.

\section{Hydrological constraints}

The hydrological constraints describe the couplings between the adjacent HPPs in the multi-reservoir hydro power system.

$$
\begin{aligned}
& x_{i}(k+1, \tilde{n})=x_{i}(k, n)-\sum_{s \in S_{i}} u_{i s}(k, n)-y_{i}(k, n)+w_{i}(k) \\
& +\sum_{j \in \Omega_{i}}\left[\sum_{s \in S_{j}} u_{j s}\left(k-\tau_{i j}, n_{\left.\tau_{i j}\right)}+y_{j}\left(k-\tau_{i j}, n_{\tau_{i j}}\right)\right],\right. \\
& \forall \quad i \in I, \forall k \in K, \forall n \in N_{k}
\end{aligned}
$$

where $x_{i}(k+1, \tilde{n}), u_{i s}(k, n), u_{j s}(k, n), y_{i}(k, n), y_{j}(k, n), x_{i}(k, n)$ are variables, $w_{i}(k)$ is a parameter; $N_{k}$ is a subset of nodes of the spot price scenario tree at hour $k$; $\tilde{n}$ is a child node of node $n, n_{\tau_{i j}}$ is relative node of node $n$ at hour $k-\tau_{i j}$, Figure 6.2 .

The reservoir content of the particular HPP is affected by water spillage and discharge of the HPPs directly upstream. The delay time $\tau_{i j}$ between HPP $j$ and HPP $i$ directly downstream is assumed to be defined in $H_{j}$ hours and $M_{j}$ minutes. The discharge considering the delay time is then expressed as:

$$
\begin{aligned}
& u_{j s}\left(k-\tau_{j i}, n_{\tau_{i j}}\right)=\frac{M_{j}}{60} u_{j s}\left(k-H_{j}-1, n_{H_{j}-1}\right) \\
& +\frac{60-M_{j}}{60} u_{j s}\left(k-H_{j}, n_{H_{j}}\right), \forall j \in \Omega_{i}, s \in S_{j}, \\
& k \quad \in K, \forall n \in N_{k-\tau_{i j}}
\end{aligned}
$$

By analogy, the spillage considering the delay time can be determined [89].

\section{Transmission constraints}

Power transmission from the studied site is limited, therefore:

$$
\sum_{i \in I_{c}} \sum_{s \in S_{i}} u_{i s}(k, n) \mu_{i s}-D(k) \leq \bar{P}_{12}, \quad \forall k \in K, \forall n \in N_{k}
$$


where $D(k)$ is hourly load in the studied site and $\bar{P}_{12}$ is power transmission limit from the studied site. Both parameters are assumed deterministic in this paper.

\section{Fixed values}

The initial reservoir content is assumed known and reservoir content at the end of the ongoing week is fixed in accordance with the mid-term production planning, as discussed in section 6.3 :

$$
\begin{gathered}
x_{i}(0)=x_{i}^{o} ; \\
x_{i}\left(n, K_{\text {last }}\right)=x_{i}^{\text {last }} \forall n \in N_{k}
\end{gathered}
$$

\section{Variable limits}

There are also reservoir content, spillage and discharge limitations:

$$
\begin{gathered}
0 \leq x_{i}(k, n) \leq \bar{x}_{i} ; \quad 0 \leq y_{i}(k, n) \leq \bar{y}_{i} \forall i \in I, \forall k \in K, \forall n \in N_{k} \\
0 \leq u_{i s}(k, n) \leq \bar{u}_{i s}, \quad \forall i \in I, \forall s \in S_{i}, \forall k \in K, \forall n \in N_{k}
\end{gathered}
$$

\section{Objective function}

The objective of the hydro power producer is to maximize the expected income from produced power:

$$
\max z^{b}=\sum_{k \in K} \sum_{n \in N_{k}} c^{s}(k, n) p^{n}(k, n) \sum_{i \in I} \sum_{s \in S_{i}} u_{i s}(k, n) \mu_{i s},
$$

where $u_{i s}(k, n)$ is the water discharge at hour $k$, at node $n$ of the decision scenario tree, at a power plant $i$, in a segment $s$ of the production function; $c^{s}(k, n)$ is a spot price at hour $k$, at node $n$ of the spot price scenario tree, $\sum_{i \in I} \sum_{s \in S_{i}} u_{i s}(k, n) \mu_{i s}$ is, the power that the hydro power producer would bid on the spot market at hour $k$, for the price $c^{s}(k, n), p^{n}(n)$ is the probability of the node $n$

To summarize, the optimization model is as follows: maximize the objective function (6.8), subjected to the constraints (6.1), (6.3)-(6.7).

As it is mentioned in section 6.3 it is also possible to use so-called water value function instead of fixing reservoir content at the end of the week. The 
objective function is then a trade off between using the water now or storing it for the future:

$$
\begin{aligned}
\max z^{b} & =\sum_{k \in K} \sum_{n \in N_{k}} c^{s}(k, n) p^{n}(n) \sum_{i \in I} \sum_{s \in S_{i}} u_{i s}(k, n) \mu_{i s} \\
& +c^{f}\left[\sum_{n \in N_{\left(K_{\text {last }}+1\right)}} p^{n}(n) \sum_{i \in I} x_{i}\left(K_{\text {last }}+1, n\right) \nu_{i}\right]
\end{aligned}
$$

where $c^{f}$ is estimated price for future power generation, $\nu_{i}$ is future production equivalent of a power plant $i$.

The optimization problem would thus be as follows: maximize the objective function (6.9), subjected to the constraints (6.1), (6.3)-(6.4) and $(6.6)-(6.7)^{4}$.

This subsection has presented the modeling details for the base case part (block 3) of the planning algorithm, Figure 6.1. The results of the base case hydro power planning (block 4): planned water discharge, HPP production, spillage, reservoir content - are passed as parameters to the re-planning program that includes coordination with wind power (block 9).

\subsubsection{Wind power forecast error scenarios}

In the re-planning part of the planning algorithm, the hydro power plants are coordinated with a wind farm. Thus, wind power production should be considered. Day ahead wind power production cannot be predicted with certainty. In this thesis wind power production scenarios are generated (blocks 5-7) and used as input data for the re-planning part of the planning algorithm.

Presently, there are many different techniques for wind speed forecasting, see [67] for review. In this work a wind speed forecast for the planning day is assumed to be available.

A model for wind speed forecast error (block 5) is developed in [88]. It is assumed that data concerning accuracy of the forecast are available. The model then simulates possible outcomes of the wind speed forecast error whose stochastic properties are close to those of the actual wind speed

\footnotetext{
${ }^{4}$ Definition of the optimization problem, using water value function is not included in Publications $\mathrm{F}$ and $\mathrm{G}$.
} 
forecast error. The model is based on ARMA, [19], defined as:

$$
\begin{gathered}
\Delta V(0)=0 ; \quad Z(0)=0 \\
\Delta V(k)=\alpha \Delta V(k-1)+Z(k)+\beta Z(k-1)
\end{gathered}
$$

where $\Delta V(k)$ is wind speed forecast error in $k$-hour forecast, $Z(k)$ is random Gaussian variable with standard deviation $\sigma_{Z}, \alpha$ and $\beta$ are the parameters. These are identified using the least square fitting, minimizing a difference between sample forecast error variance, based on data from the site, and modeled forecast error variance, see [88] for details.

An example of the standard deviations of the actual forecast error and the forecast error modeled with ARMA series are shown in Figure 6.4. In this example real wind speed data and forecasted wind speeds for 2003 for East Denmark are used. For each hour of the year there were one actual wind speed and one wind speed forecast available for the estimation of the parameters of ARMA series.

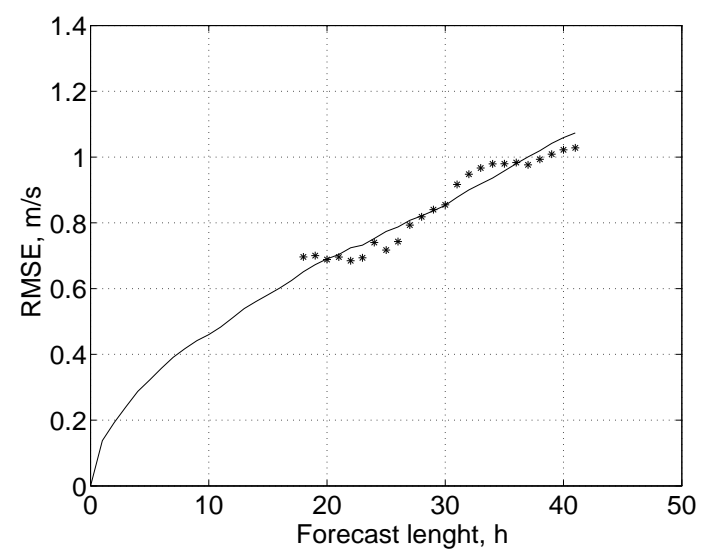

Figure 6.4: Standard deviations of the real wind forecast error $\left(^{*}\right)$ and standard deviations from ARMA series with $\alpha=1.0073, \beta=0.0327$, and $\sigma_{Z}=0.1372$ (solid line)

By sampling from the ARMA model (6.10) the set of wind speed forecast error scenarios can be generated. Equal probability is assigned to each scenario. The wind speed forecast error scenarios form a scenario tree.

A possible outcome of wind speed forecast error $\Delta V(k)$, corresponding to hour $k$ and node $m$ of the forecast error scenario tree is denoted $\Delta v(k, m)$. A 
wind speed $v(k, m)$ at hour $k$ and node $m$ of the scenario tree is calculated as a sum of wind speed forecast error $\Delta v(k, m)$ and wind speed forecast $v^{f}(k)$ for hour $k$ :

$$
v(k, m)=v^{f}(k)+\Delta v(k, m), \forall m \in M_{k}
$$

where $M_{k}$ is a subset of nodes of the forecast error scenario tree at hour $k$.

Obtained wind speed scenarios are then converted to wind power production scenarios (block 6) using power curves of the respective wind turbines of the WF, see subsection 5.3.2. Wind power production scenarios form a scenario tree with the same structure as the wind speed scenario tree. Wind power production at hour $k$, node $m$ of the wind power production scenario tree is denoted $\bar{P}_{w}(k, m)$.

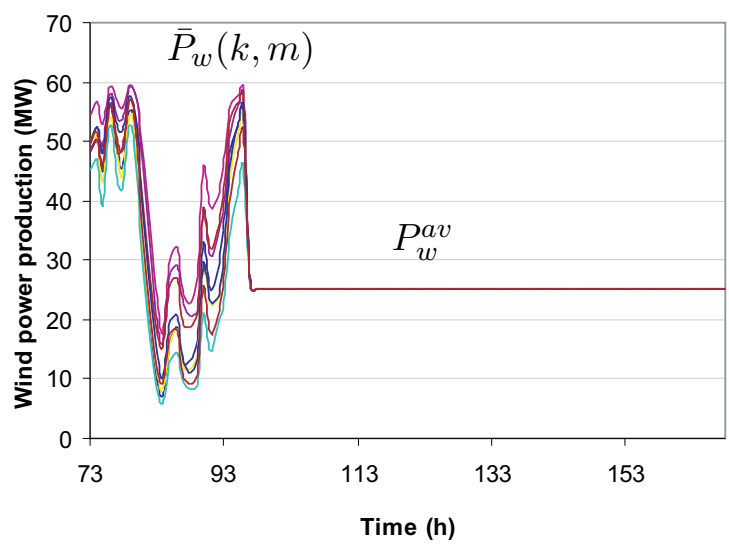

Figure 6.5: Example of wind power production scenarios for $60 \mathrm{MW}$ wind farm for the planning day (Thursday in this example) and for the rest of the ongoing week included in planning

The wind power scenario model is only applied for the planning day that is for $k \leq K_{\text {last }}^{\text {day }}$. Wind power forecasts for a longer time horizon are highly unreliable. For the remaining days of the current week included in the planning, monthly average wind power production $P_{w}^{a v}$ is used instead of wind power scenarios ${ }^{5}$, shown in Figure 6.5. It is calculated from the monthly average wind speed derived from statistical data.

\footnotetext{
${ }^{5}$ In the following subsections the equations are written in general form, however, for all $k>K_{\text {last }}^{\text {day }} \bar{P}_{w}(k, m)$ should be substituted by $P_{w}^{a v}$
} 


\subsubsection{Power market price model}

\section{Regulating market price model}

This subsection discusses block 8 in Figure 6.1. The model for generation of regulating market prices is based on ARIMA series [17] and Markov processes [76]. This model is fully described and motivated in [78] and a brief description follows.

The regulating market price series used in this thesis are characterized by the following:

- There are different prices for upward and downward regulation.

- Not all hours have defined upward and/or downward prices. The prices are defined if the corresponding quantities of regulating power is larger than zero.

- The occurrence of upward and downward regulating prices are negatively correlated.

- If defined, the regulating prices have bounds set by the spot price: the upward price is always higher and the downward price is always lower than the spot price.

The models for upward and downward regulation are partly separate, but are based on the same mathematics. The developed regulating power price model takes the occurrence of undefined prices into account by modeling the regulating power prices for hour $k$ as

$$
c^{r}(k)= \begin{cases}a(k), & b(k)=1 \\ \text { not defined, } & b(k)=0\end{cases}
$$

where $b(k)$ is a binary stochastic variable. The continuous part of the model, $a(k)$, is modeled using an ARIMA process, while the discrete part, $b(k)$, is modeled with a Markov process.

The continuous part reflects the behavior of the prices when they are defined and can be expressed in terms of the spot price and the difference between the spot and regulating price as $a(k)=c^{s}(k)+\delta(k)$. The spot prices $c^{s}(k)$ are known at this stage, while $\delta(k)$ are stochastic variables modeled 
with an $\operatorname{ARIMA}(2,1,2)$ process:

$$
\begin{aligned}
& (1-B) \Phi(B)\left(\delta(k)-\delta^{a v}\right)=\Theta(B) Z(k) \\
& \Phi(B)=1-\phi_{1} B-\phi_{2} B^{2} \\
& \Theta(B)=1+\theta_{1} B+\theta_{2} B^{2}
\end{aligned}
$$

The correlation between the occurrence of upward and downward prices are handled by using Markov processes to model $b^{u}(k)$ and $b^{d}(k)$, i.e., $b(k)$ for upward and downward respectively. Four states covering all possible combinations of $b^{u}(k)$ and $b^{d}(k)$ can be identified: $\left(b^{u}(k), b^{d}(k)\right)=$ $\{(0,0),(0,1),(1,0),(1,1)\}$, with associated probabilities for transition between states.

The parameters of $a(k)$ and $b(k)$ are estimated by using historical price series, see [78] for details.

\section{Power price scenario tree}

As it is described in subsection 6.3, the planning is conducted before the spot market closure, and the uncertainty of spot prices, upward and downward regulating prices should therefore be considered. The stochastic power market price process is then three-dimensional:

$$
\xi=\left\{C^{u}(k), C^{d}(k), C^{s}(k) ; \forall k \in K\right\},
$$

where $C^{s}(k)$ denotes the stochastic spot price at hour $k$. The regulating price model described in the previous subsection requires that the spot prices are known when generating the regulating price scenarios. In this model, observed historical price series spot market are used as spot price scenarios. From each spot price scenario, one upward regulation price scenario, and one downward regulation price scenario are generated by sampling from the ARIMA model presented in the previous subsection. Therefore three different types of prices in the expression (6.14) are available. Equal probability is assigned to each power market price scenario. The power market price scenarios form a scenario tree. An outcome of the three dimensional stochastic market price process $\xi$, corresponding to hour $k$ and node $n$ of the power market price scenario tree is denoted $c^{u}(k, n), c^{d}(k, n), c^{s}(k, n)$. 


\subsubsection{Scenario reduction and bundling}

Wind power production scenarios (blocks 5-6) and power price scenarios (blocks 2 and 8) generated as described in the previous subsections form the scenario trees. To assure that stochastic properties of the process are represented correctly many scenarios should be generated.

The computational effort for solving scenario-based optimization models depends on the number of scenarios. Therefore it is necessary to reduce the original scenario tree so that it would have a smaller number of scenarios but stochastic properties would not be changed more than necessary compared to the original scenario tree.

The scenario reduction approach applied here (block 7) is presented in details in [51] and [29]. The method is based on comparison of the probability distance between sample probability distribution of the original scenario tree, $P$, and sample probability distribution of the reduced scenario tree, $Q$. The probability distance trades off scenario probabilities and distance between scenario values. This method uses the Kantorovich distance, $D_{K}$, of probability distribution. For discrete probability distributions with finitely many scenarios the $D_{K}$ is found by solving:

$$
D_{K}(P, Q)=\sum_{i \in \mathcal{J}} p_{i} \min _{j \notin \mathcal{J}} c_{K}\left(\xi^{i}, \xi^{j}\right),
$$

where $\xi=\left\{\xi_{k}\right\}_{k=1}^{K}$ is n-dimensional stochastic process with the probability distribution $P$, which is approximated by finitely many scenarios $\xi^{i}=$ $\left\{\xi_{k}^{i}\right\}_{k=1}^{K}, \quad i=1, \ldots S$ and their probabilities $p_{i} ; Q$ is reduced probability distribution of $\xi$, i.e., support of $Q$ consists of scenarios $\xi^{j}, j \in\{1 \ldots S\}$ and $\mathcal{J}$ denotes the set of reduced scenarios, $\mathcal{J} \subset\{1 \ldots . S\}$.

$$
c_{K}\left(\xi^{i}, \xi^{j}\right)=\sum_{k=1}^{K}\left|\xi_{k}^{i}-\xi_{k}^{j}\right|,
$$

where $|\cdot|$ denotes some norm on $\mathbb{R}^{n}$, i.e., $c_{K}$ measures the distance between scenarios on the whole time horizon.

The probabilities of the scenarios in the reduces scenario tree are calculated as:

$$
q_{j}=p_{j}+\sum_{i \in \mathcal{J}(j)} p_{i}
$$

where $\mathcal{J}(j)=\{i \in \mathcal{J}: j=j(i)\}, j(i) \in \arg \min _{j \notin \mathcal{J}} c_{K}\left(\xi^{i}, \xi^{j}\right), \forall i \in \mathcal{J}$ 
In this reduction method it is possible either to reduce a fixed number of scenarios or to use a tolerance criteria to decide how many scenarios should be reduced. The tolerance criteria represents the difference between the original scenario tree and reduced scenario tree.

The reduction algorithm presented in [51] allows to recursively reduce the number of nodes in the scenario tree and also modify the tree structure by bundling scenarios by successive scenario reduction technique. The algorithm compares the Kantorovich distance of original and reduced subtrees on $\{1, \ldots, K\}, k=K, K-1, \ldots, 2,1$ and deletes nodes if the reduced tree is still close enough to the original, Figure 6.6.

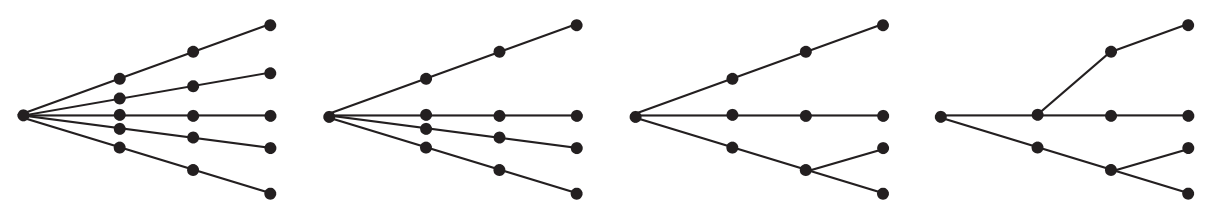

Figure 6.6: Construction of a scenario tree by successive scenario reduction and bundling

Summarizing, subsections 6.4.2, 6.4.3 and 6.4.4 has presented the models for the input data (wind power production scenario tree, power market price scenario tree) to the re-planning part (block 9) of the coordinated planning algorithm.

\subsubsection{Hydro power re-planning coordinated with wind power}

This subsection discusses the re-planning part (block 9) of the planning algorithm, Figure 6.1. If, according to the base case hydro power production plan (block 4) and wind power production scenario (block 7), transmission congestion is expected, then planned hydro power production could be decreased, in order to allow the WF to use available transmission capacity. For each hour $k$ the subset of node combinations $(n, m)$ of the market price scenario tree and the wind power production scenario tree, at which congestion on the transmission lines is expected, can be defined from the 
following condition:

if $\sum_{i \in I_{c}} \sum_{s \in S_{i}} \mu_{i s} u_{i s}(k, n)+\bar{P}_{w}(k, m)-D(k)>\bar{P}_{12}$, then $k, n, m \in K^{c}(n, m)$.

For each hour $k$ the subset of node combinations $(n, m)$, at which no congestion on the transmission lines is expected, can be defined from the condition:

if $\sum_{i \in I_{c}} \sum_{s \in S_{i}} \mu_{i s} u_{i s}(k, n)+\bar{P}_{w}(k, m)-D(k) \leq \bar{P}_{12}$, then $k, n, m \in K^{n c}(n, m)$,

where $\sum_{i \in I_{c}} \sum_{s \in S_{i}} \mu_{i s} u_{i s}(k, n)$ is planned hydro power production in a plant $i$, at hour $k$ according to the base case, $\bar{P}_{w}(k, m)$ is potential wind power production at node $m$ of the wind power production scenario tree, at hour $k$ and $\bar{P}_{12}$ is available transmission capacity.

It is assumed that the hydro power producer is paid for reducing power production at the stations $I_{c}$, which are sharing the transmission capacity with the wind farm, as this relieves congestion on the transmission lines and allows the WF to produce energy that would otherwise be curtailed. The price $c$, SEK/MWh, is estimated as yearly average economic losses of the wind power utility due to wind energy curtailments, based on historical data:

$$
c<\frac{\sum_{k \in K_{c}} c^{s}(k)\left(\sum_{i \in I_{c}} P_{i}^{h}(k)+\bar{P}_{w}^{h}(k)-P_{12}\right)}{\sum_{k \in K_{c}}\left(\sum_{i \in I_{c}} P_{i}^{h}(k)+\bar{P}_{w}^{h}(k)-P_{12}\right)}
$$

where $P_{i}^{h}(k)$ is hydro power production in stations $I_{c}$ without coordination, obtained from historical data, $\bar{P}_{w}^{h}(k)$ is wind power production calculated from historical wind speed data and $c^{s}(k)$ is a spot price for the same period in the past. The numerator corresponds to the economical losses due to wind energy curtailments according to historical data and the denominator corresponds to total wind energy curtailments in that period. Thus $c$ is the upper limit for the price that the wind power utility is prepared to pay the hydro power utility for the coordination. The exact value of the coordination service price depends on the agreement between the wind power utility and the hydro power utility. More flexibility could be added, for example by estimating $c$ as monthly average economic losses due to wind energy curtailments. Different value of $c$ would then apply to each month.

The stochastic optimization (block 9) determines an optimal decision that is hydro power production bid to the spot and regulating markets 
for each combination of power market price and wind power production scenarios. The stochastic decision process then has a tree structure consisting of combinations $(n, m)$ of nodes of the market price scenario tree and wind power production scenario tree as shown in Figure 6.7.

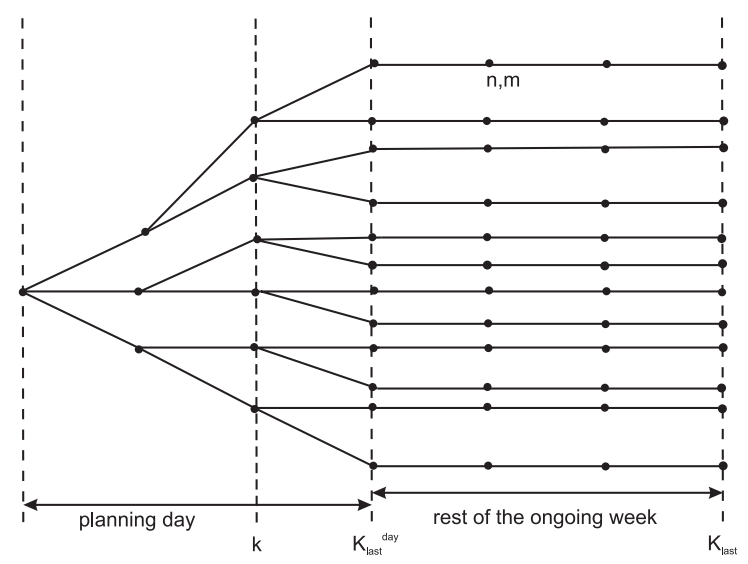

Figure 6.7: Schematic structure of the scenario tree

\section{Hydrological constraints}

In the re-planning part of the planning algorithm two new variables are introduced: additional discharge $\Delta u_{i s}(k, n)$ and power production decrease $\Delta P_{i s}(k, n)$. The new variables make it possible to track changes in the coordinated production plan compared to the base case plan. Additional discharge $\Delta u_{i s}(k, n)$ converted to power and power production decrease $\Delta P_{i s}(k, n)$ are added to the hydro power production bids to the spot market calculated in the base case planning. The details are explained bellow, when defining objective function. Also, as wind power production forecast is uncertain, hydro power production adjustments are planned for each wind power production scenario, $P_{i s}^{u p}(k, n, m)$ and $P_{i s}^{d}(k, n, m)$. Bids for these adjustments can be made later during the day as upward or downward regulation bids to the regulating market, when wind power forecast would become more precise. The re-planning is thus formulated as a two-stage stochastic optimization program with recourse [56] and hydro power production adjustments are the recourse variables. The recourse 
variables will emerge in the transmission constraints, as will be shown further.

$$
\begin{aligned}
& x_{i}(k+1, \tilde{n}, \tilde{m})=x_{i}(k, n, m)-\sum_{s \in S_{i}} u_{i s}(k, n)-y_{i}(k, n)+w_{i}(k) \\
& +\sum_{j \in \Omega_{i}}\left[\sum_{s \in S_{j}} u_{j s}\left(k-\tau_{i j}, n_{\tau_{i j}}\right)+y_{j}\left(k-\tau_{i j}, n_{\tau_{i j}}\right)\right] \\
& +\sum_{s \in S_{i}}\left(\frac{\Delta P_{i s}(k, n)-P_{i s}^{u p}(k, n, m)+P_{i s}^{d}(k, n, m)}{\mu_{i s}}-\Delta u_{i s}(k, n)\right) \\
& -\sum_{j \in \Omega_{i}} \sum_{s \in S_{i}} \frac{\Delta P_{j s}\left(k-\tau_{j i}, n_{\tau_{i j}}\right)+P_{j s}^{u p}\left(k-\tau_{j i}, n_{\tau_{i j}}, m_{\tau_{i j}}\right)}{\mu_{j s}} \\
& +\sum_{j \in \Omega_{i}} \sum_{s \in S_{i}}\left(\frac{P_{j s}^{d}\left(k-\tau_{j i}, n_{\tau_{i j}}, m_{\tau_{i j}}\right)}{\mu_{j s}}+\Delta u_{j s}\left(k-\tau_{j i}, n_{\tau_{i j}}\right)\right) \\
& \forall i \in I, \forall k \in K, \forall n \in N_{k}, \forall m \in M_{k}
\end{aligned}
$$

Here discharges $u_{i s}(k, n), u_{j s}(k, n)$ and spillages $y_{i}(k, n), y_{j}(k, n)$ are already known parameters calculated in the base case planning (blocks 3-4) and other quantities are variable. The last three rows in (6.21) include the effect on the hydro reservoir content from the hydro power production reduction and from the disposal of stored water, in the local station and the stations directly upstream. The hydro power production reduction $\Delta P_{i s}(k, n)$ and upward and downward adjustments for the regulating market $P_{i s}^{u p}(k, n, m)$ and $P_{i s}^{d}(k, n, m)$ are in MW. However the reservoir content in the hydrological constraints is expressed in hour equivalents (HE). Therefore $\Delta P_{i s}(k, n), P_{i s}^{u p}(k, n, m)$ and $P_{i s}^{d}(k, n, m)$ are converted to the corresponding water discharge in $\mathrm{HE}$, using the production equivalent $\mu_{i s}$ of the plant $i$, segment $s$ of the production function, see Figure 6.3.

For the rest of the current week included in the planning, $K_{\text {last }}^{\text {day }}<k \leq K_{\text {last }}$, deterministic prices and wind power production are assumed, subsection 6.4.2, however, the decision variables in the last hour of the planning day differ, depending on market price scenarios and wind power production scenarios. Thus, the decision scenario tree from the last hour of the planning day till the end of the week will still consist of parallel branches, each emanating from one scenario dependent state in the last hour of the planning day, Figure 6.7. 


\section{Transmission constraints}

Formulating the transmission constraints, let us, first, consider the situation, where planning for the spot market only is done (Publication F); and the production plan, once submitted to the spot market, could not be changed during the day. This means that the solution of the stochastic optimization problem should satisfy all constraints at any outcome of wind power production scenarios, the so-called "fat solution", [56].

In the coordinated planning, hydro power production at the stations $I_{c}$ should only be reduced during the congestion on the line, in order to decrease wind energy curtailment.

$$
\begin{aligned}
& \sum_{i \in I_{c}} \sum_{s \in S_{i}} \Delta P_{i s}(k, n) \leq \sum_{i \in I_{c}} \sum_{s \in S_{i}} \mu_{i s} u_{i s}(k, n)+\bar{P}_{w}(k, m)-D(k)-\bar{P}_{12}, \\
& \forall k, n, m \in K^{c}(n, m) .
\end{aligned}
$$

Constraint (6.22) states that stored wind energy should be less than or equal to potential wind energy curtailment during the congestion situation (6.18). Here for each hour $k$ the minimal wind power production scenario determines the solution. The excess wind power, compared to minimal wind power production scenario, would be curtailed in the real time operation in order to meet the transmission constraint.

Conversely, during the hours when no congestion on the lines is expected as expressed in equation (6.19), additional hydro power production should not exceed the transmission capacity margin:

$$
\begin{aligned}
& \sum_{i \in I} \sum_{s \in S_{i}} \Delta u_{i s}(k, n) \mu_{i s} \leq \bar{P}_{12}+D(k)-\sum_{i \in I} \sum_{s \in S_{i}} \mu_{i s} u_{i s}(k, n)-\bar{P}_{w}^{n}(k, m), \\
& \forall k, n, m \in K^{n c}(n, m) .
\end{aligned}
$$

In this constraint for each hour $k$ the maximal wind power production scenario determines the solution and this corresponds to reserving higher transmission capacity for the wind, when no congestion is expected in the transmission line.

Obviously the constraints (6.22) and (6.23) would lead to higher wind energy curtailments on the one hand and less intensive utilization of the transmission capacity on the other. These constraints do not include the flexibility that is offered in the presence of the regulating market.

Now let us assume that after the outcome of wind power production, $\bar{P}_{w}\left(k, m^{*}\right)$, becomes known the violation of transmission constraints $(6.22)$ 
and (6.23) can be compensated by respective decrease or increase of hydro power production. These hydro power production adjustments are assumed to be traded on the regulating market, shortly before the operating hour, i.e., when more precise wind forecast is available. The transmission constraints (6.22) and (6.23) should then be rewritten as follows:

$$
\begin{aligned}
& \sum_{i \in I_{c}} \sum_{s \in S_{i}} \Delta P_{i s}(k, n)+P_{i s}^{d}(k, n, m) \leq \sum_{i \in I_{c}} \sum_{s \in S_{i}} \mu_{i s} u_{i s}(k, n) \\
& +\bar{P}_{w}(k, m)-D(k)-\bar{P}_{12}, \forall k, n, m \in K^{c}(n, m), \\
& \quad \sum_{i \in I_{c}} \sum_{s \in S_{i}} \Delta u_{i s}(k, n) \mu_{i s}+P_{i s}^{u p}(k, n, m) \leq \bar{P}_{12}+D(k) \\
& \quad-\sum_{i \in I} \sum_{s \in S_{i}} \mu_{i s} u_{i s}(k, n)-\bar{P}_{w}(k, n, m), \\
& \quad \forall k, n, m \in K^{n c}(n, m) .
\end{aligned}
$$

$P_{i s}^{u p}(k, n, m)$ and $P_{i s}^{d}(k, n, m)$ are recourse variables, corresponding to upward and downward power production adjustments at power plant $i$, segment $s$ of the production curve, at hour $k$, at node combination $(n, m)$. Such constraints better represent the flexibility of the power market and would lead to lower energy curtailments.

If transmission is not congested, no additional energy is stored in hydro reservoirs of the $I_{c}$ stations:

$$
\begin{aligned}
& \sum_{i \in I_{c}} \sum_{s \in S_{i}} \Delta P_{i s}(k, n)+P_{i s}^{d}(k, n, m)=0 \\
& \forall k, n, m \in K^{n c}(n, m)
\end{aligned}
$$

Otherwise, if transmission is congested there should be no additional hydropower production in the $I_{c}$ stations that is:

$$
\begin{aligned}
& \sum_{i \in I_{c}} \sum_{s \in S_{i}} \Delta u_{i s}(k, n) \mu_{i s}+P_{i s}^{u p}(k, n, m)=0 \\
& \forall k, n, m \in K^{c}(n, m)
\end{aligned}
$$

Average wind power production is assumed from the end of the planning day until the rest of the week, instead of wind power production scenarios, Figure 6.5. 


\section{Fixed values}

As average wind power production is assumed for the rest of the week included in planning, see subsection 6.4.2, the adjustment bids to regulating market are not considered for this period.

$$
P_{i s}^{u p}(k, n, m)=0, P_{i s}^{d}(k, n, m)=0, \forall k>K_{\text {last }}^{\text {day }}
$$

Initial reservoir content is assumed known, as in (6.4):

$$
x_{i}(0, n, m)=x_{i}^{o}, \forall n \in N_{0}, m \in M_{0}
$$

The reservoir content at the end of the planning period is fixed in accordance with mid-term production planning, similar to (6.5) :

$$
x_{i}\left(K_{\text {last }}, n, m\right)=x_{i}^{\text {last }}, \forall n \in N_{K_{\text {last }}}, m \in M_{K_{\text {last }}}
$$

\section{Variable limits}

There are also reservoir content limitations, similar to base case part of the planning (6.6) and (6.7):

$$
0 \leq x_{i}(k, n, m) \leq \bar{x}_{i}, \quad \forall i \in I, \forall k \in K, \forall n \in N_{k}, m \in M_{k}
$$

The decrease of discharge should not exceed planned discharge $u_{i s}(k, n)$, according to the base case part:

$$
\begin{aligned}
& \Delta P_{i s}(k, n)+P_{i s}^{d}(k, n, m) \leq u_{i s}(k, n) \mu_{i s}, \\
& \quad \forall i \in I, \forall s \in S_{i}, \forall k \in K, \forall n \in N_{k}, m \in M_{k}
\end{aligned}
$$

Also, water discharge should always be within the limits set by technical and environmental constraints that is:

$$
\begin{aligned}
& \Delta u_{i s}(k, n)+\frac{P_{i s}^{u p}(k, n, m)}{\mu_{i s}} \leq \bar{u}_{i s}-u_{i s}(k, n), \\
& \forall i \in I, \forall s \in S_{i}, \forall k \in K, \forall n \in N_{k}, m \in M_{k}
\end{aligned}
$$

The new variables, introduced in coordinated planning, should be positive:

$$
\begin{gathered}
\Delta u_{i s}(k, n), \Delta P_{i s}(k, n), P_{i s}^{d}(k, n, m), P_{i s}^{u p}(k, n, m) \geq 0 \\
\forall i \in I, \forall s \in S_{i}, \forall k \in K, \forall n \in N_{k}, m \in M_{k}
\end{gathered}
$$

Additional water spillage due to energy storage in hydro reservoirs is not allowed in the coordination strategy. It seems meaningless to integrate wind power if it results in energy curtailments at other power plants. 


\section{Objective function}

The objective of the hydro power producer is, as in the base case planning (6.8), to maximize the expected income of the hydro power producer:

$$
\max z^{t o t}=z^{c}+z^{u p}-z^{d}
$$

where $z^{c}$ is the expected income from trading on the spot market and from coordination with wind power and $z^{d}$ and $z^{u p}$ are expected recourse costs/income from trading respectively downward and upward hydro power production adjustments on the regulating market. These are defined as follows:

$$
\begin{aligned}
z^{c} & =\sum_{k \in K} \sum_{n \in N_{k}}\left(c^{s}(k, n) q^{s}(k, n)+\sum_{i \in I_{c}} \sum_{s \in S_{i}} c \cdot \Delta P_{i s}(k, n)\right) p^{n}(n), \\
z^{d} & =\sum_{k \in K} \sum_{n \in N_{k}} \sum_{m \in M_{k}} q^{d}(k, n, m) \cdot p^{n}(n) \cdot p^{m}(m) \cdot c^{d}(k, n), \\
z^{u p} & =\sum_{k \in K} \sum_{n \in N_{k}} \sum_{m \in M_{k}} q^{u p}(k, n, m) \cdot p^{n}(n) \cdot p^{m}(m) \cdot c^{u p}(k, n),
\end{aligned}
$$

where $q^{s}(k, n), q^{d}(k, n, m)$ and $q^{u p}(k, n, m)$ are bids on the spot market and downward and upward regulation bids on the regulating market respectively. These are defined as follows:

$$
\begin{aligned}
q^{s}(k, n) & =\sum_{i \in I} \sum_{s \in S_{i}}\left(\left(u_{i s}(k, n)+\Delta u_{i s}(k, n)\right) \mu_{i s}-\Delta P_{i s}(k, n)\right), \\
q^{d}(k, n, m) & =\sum_{i \in I} \sum_{s \in S_{i}} P_{i s}^{d}(k, n, m), \\
q^{u p}(k, n, m) & =\sum_{i \in I} \sum_{s \in S_{i}} P_{i s}^{u p}(k, n, m),
\end{aligned}
$$

where $P_{i s}^{u p}(k, n, m)$ and $P_{i s}^{d}(k, n, m)$ are upward and downward adjustments at HPP $i$ and segment $s$ of the production function.

The hourly bids to the spot market are assumed to consist of quantity $q^{s}(k, n)$ in MWh per hour $k$ at price $c^{s}(k, n)$ in SEK/MWh. Bids to the regulating market are assumed to be made as close to the operating hour as possible (e.g., regulating market closure in Nordic market is half an hour before the operating hour, section 2.4). Thus, it is assumed that the 
realization of wind power production scenario $\bar{P}_{w}\left(k, m^{*}\right)$ for the operating hour $k$ is known with certainty and corresponding quantities $q^{d}\left(k, n, m^{*}\right)$ and $q^{u p}\left(k, n, m^{*}\right)$ can be chosen to bid on the regulating market.

Summarizing, the re-planning program is formulated as follows: maximize the objective function (6.35), subject to the constraints (6.21), (6.24)-(6.34) and (6.36)-(6.41).

If water value function is used, instead of fixing the reservoir content at the end of the week, the objective function (6.35) would be changed as follows:

$$
\begin{aligned}
& \max z^{t o t}=z^{c}+z^{u p}-z^{d}+ \\
& +c^{f}\left[\sum_{n \in N_{\left(K_{\text {last }}+1\right)}} \sum_{m \in M_{\left(K_{\text {last }}+1\right)}} p^{n}(n) p^{m}(m) \sum_{i \in I} x_{i}\left(K_{\text {last }}+1, n, m\right) \nu_{i}\right]
\end{aligned}
$$

The optimization problem would thus be as follows: maximize the objective function (6.42), subjected to the constraints (6.21), (6.24)-(6.29), (6.31)-(6.34) and (6.36)-(6.41) $)^{6}$

This subsection has presented the modeling details for the re-planning part (block 9) of the planning algorithm, Figure 6.1. The results of the re-planning part of the optimization: re-planned water discharges, re-planned HPP production to bid on the spot and regulating markets, new reservoir content at the end of the day (block 10).

\subsubsection{Evaluation}

It is important to evaluate the long term impact of the coordinated planning algorithm presented above on the operation of the hydro power utility and the wind power utility. In this thesis the evaluation algorithm is developed for this purpose, Figure 6.8 .

For each day in the evaluation period the coordinated planning is done according to Figure 6.1. The results of the optimization: re-planned water discharge, water spillage, reservoir content at the end of the day (block 10). These are stochastic decision variables. In order to find the outcome of the decision variable one needs to know the actual outcome of wind speed as well

\footnotetext{
${ }^{6}$ Definition of the optimization problem, using water value function is not included in Publications F and G.
} 
as spot and regulating market prices. It is therefore convenient to choose a period in the past for the evaluation, thus, the actual wind speed and market prices would be already known for the whole period. Hence, total re-planned water discharges $u_{i s}^{\text {tot }}\left(k, n^{*}, m^{*}\right)^{7}$, water spillage $y\left(k, n^{*}\right)$, reservoir content at the end of the day $x\left(K_{\text {day }}^{\text {last }}+1, n^{*}, m^{*}\right)$ can be chosen from the solution of the coordinated planning, $\left(n^{*}, m^{*}\right)$ is the combination of the nodes of the decision scenario tree, Figure 6.7, corresponding to actual realization at hour $k$.

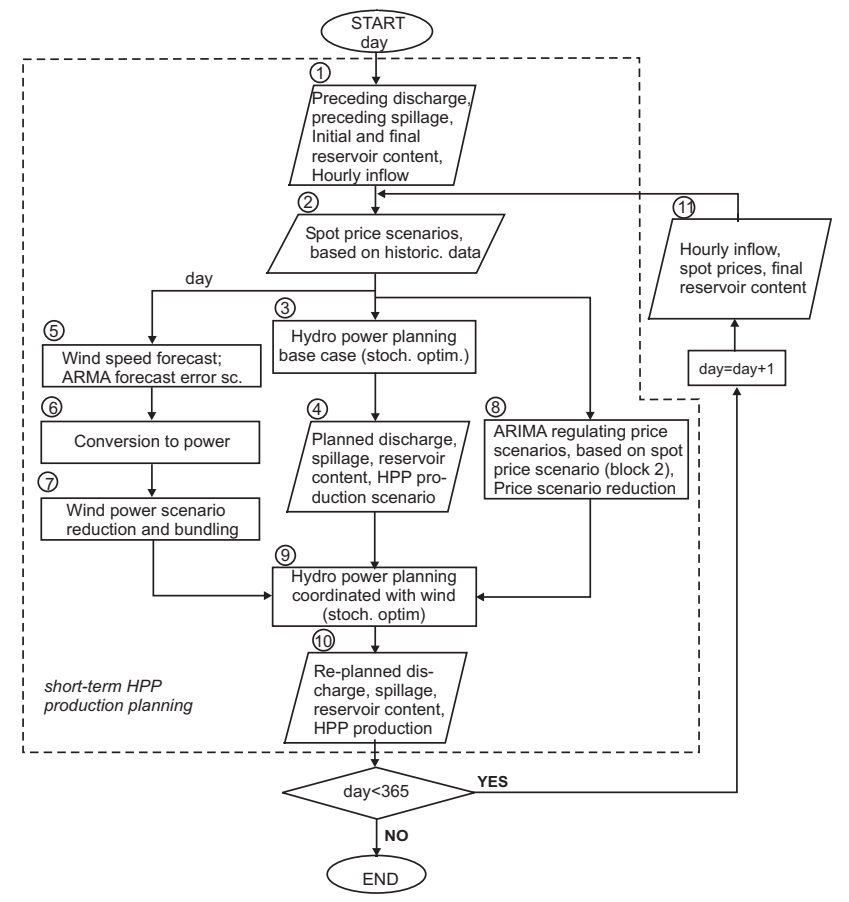

Figure 6.8: Evaluation algorithm of the short term hydro power production planning coordinated with wind power (evaluation period 1 year)

Actual daily income of HPP system is calculated substituting actual power prices and wind power production as follows:

\footnotetext{
${ }^{7} u_{i s}^{\text {tot }}\left(k, n^{*}, m^{*}\right)$ corresponds to total discharge, i.e., includes base case discharge and the discharge changes due to coordination
} 


$$
\begin{aligned}
z^{\text {tot }} & =z^{c}+z^{u p}-z^{d}, \\
z^{c} & =\sum_{k \in K}\left(c^{s}(k) q^{s}\left(k, n^{*}\right)+\sum_{i \in I_{c}} \sum_{s \in S_{i}} c \cdot \Delta P_{i s}\left(k, n^{*}\right),\right) \\
z^{d} & =\sum_{k \in K} q^{d}\left(k, n^{*}, m^{*}\right) \cdot c^{d}(k), \\
z^{u p} & =\sum_{k \in K} q^{u p}\left(k, n^{*}, m^{*}\right) \cdot c^{u p}(k),
\end{aligned}
$$

$u_{i s}^{\text {tot }}\left(k, n^{*}, m^{*}\right), x\left(K_{\text {day }}^{\text {last }}+1, n^{*}, m^{*}\right), y\left(k, n^{*}\right)$ are then used as input data for the next day planning. The cycle continues until the end of the evaluation period as shown in Figure 6.8.

For comparison the uncoordinated planning for the same period of time should be performed. The same work flow as in Figure 6.8, excluding the blocks 5-10, is used. As above, the decision variables (discharge, spillage, reservoir content) are chosen here depending on the actual values of the spot prices and passed to the next day as input data.

Actual daily income of HPP system is then calculated substituting actual power prices as follows:

$$
z^{b}=\sum_{k \in K} c^{s}\left(k, n^{*}\right) \sum_{i \in I} \sum_{s \in S_{i}} u_{i s}\left(k, n^{*}\right) \mu_{i s}
$$

where $n^{*}$ is the node of power price scenario tree, corresponding to actual realization of the spot price at hour $k$.

To evaluate the impact of coordination on the wind power utility WF production and income of the utility are calculated for each day in the evaluation period, for the coordinated and uncoordinated cases. In both cases during the hours without transmission congestion (6.19) all wind power production that correspond to actual realization $m^{*}$ of the wind speed $v\left(k, m^{*}\right)$ at hour $k$ can be fed to the grid. In hours with transmission congestion (6.18) wind power production can be at most equal to the available transmission margin, calculated as a difference between available transmission capacity and actual hydro power production. The daily income of the wind power utility is calculated separately for hours with and without transmission congestion. In coordinated case wind power utility is assumed 
to pay hydro power utility for each MW of transmission capacity that is made available due to coordinated planning, see subsection 6.4.5 :

$$
\begin{aligned}
z_{n c}^{w}= & \sum_{k \in K} c^{s}\left(k, n^{*}\right) \bar{P}_{w}\left(k, m^{*}\right), \forall k \in K_{n c}\left(n^{*}, m^{*}\right) \\
z_{c}^{w}= & \sum_{k \in K} c^{s}\left(k, n^{*}\right)\left(\bar{P}_{12}-q^{s}\left(k, n^{*}\right)-q^{u p}\left(k, n^{*}, m^{*}\right)+q^{d}\left(k, n^{*}, m^{*} \dot{\phi}\right) 46\right) \\
& -\sum_{k \in K} \sum_{i \in I_{c}} \sum_{s \in S_{i}} c \cdot \Delta P_{i s}\left(k, n^{*}\right), \forall k \in K_{c}\left(n^{*}, m^{*}\right)
\end{aligned}
$$

Hence, the total daily income of wind power utility is

$$
z^{w}=z_{n c}^{w}+z_{c}^{w}
$$

To calculate the income of wind power utility in the uncoordinated case same equations (6.45) and (6.46) are used but $q^{u p}\left(k, n^{*}, m^{*}\right), q^{d}\left(k, n^{*}, m^{*}\right)$, $\Delta P_{i s}\left(k, n^{*}\right)$ are equal to zero, and $q^{s}\left(k, n^{*}\right)=\sum_{i \in I} \sum_{s \in S_{i}} u_{i s}\left(k, n^{*}\right) \mu_{i s}$.

\subsection{Case study}

The developed planning algorithm is tested in a case study. The case study is based on the actual case where a company is interested in building a WF in the mountainous area in northern Sweden near the Norwegian border. The capacity of the planned wind power installation is 30 to $90 \mathrm{MW}$. The wind conditions are very good in this area but the transmission capacity of the lines is limited to $350 \mathrm{MW}$. On the Swedish side of the border $250 \mathrm{MW}$ is reserved for hydro power production from five HPP stations on the Ume river and the other $100 \mathrm{MW}$ is reserved for power exchange with Norway. Although the power line is not always utilized to $100 \%$, the connection of the WF has been rejected [74].

In the case study nine stations of the Ume river shown in Figure 6.9 are modeled and production of the five upper stations with a total installed capacity of $250 \mathrm{MW}$ are assumed to be coordinated with a $60 \mathrm{MW}$ wind farm $^{8}$. These stations and the wind farm are sharing $250 \mathrm{MW}$ of the transmission capacity.

\footnotetext{
${ }^{8}$ In the "pre-feasibility" study of the wind-hydro coordination (Publication E) cases with 30,60 and $90 \mathrm{MW}$ wind power, were tested
} 


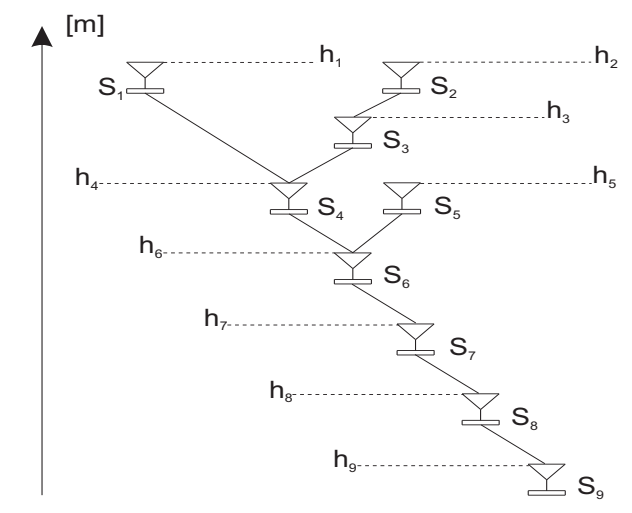

Figure 6.9: Studied HPP system of Ume river

The methods developed in this thesis and presented in previous subsections are applied to this case study. However the assumptions and available input data differ between Publications E,F and G. In the next section, the main findings and conclusions of the case study are summarized from these three publications. A reader is suggested to consult the respective publications for the further details.

\subsection{Conclusions}

In Publication E, the pre-feasibility study of coordination possibility was conducted. Three different coordination strategies were modeled for the case discussed in the preceding section. Water inflow data, wind speed data, power prices from 2001 were used as input data. HPP system operation was simulated for a period of one month. The results of the coordinated strategies were compared to HPP system operation, without coordination for the same period.

The results of the conducted pre-feasibility study has proven that it is possible to find strategies, which make installation of wind power near a hydro power system profitable for all parts (hydro power owner, wind power owner and the system operator) involved. Three strategies were tested and compared to the case when no coordination strategy is applied. In all three coordination strategies the wind energy curtailments are significantly reduced. Coordinated regulation results in more transferred power in the 
existing network. Water spillage could also be reduced due to coordination. It is difficult to conclude which of the tested strategies is the best due to short simulation periods and also as the effect of each strategy on the involved actors is different. The decision on which strategy is the best totaly depends on acceptance of the involved parts.

In Publication F the planning algorithm Figure 6.1 (excl. block 8) is also applied to the same case study. Here only the planning for the spot market is considered, spot market prices are assumed deterministic. These simplifications lead to rather short computation time, allowing to evaluate the developed coordinated planning method for a period of one year or more. The case study has shown that for the whole year wind energy curtailment is reduced from about $38 \mathrm{GWh}$ in the uncoordinated case to about $17 \mathrm{GWh}$ in the coordinated case, i.e., more than $50 \%$. Some wind energy curtailment still prevails due to the technical limitations of the considered HPP system and also due to the fact that only the spot market is considered in the planning. For the whole year the difference in income of the studied HPP system between the coordinated and the uncoordinated cases is $5.5 \times 10^{6}$ SEK.

If water value function is included in the objective function, instead of limiting the reservoir content at the end of the week, the advantage of the HPP system from the coordination about is $13 \%$ higher, than above, but on the other hand wind energy curtailments are increased to $60 \%$.

The income of the wind farm owner in the uncoordinated case and in the case with coordination is almost the same, due to the fact that maximum price for coordination service (6.20) is applied in this case study. In practice this price should be based on agreement between HPP and WF owners and should be less than the maximal value.

The results of the case study in Publication $\mathrm{F}$ has confirmed that "fat solution" of the stochastic optimization problem, leads to unnecessary wind energy curtailments during congestion hours and to reserving excessive transmission capacity in other hours. Thus, in Publication G the possibility to trade on the regulating market is also included in the planning algorithm. The market prices are represented with 3-dimensional scenario tree, as discussed in section 6.4.3. This improved planning algorithm is applied to the same case study as before. Due to longer computation times, the period of one week was chosen to evaluate the improved coordinated planning algorithm. Wind energy curtailments are reduced during the studied week from $1414 \mathrm{MWh}$ in the uncoordinated case to $372 \mathrm{MWh}$ in the coordinated 
case, i.e., by almost $75 \%$ (for comparison, with planning algorithm in Publication $\mathrm{F}$ for the same week, wind energy curtailments are reduced from $1312 \mathrm{MWh}$ in the uncoordinated case to $659 \mathrm{MWh}$ in the coordinated case, i.e., by about $50 \%$ ). Some wind energy curtailment still prevails due to the technical limitations of the considered HPP system.

For the studied week the income of 9 HPP stations of Ume river is $1.6 \times 10^{7}$ SEK in uncoordinated case and $1.9 \times 10^{7}$ SEK in case if hydro power planning is coordinated with the WF (for comparison, with planning algorithm used in Publication $\mathrm{F}$ for the same week, the income of $9 \mathrm{HPP}$ stations of Ume river is $8.9 \times 10^{6}$ SEK in uncoordinated case and $8.7 \times 10^{6}$ SEK in coordinated case).

For the studied week, the income of the wind farm owner in the uncoordinated case is $8.3 \times 10^{5} \mathrm{SEK}$ and in the case with coordination is $8.6 \times 10^{5}$ SEK. As in Publication F, the difference is not high due to the fact that maximum price for coordination service (6.20) is applied in this case study.

For the sake of summary, the table bellow illustrates how the research on coordination of wind power and hydro power in areas with limited power export capability is progressing from Publication E to Publication F:

Table 6.1: Differences between Publications E-F

\begin{tabular}{|l|l|l|l|}
\hline Property & Publication E & Publication F & Publication G \\
\hline Focus & pre-feasibility study & short-term planning & short-term planning \\
\hline Considered market & spot market & spot market & spot, regulating market \\
\hline Problem type & deterministic & stochastic & stochastic \\
\hline Uncertainty & - & wind forecast & $\begin{array}{l}\text { wind forecast, } \\
\text { power market prices }\end{array}$ \\
\hline Optimization type & linear & $\begin{array}{l}\text { linear, stochastic } \\
\text { "fat solution" }\end{array}$ & $\begin{array}{l}\text { linear, stochastic } \\
2 \text {-stage with recourse }\end{array}$ \\
\hline $\begin{array}{l}\text { Number of } \\
\text { considered strat. }\end{array}$ & 3 & 1 (strat. 3 from E) & 1 (strat. 3 from E) \\
\hline Evaluation period & 1 month & 1 year & 1 week \\
\hline
\end{tabular}

Summarizing, coordination of wind power and hydro power can be mutually beneficial for the wind power utility and hydro power utility. The coordination greatly decreases wind energy curtailments and also leads to more efficient utilization of the existing transmission lines, without negative economical impact on hydro power producer. The following improvements of the planning model need to be addressed in the future:

- The case study is applied to a period in the past. It is thus assumed 
that the outcomes of all stochastic variables are known when the planning for the next day is being conducted. In reality planning the realization of some stochastic variables for the current day would still be unknown. This problem would need to be dealt with in future work.

- A longer case study would need to be conducted in the future.

- The impact of the coordination on start-ups of the hydro power plants would need to be investigated. 



\section{Chapter 7}

\section{Minimization of imbalance cost trading wind power on the short term power market.}

\section{Publication $\boldsymbol{H}$}

In this chapter the strategy for minimization of imbalance costs of the wind power utility, trading wind power on the short term power market will be presented. First, some background and an overview of the previous research on this subject will be provided. Then the flow chart of the bidding strategy will be presented briefly, followed by modeling details that will be given in the subsequent sections. The developed bidding strategy is applied to the case study. The short summary of the case study and its main findings will conclude this chapter.

The present short term power markets are designed for trading conventional (dispatchable) generation. The time span after the market clearing until the delivery hour can be up to 36 hours (Scandinavia) and up to 38 hours (Spain), any deviations from the submitted production plan are penalized. Although the wind power forecasting techniques have considerably improved over the last decade, those will never give perfect results. Furthermore, the forecast error increases with increasing prediction horizon. With forecast being needed 36 or 38 hours ahead of time, wind generators may be 
subjected to substantial imbalance costs.

In the Nordic countries, all bulk electricity production must be traded through a balance responsible player. For a wind power owner there are, thus, three options available. One option is to become a balance responsible player, second is to trade wind power and have a contract with balance responsible for balancing any mismatches, third is to sell all wind power to the balance responsible player [52]. In the first case wind power owner is paying a market imbalance price for its imbalances. In the other two cases wind power owner is paying contracted imbalance price, which is often lower than market imbalance price, due to the fact that the balance responsible player has other energy sources in its portfolio and can balance wind power mismatches internally. When trading wind power on the short term power market the balance responsible player may choose the following strategies:

1. Assume wind power forecast as certain, bid it on the market and pay the imbalance penalties for the mismatches.

2. Bid the amount that minimizes expected costs for imbalances considering possible scenarios of wind power production and imbalance costs.

\subsection{Overview of previous research}

The minimization of imbalance costs of wind power utility has been previously studied in [12]. In [12] wind power production scenarios are generated using statistical methods based upon historically observed power production. The energy output of the wind farm is divided into several energy bands and, given the band where the WF production resides initially, the probabilities that the WF production resides in each of the energy bands are calculated for each forecast delay and form probability tables. There is, however, a difficulty with generating these probabilities as they require significant quantity of historical data. The drawbacks of this method, reported in [12]: one year of data is not enough to produce smooth probability tables; and, since wind exhibits seasonal behavior, probability tables are likely to differ between seasons and years. The imbalance prices are assumed deterministic in [12]. The method for minimization of imbalance costs suggested in [12] is applicable only for a small number (about 10) of energy bands. 
The same problem is also studied in [7]. The methods are rather close to [12]. The energy output of the wind farm (WF) is discretized and, given the production state, in which the WF production resides initially, the probabilities that the WF production resides in each of the production states are calculated (from historical data) for each forecast delay and form probability distributions. The imbalance prices are assumed deterministic in [7]. The optimization problem is only summarized in the paper and the details about the optimization approach are not discussed.

\subsection{Overview of the bidding strategy}

In this thesis the imbalance cost minimization, trading wind power on the spot market, is studied further.

As in Chapter 6, the "planning" of wind power production for the coming day is assumed to be performed at 11 am the day before, in order to place the hourly bids on the spot market that closes at $12 \mathrm{am}$. The bidding strategy is formulated as a stochastic optimization problem with the objective to minimize the expected imbalance costs.

Note that the wind power producer is assumed to be a "price taker" here, it means its bidding strategy does not effect power prices. In countries with small amounts of wind power (less than $5 \%$ of total power production according to a study in [58]) this is a reasonable assumption. It is also assumed that the WF has low marginal costs and its bid on the spot market is always taken.

The flowchart for the developed bidding strategy and its evaluation is given in Figure 7.1. In this section a brief overview of the flowchart is presented. The modeling details are provided in the subsequent section.

Wind power production scenarios are generated based on day ahead wind speed forecast and statistical data about the forecast error. A wind speed forecast for the coming day is obtained from, e.g., numerical meteorological programs (block A1). Wind speed forecast error scenarios are modeled (block A2) by ARMA series in the same manner as in subsection 6.4.2. The sum of wind speed forecast and forecast error scenarios represents wind speed scenarios for each hour of the coming day. Wind speed scenarios are then converted to power production scenarios (block B) as in subsection 5.3.2.

The advantage of this method is that the forecast error is modeled and added on top of the day ahead wind power production forecast that already 
accounts for seasonal and daily wind variations. In contrast to [12] one year of the forecast error data proved to be sufficient to calibrate the forecast error model [88].

In block $\mathrm{C}$, scenario reduction is applied to reduce computational effort. Same scenario reduction techniques as described in subsection 6.4.4 is used here.

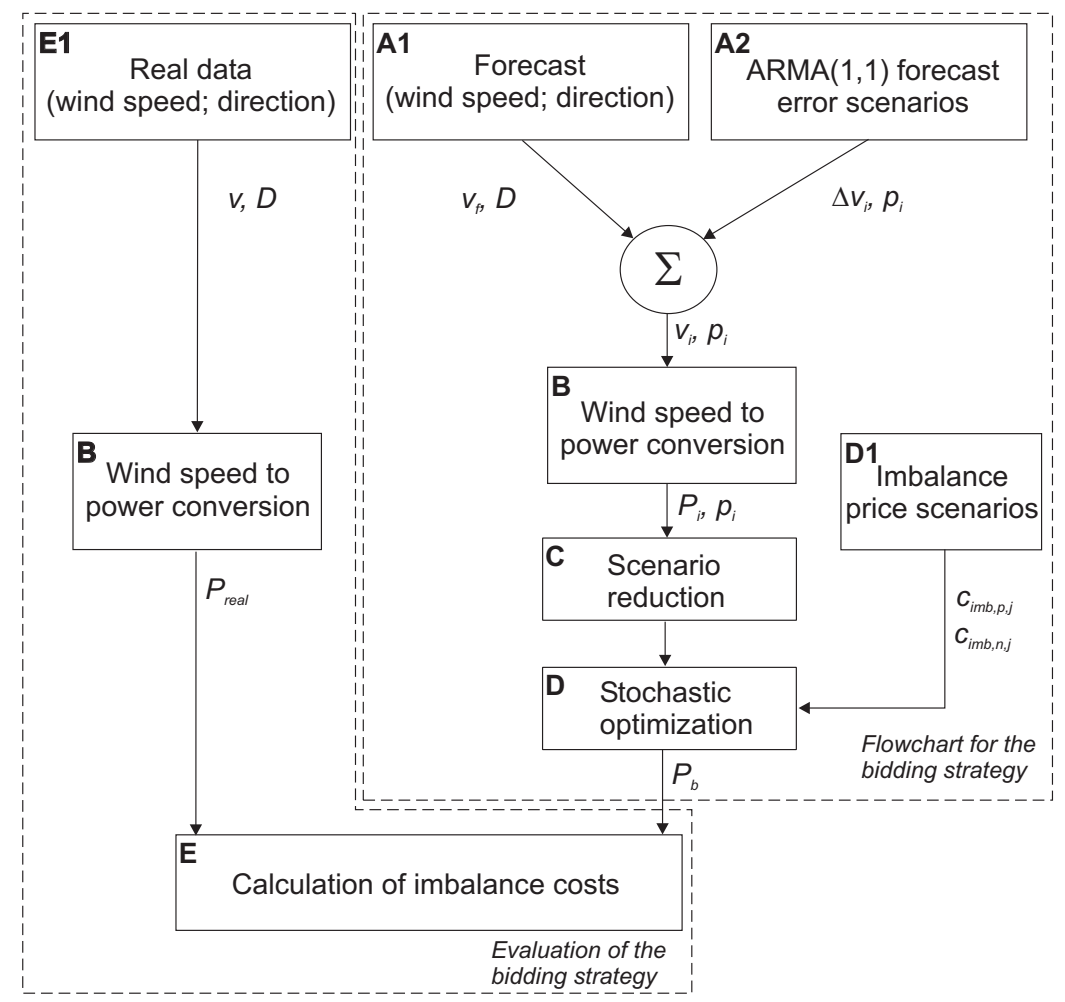

Figure 7.1: Flowchart for the bidding strategy and its evaluation.

The imbalance price depends on spot market price and regulating market prices, section 2.4.4. As an illustration, in this thesis the regulating market prices from the previous days are used as regulating price scenarios for the planning day. The spot market price is assumed deterministic or the spot price forecast can be used. From this data several imbalance price scenarios are derived (block D1). 
There is no coupling between the subsequent hours of the planning, hence the stochastic optimization problem is formulated for each hour to maximize the expected profit of the WF and, consequently, minimize the imbalance costs (block D). Mixed integer programming is used here to obtain the solution for larger number of wind power production scenarios and imbalance price scenarios.

In order to evaluate actual imbalance costs resulting from the suggested bidding strategy, it can be tested against actual data for the same period, for which forecast error statistics and imbalance prices are available. Real wind speed measurements (block E1) should be converted to power following the same procedure as wind speed scenarios above (block B). If actual power production measurements are available no conversion is needed. The actual power production data and bids, obtained from the optimization are then used to calculate imbalance costs (block E) from the suggested bidding strategy, using actual imbalance prices.

The proposed method, Figure 7.1, can be used to:

- determine the energy level to bid on the day ahead market, to minimize the imbalance costs of the WF;

- estimate the value of using better forecasting techniques.

The imbalance cost minimizing strategy is developed with Nordic power market in mind, see section 2.4 for the overview, but with some minor adjustments it can be applied in other power markets.

\subsection{Mathematical formulation}

The models of blocks A1, A2, B and C have already been discussed in details in subsections $6.4 .2,5.3 .2,6.4 .4$ respectively. The following subsections would thus present the imbalance price model, the formulation of the optimization problem as well as the expressions for calculation of actual imbalance costs (block E).

\subsubsection{Imbalance price scenarios}

In accordance with subsection 2.4.4, the imbalance prices are expressed as follows: 
- $c_{i m b, p}(k)=c^{s}(k)$, where $c^{s}(k)$ is a spot price at hour $k$, if the actor is in positive imbalance in hour $k$ and no downward regulation is undertaken;

- $c_{i m b, p}(k)=c^{d}(k)$, where $c^{d}(k)$ is a price for downward regulation at hour $k$, if actor is in positive imbalance in hour $t$ and downward regulation is undertaken with $c^{d}(k)<c^{s}(k)$;

- $c_{i m b, n}(k)=-c^{s}(k)$, where $c^{u p}(k)$ is a price for upward regulation at hour $k$, if actor is in negative imbalance in hour $k$ and no upward regulation is undertaken or $c^{u p}(k)<c^{s}(k)$;

- $c_{i m b, n}(k)=-c^{u p}(k)$, if actor is in negative imbalance in hour $k$ and upward regulation is undertaken with $c^{u p}(k)>c^{s}(k)$;

The negative sign means that the balance responsible player is paying the price for imbalance, the positive sign means that the balance responsible player is getting paid.

The spot market prices for the coming day are assumed deterministic. The regulating prices $c_{j}^{d}(k)$ and $c_{j}^{u p}(k)$ from the previous days of operation are used as regulating price scenarios for the coming day. Imbalance price scenarios $c_{i m b, p, j}(k)$ and $c_{i m b, n, j}(k)$ are then calculated as described above and probability $q_{j}$ is assigned to each scenario (block D1).

In this thesis the optimization problem and its solution as well as the general work flow for the suggested bidding strategy was of major interest therefore this simplified imbalance price model is applied. The price model does not affect the optimization method chosen in this thesis and the analysis of the optimization problem, provided in Publication $\mathrm{H}$, is also general, and does not depend on the price model. In the real application of this bidding strategy, the stochastic model of the market prices developed in [78] and briefly covered in subsection 6.4.3, can be used to obtain more realistic imbalance price scenarios.

\subsubsection{Optimization problem}

\section{Formulation}

In contrast to a multi-reservoir hydro power systems, see Chapter 6 , in wind farm(s) operation there is no coupling between subsequent hours. The stochastic optimization problem can thus be formulated separately for each 
hour of the coming day. The objective is to maximize WF owners expected profit and, consequently, minimize the imbalance costs:

$$
\max \left\{c^{s} P_{b}+\left[\begin{array}{l}
\sum_{j} c_{i m b, p, j} q_{j} \sum_{i}\left(P_{i}-P_{b}\right) p_{i}, P_{b} \leq P_{i} \\
\sum_{j} c_{i m b, n, j} q_{j} \sum_{i}\left(P_{b}-P_{i}\right) p_{i}, P_{b} \geq P_{i}
\end{array}\right]\right\}
$$

where $P_{b}$ is variable and the rest are parameters. $P_{b}$ is a bid of the WF operator to the spot market, $P_{i}$ is wind power production according to scenario $i, p_{i}$ is probability of wind speed scenario $i, q_{j}$ is probability of the imbalance price scenario $j, c^{s}$ is spot price forecast. The terms $\sum_{j} c_{i m b, j} q_{j}$ are equivalent to mean imbalance price $c_{i m b}$ of the given set of price scenarios $J$.

For the small number of the production scenarios the optimization problem (7.1) can be solved analytically, as in [12]. With ARMA series thousands of scenarios can be generated, this improves the solution, but makes it impossible to solve (7.1) by hand. Therefore here mixed integer programming is applied to solve (7.1). The hourly optimization problem is expressed as follows (block D):

$$
\begin{aligned}
& z=\max \left[c_{s p} P_{b}+\sum_{j} c_{i m b, n, j} \cdot q_{j} \cdot \sum_{i}\left(P_{b}-P_{i}\right) \times\right. \\
& \left.\times p_{i} b_{i}+\sum_{j} c_{i m b, p, j} \cdot q_{j} \cdot \sum_{i}\left(P_{i}-P_{b}\right) \cdot p_{i} \cdot\left(1-b_{i}\right)\right] \\
& \left(P_{b}-P_{i}\right) \leq M \cdot b_{i}, \forall i \in I_{r} \\
& \left(P_{i}-P_{b}\right) \leq M \cdot\left(1-b_{i}\right), \forall i \in I_{r} \\
& P_{b} \leq P_{W F},
\end{aligned}
$$

where $P_{W F}$ is total installed capacity of the WF, $b_{i}$ is a binary variable, $M$ is a large positive number that exceeds any maximum feasible value of $P_{b}$ and $I_{r}$ is a set of preserved scenarios after scenario reduction, see section 6.4.4 for brief description of scenario reduction method. $b_{i}=1$, if it is optimal to keep $P_{b} \geq P_{i}$ (underproduction), and the third term of the objective function would disappear; $b_{i}=0$, if it is optimal to keep $P_{i} \geq P_{b}$ (overproduction), and the second term of the objective function would vanish.

The detailed analysis of the solution to the optimization problem (7.2) is provided in section IV of Publication G. 


\subsubsection{Evaluation of bidding strategy}

The actual power production data and bids, obtained from the optimization are used to calculate actual imbalance costs (block E) as follows:

$$
z_{i m b}=\left[\begin{array}{l}
c_{i m b, p, r e a l}\left(P_{\text {real }}-P_{b}\right), P_{b}<P_{\text {real }} \\
c_{\text {imb }, n, \text { real }}\left(P_{b}-P_{\text {real }}\right), P_{b}>P_{\text {real }}
\end{array}\right]
$$

where, $c_{i m b, p, r e a l}$ and $c_{i m b, n, \text { real }}$ are actual imbalance prices, known ex-post for the studied hour for the balance settlement, see subsection 2.4.4. The use of actual imbalance prices allows more realistic evaluation of the imbalance cost minimizing bidding strategy compared to [12] and [7], where same imbalance prices are used for the planning and for calculation of imbalance costs.

The imbalance costs from imbalance cost minimizing bidding strategy can then be compared to imbalance costs from, e.g., bidding forecast strategy.

\subsection{Case study}

The bidding strategy has been applied in case studies. Real wind speed data and forecasted wind speeds for 2003 for East Denmark were available. For each hour of the year there is one wind speed and one wind speed forecast. These wind speeds are calculated backwards from the total wind power production of East Denmark and, thus, smoothing effect due to geographical dispersement of WTGs is imbedded in the wind speed series. For a single wind farm larger forecast error could be expected.

By using the method defined in [88] and briefly described in subsection 6.4.2, the parameters of ARMA series are estimated. Figure 6.4 in subsection 6.4.2 illustrates the standard deviations of the actual forecast error from East Denmark and the forecast error modeled with ARMA series.

Wind direction data and data about WF layouts were not available therefore the production characteristics of one V80 (Vestas, 2 MW) wind turbine is used to test the bidding strategy.

Six days from 2003 are tested. During these days, according to data, the forecast errors were large. Spot prices from corresponding hours of 2003 are used. Regulating prices from days before and after $^{1}$ the tested day were

\footnotetext{
${ }^{1}$ Such sampling is chosen here for the sake of testing, in order to use representative regulating price scenarios, i.e., if the tested day is working day, the regulating price scenarios should be sampled from the working days and vice versa.
} 
used as price scenarios to calculate respective imbalance price scenarios. The results of the bidding strategy are compared against the alternative strategy, where the wind power forecast is bidden on the spot market.

Profit evaluation is also made for the whole January 2003, see Publication $\mathrm{H}$ for more detailed results of the case study. The main conclusions are summarized in the next section.

\subsection{Conclusions}

The results of the case study have shown that imbalance cost minimizing bidding strategy generally results in higher or equal profits than the strategy where a wind power utility bids the forecasted wind power production and then pays imbalance costs. The calculation of optimal bids with suggested strategy does not require any additional data inputs and is fast with regards to computational efforts. The bidding strategy was designed having Nordic electricity market in mind, however it can be easily adjusted to fit other markets, e.g., with different market closure delay. The following improvements can be made in future:

- As the outcome of bidding strategy is sensitive to the choice of imbalance price scenarios, in the future they will be substituted by stochastic price model developed in [78] and briefly presented in subsection 6.4 .3 ;

- Here wind power producer is assumed to be a price taker, but, as it can be seen from the simulation results, the use of this bidding strategy may lead to higher imbalances in the system and thus will effect imbalance prices. This effect should also be considered in the future.

- In [7] coordination with hydro power utility on the intra-day market is used in order to minimize imbalance costs of the wind power utility. It would be interesting, to add this possibility to the coordinated planning method presented in Chapter 6 and study it further. 



\section{Bibliography}

[1] T. Ackermann, L. Söder, Wind Energy Technology and Current Status: Review, Renewable \& Sustainable Energy Reviews, Pergamon, No. 4, 2000, pp 315-374

[2] T. Ackermann (edited by), Wind Power in Power Systems, John Wiley and Sons, 2005.

[3] V. Akhmatov, Modeling of Variable-Speed Wind Turbines with Double-Fed Induction Generators in Short-Term Stability Investigations, Second International Workshop on Transmission Networks for Offshore Wind Farms, Stockholm, 2002.

[4] V. Akhmatov, H. Knudsen, M. Bruntt, A. H Nielsen, J. K. Pedersen and N.K. Poulsen, A Dynamic Stability Limit of Grid-Connected Induction Generators, IASTED International Conference POWER AND ENERGY SYSTEMS, Marbella, 2000.

[5] V. Akhmatov, H. Knudsen, A.H. Nielsen, J. K. Pedersen and N.K. Poulsen, Modelling and Transient Stability of Large Wind Farms, Electrical Power and Energy Systems 25, pp.123-144, Elsavier, 2003.

[6] V. Akhmatov, Variable-Speed Wind Turbines with Doubly-Fed Induction Generators - Part II: Power System Stability, Wind Engineering 26[3], pp.171-188, 2002.

[7] J. M. Angarita, J. G. Usoala, Combining Hydro-Generation and Wind Energy. Bidding and Operation on Electricity Spot Markets, Electric Power Systems Research, Elsevier, In press, June 2006, available at: www.sciencedirect.com 
[8] S. Arnborg, Overall Prerequisites for Expansion Large-Scale Wind Power Offshore and in Mountainous Areas, Svenska Kraftnät, Stockholm, 2002 (in Swedish)

[9] M. Asari, T. Nanahara, T. Maejima, K. Yamaguchi, T. Sato, A Study on Smoothing Effect on Output Fluctuation of Distributed Wind Power Generation, Transmission and Distribution Conference and Exhibition 2002: Asia Pacific. IEEE/PES, Vol. 2, 2002, pp 938-943

[10] Data provided by Christer Bäck, SvK

[11] H. Baleriaux, E. Jamoulle, Fr. Linard de Guertechin, Simulation de l'exploitation d'un parc de machines thermiques de production d'électricité couple à des stations de pomage, Electricite Electronique Generale, Courants Forts \& Applications, Vol. V, No. 7, 1967, pp 225-264 (in French)

[12] G. N. Bathurst, J. Weatherill, and G. Strbac, Trading Wind Generation in Short Term Energy Markets, IEEE Trans. on Power Systems, vol. 17, pp. 782-789, Aug. 2002.

[13] H. Bergström and B. Källstrand, Measuring and Modeling the Wind Climate in Mountain Valley in Northern Sweden, Wind Power Production in Cold Climate Conference, BOREAS V, Finland, 2000

[14] R.R. Booth, Power System Simulation Model Based on Probability Analysis, IEEE Transactions on Power Apparatus and Systems, Vol. PAS-91, 1972, pp 62-69

[15] S. Bolik, Grid Requirements Challenges for Wind Turbines, Fourth International Workshop on Large-Scale Integration of Wind Power and Transmission Networks for Offshore Wind Farms, Billund, Denmark, Oct. 2003.

[16] Bonus Energy A/S, Specifications of Bonus 600 kW Mk IV, 2002

[17] G.E.P. Box, G. M. Jenkins, Time Series Analysis: Forecasting and Control, Holden-Day Inc., 1976.

[18] O. Breidablik, F. Giaever, I. Glende, Innovative Measures to Increase the Utilization of Norwegian Transmission, IEEE Power Tech Conference, Bologna, 2003 
[19] P. J. Brockwell and R. A. Davis, Time Series: Theory and Methods, (2nd ed.), Springer-Verlag, 1991

[20] A. Brooke, D. Kendrick, A. Meeraus, R. Raman, R. E. Rosenthal, GAMS A User Guide, GAMS Development Corporation, 2004 available at: www.gams.com

[21] Caddet Renewable Energy, An Arctic Wind turbine in Northern Sweden, Technical Brochure No. 135, 2001, available at: www.vattenfall.se/downloads/informationsmaterial/sourvacaddet.pdf

[22] E. D. Castronuovo and J. A. Pecas Lopes, On the Optimization of the Daily Operation of Wind-Hydro Power Plant, IEEE Transactions on Power Systems, vol.19, pp. 1599-1606, Aug. 2004.

[23] P. Christiansen and J. Kristoffersen, The Wind Farm Main Controller and the Remote Control System of the Horns Rev Wind Farm, International Workshop on Large-Scale Integration of Wind Power, 2003

[24] CIGRE, Impact of Increasing Contribution of Dispersed Generation on the Power System, CIGRE Study Committee No. 37, (WG 37-23), Final Report, Paris, 1998

[25] A. J. Conejo, Self-Scheduling of a Hydro Producer in a Pool-Based Electricity Market, IEEE Transactions of Power Systems, vol. 17 pp. 1265-1272, Nov. 2002.

[26] DEFU, Connection of Wind Turbines to Low and Medium Voltage Networks, Committee report 111-E, October 1998, 2 Edition, Lyngby, Denmark.

[27] DEFU, Vindmøller Tilsluttet Net med Spcendinger under $100 \mathrm{kV}$, Teknisk Forskrift For Vindmøllers Egenskaber og Regulering, 15 draft version, 17 June 2003, Lyngby, Denmark, (in Danish), available at: www.energinet.dk

[28] D. Douglas, Can Utilities Squeeze More Capacity out of the Grid?, Transmission and Distribution World, November 2003, pp 38-43, available at: www.tdworld.com 
[29] J. Dupacova, N. Gröwe-Kuska and W. Römisch Scenario Reduction in Stochastic Programming an Approach Using Probability Metrics, Mathematical Programming, Ser. A 95: 2003, pp. 493-511.

[30] Electricity Association, Engineering Recommendation G59/1 (ER G59 1990), Recommendations for the Connection of Embedded Generating Plant to the Regional Electricity Companies Distribution System, London, UK, 1990

[31] Electricity Association,Engineering Recommendation G75 (ER G59 1996), Recommendations for the Connection of Embedded Generating Plant to the Public Electricity Supplies' distribution systems above 20 $k V$ or with outputs over 5 MW, London, UK, 1996

[32] Eltra, Specifications for Connecting Wind Farms to the Transmission Networks, Second Edition, Fredericia, Denmark, 2002

[33] E.ON Netz GmbH, Netzanschlussregeln, Hoch- und Höchstspannung (English version: Grid Code, High and extra high voltage), Bayreuth, Germany, Aug. 2003, available at: www.eon-netz.com/

[34] I. Erlich, U. Bachmann, Crid Code Requirements Concerning Connection and Operation of Wind Turbines in Germany IEEE Power Engineering Society General Meeting, pp 1253 - 1257 vol. 2, June 2005

[35] ESB National Grid, Grid Code, Draft Version 1.0, Ireland, Feb. 2002.

[36] European Commission, Proposal for a Regulation of the European Parliament and of the Council on Conditions for Access to the Network for Cross-Border Exchanges in Electricity, Brussels, 2001, available at: www.europa.eu.int/comm/energy/library/regulation-en.pdf

[37] European Transmission System Operators, Definitions of Transfer Capacities in Liberalized Electricity Markets, Final report, Apr. 2001, available at: www.etso-net.org

[38] European Wind Energy Association, webpage:www.ewea.org

[39] M.C. Ferris, Matlab and GAMS: Interfacing Optimisation and Visualisation Software, Mathematical Programming, 
Technical Report 98-19, Computer Science Dept., University of Wisconsin-Madison, November 1998, available at: www.cs.wisc.edu/math-prog/matlab.html

[40] U. Focken, M. Lange, K. Mönnich, H-P. Waldl, H. G. Beyer, A. Luig, Short-Term Predication of Aggregated Power Output of Wind Farms - a Statistical Analysis of the Reduction of Prediction Error by Spatial Smoothing Effect, Journal of Wind Engineering and Industrial Aerodynamics, Mar. 2002, pp 231-246, available at: www.sciencedirect.com

[41] O. B. Fosso, A. Gjelsvik, A. Haugstad and B. Mo, I. Wangensteen, Generation Scheduling in a Deregulated System. Norwegian case, IEEE Transactions on Power Systems, vol. 14, pp. 75-81,Feb. 1999

[42] P. Gardner, H. Snodin, A. Higgins, S. McGoldrick, The Impacts of Increased Levels of Wind Penetration on the Electricity Systems of the Republic of Ireland and Northern Ireland: Final report, Garrad Hassan and Partners Limited, 2003

[43] R. Gasch, J. Twele, Wind Power Plants: Fundamentals, Design, Construction and Operation, Solarpraxis Berlin, James \& James, London, 2002

[44] P. Giorisetto, K. F. Utsurogi, Development of a New Procedure for Reliability Modeling of Wind Turbine Generators, IEEE Transaction of Power Apparatus and Systems, Vol. PAS-102, No. 1, 1983, pp 134-143

[45] Government bill 2001/02:143, Collaboration for Secure, Efficient and Environmentally Friendly Energy Supply, Stockholm, 2001 (in Swedish)

[46] G. R. Grimmett, D. R. Strizaker, Probability and Random Processes, Oxford: Clarendon Press, 1992, pp 33-114.

[47] H. Habibollahzadeh and J.A. Bubenko, Applications of Decomposition Techniques to Short-Term Operation Planning of Hydro-Thermal Power Systems, IEEE Transactions on Power Systems, vol. PWRS-1, pp.41-47, Feb. 1986. 
[48] M. O. L. Hansen, Basic Rotor Aerodynamics Applied to Wind Turbines, Department of Energy Engineering, Fluid Mechanics, Technical University of Denmark, 1998.

[49] H-J. Haubrich, Ch. Zimmer, K. von Sengbusch, W. Fritz, S. Kopp, Analysis of Electricity Network Capacities and Identification of Congestion, Report commissioned by the European Commission Directorate-General Energy and Transport, 2001

[50] M. Häusler, G. Schlayer, G. Fitterer, Converting AC Power Lines to DC for Higher Transmission Ratings, ABB Review, No. 3, 1997, pp 4-11

[51] H. Heitsch and W. Römisch, Scenario Reduction Algorithms in Stochastic Programming, Computational Optimization and Applications, Kluwer Academic Publishers, No. 24, pp. 187-206, 2003.

[52] H. Holttinen, The Impact of the Large Scale Wind Power Production on the Nordic Electricity System, Doctoral Thesis, VTT Publications, ISBN 951-38-6427-8, Dec. 2004, available: www.vtt.fi/inf/pdf

[53] H. E. House, P. D. Tuttle, Carrying Capacity of ACSR, AIEE Winter General Meeting, New York, 1958

[54] IEEE/PES Power System Stability Subcommittee Special Publication, Voltage Stability Assessment: Concepts, Practices and Tools, Final document, Aug. 2002

[55] C. G. Justus, Winds and System Performance, Franklin Institute Press, Philadelphia, 1978

[56] P. Kall, S. W. Wallace, Stochastic Programming, 1st ed., John Wiley and Sons, 1994.

[57] I. Katic, D. Højstrup, N. O. Jensen, A Sample Model for Cluster Efficiency, European Wind Energy Association Conference, 1986.

[58] B. Kirby, M. Milligan, Y. Makarov, D. Hawkins, K. Jackson, H. Shiu, California Renewables Portfolio Standard. Renewable Generation Integration Cost Analysis. Phase I., California Energy Commission/California Public Utilities Commission, 2003, available at: www.cwec.ucdavis.edu/rpsintegration/ 
[59] F. W. Koch, I. Erlich , F. Shewarega and U. Bachmann, Simulation of the Dynamic Interaction of Large Offshore Wind Farms with the Electric Power System, OWEMES, Naples, Italy . 2003.

[60] M. Korpås, A. T. Holen, R. Hildrum, Operation and Sizing of Energy Storage for Wind Power Plants in a Market System, Electrical Power \& Energy Systems, No. 25, 2003, pp 599-606, available at: www.elsevier.com/locate/ijepes

[61] M. Korpås, J. O. G. Tande, K. Uhlen, E. S. Hause and T. Gjengedal, Planning and Operation of Large Wind Farms in Areas with Limited Power Transfer Capacity, European Wind Energy Conference, 2006

[62] S. Krau, G. Lafrance, L. Lafond, Large Scale Wind Farm Integration: a Comparison with a Traditional Hydro Option, EWEA Global Wind Power Conference, Paris, 2002

[63] P. Kundur, Power System Stability and Control, The EPRI Power System Engineering Series, McGraw-Hill, Inc., 1993

[64] A. Larsson, The Power Quality of Wind Turbines, PhD thesis, Dept. of Electric Power Engineering, Chalmers University of Technology, 2000, available at: www.elkraft.chalmers.se

[65] P. Ledesma, J. Usaola and J. L. Rodriguez, Transient Stability of a Fixed Speed Wind Farm, Renewable Energy 28, pp.1341-1355, 2003.

[66] M. Lommerdal, Simulation of Congestion Management Methods, IEEE Power Tech Conference, Bologna, 2003

[67] D. Milborrow, L. Harrison, J. Jackson, S. Knight, N. Martin, M. O'Bryant, M. McGovern, Forecasting Output (collection of articles), Wind Power Monthly, pp 37-46, Dec. 2003.

[68] Ministry of Sustainable Development, Renewable Electricity with Green Certificates, Government Bill 2005/06:154, Facts Sheet, May 2006

[69] V. Neimane, Collaboration between Wind Power and Hydropower, Vattenfall Utveckling AB, Report No. U03:78, Stockholm, 2003

[70] O. Nilsson, D. Sjelvgren, Mixed-integer Programming Applied to Short-Term Planning of a Hydro-Thermal System, IEEE Transactions on Power Systems, Vol. 11 No. 1, 1996, pp 281-286 
[71] Nordel, Annual Report, 2002, available at: www.nordel.org

[72] Nordel, Annual Report, 2003, available at: www.nordel.org

[73] Nordel, Congestions Management in Electrical Networks, in Nordel Annual Report, 2000, pp 35-47

[74] Nordic Wind Power AB, Pilotprojekt Anjona-Brakko, Project discription, 2003 (in Swedish)

[75] P. Norgaard, H. Holttinen, A Multi-turbine Power Curve Approach, Nordic Wind Power Conference, Chalmers University of Technology, March 2002, Göteborg

[76] J. R. Norris, Markov Chains, Cambridge university Press, 1997.

[77] M. Olsson, L. Söder, Generation of Regulation Power Price Scenarios, PMAPS, 2004.

[78] M. Olsson, Optimal Regulating Power Marker Bidding Strategy in Hydropower Systems, Licentiate Thesis, Dept. of Electrical Engineering, Royal Institute of Technology, Stockholm, 2005, available at: http://www.diva-portal.org/kth/theses/abstract.xsql?dbid $=596$

[79] Vindforsk, Operation Follow up of Wind Turbines, Wind Statistics, Monthly report May 2006 and Annual report 2005 (in Swedish), available at: www.vindenergi.org/driftuppfolj.htm

[80] M. Palsson, T. Toftevaag, K. Uhlen, J. O. G. Tande, Large-Scale Wind Power Integration and Voltage Stability Limits in Regional Networks, Power Engineering Society Summer Meeting, 2002 IEEE, Vol. 2, July 2002, pp $762-769$

[81] Renewable Electricity Facts Sheets, EU Countries, 2003 , available at: www.renewable-energy-policy.info/relec/sweden/

[82] Scottish Hydro Electric, Guidance Note for the Connection of Wind Farms, Issue No. 2.1.4, Dec. 2002.

[83] C. Shuyong, D. Huizhu, B. Xaiomin, Z. Xiaoxin, Evaluation of Grid Connected Wind Power Plants, POWERCON '98, International Conference, Vol. 2, 18-21 Aug. 1998, pp. 1208-1212. 
[84] Sintef Energiforskning AS, Retningslinjer for Nettilkobling av Vindkraftverk (revidert utgave) , Trondheim, Norway, 2001 (in Norwegian).

[85] J.G. Slootweg and W. L. Kling, Modelling and Analysing Impacts of Wind Power on Transient Stability of Power Systems, Wind Engineering 25[6], 3-20. 2001.

[86] J. G. Slootweg, E. de Varies, Inside Wind Turbines - Fixed vs. Variable Speed Renewable energy world, Vol. 6, No. 1, 2003, available at: www.jxj.com/magsandj/rew

[87] L. Söder, Wind Power Systems, Encyclopedia of Physical Science and Technology, Third Edition, Vol. 17, 2002, p. 842

[88] L. Söder, Simulation of Wind Speed Forecast Errors for Operation Planning of Multi-Area Power System, International Conference on Probability Methods Applied to Power Systems (PMAPS), 2004

[89] L. Söder, A Mixed Rule Based Linear Programming Applied to Daily Operation Planning of a Hydro Power System, IEEE PowerTech Conference, 1995 pp. 93-98.

[90] P. Sørensen, A. K. Unnikrishnan and S. A. Mathew, Wind Farms Connected to Weak Grids in India, Wind Energy 4[3], pp.137-149, 2001.

[91] Svensk Energi, Energifakta, available at: http://www.svenskenergi.se/energifakta/tillverkas.htm

[92] Svensk Energi, AMP - Anslutning av Mindre Produktionsanläggningar till Elnätet, Stockholm, Sweden (in Swedish).

[93] Svenska Kraftnät, Affärsverket Svenska Kraftnäts Föreskrifter om Driftsäkerhetsteknisk Utformning av Produktionsanläggningar, Stockholm, 2004 (in Swedish)

[94] Svenska Kraftnät, The Swedish Electricity Market and the Role of Svenska Kraftnät, Sweden, Nov. 2004, available at: www.svk.se

[95] Svenska Kraftnät, Avtal om Balansansvar m.m. med balansreglering , 2005-10-03,(in Swedish) avaialble at: www.svk.se 
[96] Swedish Standard SS 04240807, Aluminium Stranded Conductors, Steel Reinforced for Overhead Lines, ACSR

[97] J. O. G. Tande, K. Uhlen, Cost Efficient Grid Integration of Large Wind Farms, EWEA European Wind Energy Conference, Madrid, 2003

[98] J. O. G. Tande, K. Uhlen and T. Gjengedal, Options for Large Scale Integration of Wind Power, IEEE PowerTech Conference, St. Petersburg 2005.

[99] C. W. Taylor, Power System Voltage Stability, The EPRI Power System Engineering Series, McGraw-Hill, Inc., 1994

[100] K. Uhlen, G.H. Kjølle, G.G. Løvås, Ø. Breidablik, A Probabilistic Security Criterion for Determination of Power Transfer Limits in a Deregulated Environment, CIGRE Session, Paris, 2000

[101] T. Van Cutsem, C. Vournas, Voltage stability of Electric Power Systems, Kluwer Academic Publisher, Dordrecht, 1998

[102] Vereinigung Deutscher Elektrizitätswerke, Eigenerzeugungsanlagen am Mittelspannungsnetz, Richtlinie für Anschluss und Parallelbetrieb von Eigenerzeugungsanlagen am Mittelspannungsnetz, 2 Edition, Frankfurt, Germany, 1998 (in German)

[103] K.-O. Vogstad, Utilizing the Complementary Characteristics of Wind Power and Hydropower through Coordinated Hydro Production Scheduling using EMPS Model, Nordic Wind Energy Conference, Trondheim, 2000, available at: www.stud.ntnu.no/ klausv

[104] K.-O. Vogstad, H. Holttinen, A. Botterud, J. O. G. Tande, System Benefits of Coordinating Wind Power and Hydropower in a Deregulated Market, Wind Power for the 21st century, Kassel, 2000, available at: www.stud.ntnu.no/ klausv

[105] L. J. Vries, Capacity Allocation in a Restructured Electricity Market: Technical and Economic Evaluation of Congestion Management Methods on Interconnectors, IEEE Power Tech Conference, Porto, 2001 
[106] X. Wang, H-Z Dai, R. J. Thomas, Reliability of Large Wind Farms and Associated Electric Utility Interface Systems, IEEE Transactions Power Apparatus and Systems, Vol. PAS-103, No. 3, 1984, pp 569-575 



\section{Appendix A}

\section{Mathematical definitions}

\section{A.1 Correlation Coefficient}

The correlation coefficient is a quantity, which gives the quality of the least square fitting to the original data. To define the correlation coefficient let us first consider the sum of squared values $s s_{x x}, s s_{y y}, s s_{x y}$ of a set of $n$ points $\left(x_{i}, y_{i}\right)$ about their respective means.

$$
\begin{gathered}
s s_{x x}=\sum_{i=1: n}\left(x_{i}-\bar{x}\right)^{2}=\sum_{i=1: n} x_{i}^{2}-n \bar{x}^{2} \\
s s_{y y}=\sum_{i=1: n}\left(y_{i}-\bar{y}\right)^{2}=\sum_{i=1: n} y_{i}^{2}-n \bar{y}^{2} \\
s s_{x y}=\sum_{i=1: n}\left(x_{i}-\bar{x}\right)\left(y_{i}-\bar{y}\right)=\sum_{i=1: n} x_{i} y_{i}-n \bar{x} \cdot \bar{y}
\end{gathered}
$$

For linear least square fitting, the coefficient $b$ in $y=a+b x$ is given by:

$$
b=\frac{n \sum_{i=1: n} x_{i} y_{i}-\sum_{i=1: n} x_{i} \sum_{i=1: n} y_{i}}{n \sum_{i=1: n} x_{i}^{2}-\left(\sum_{i=1: n} x_{i}\right)^{2}}=\frac{s_{x y}}{s_{x x}}
$$

and coefficient $b^{\prime}$ in $x=a^{\prime}+b^{\prime} y$ is given by

$$
b^{\prime}=\frac{n \sum_{i=1: n} x_{i} y_{i}-\sum_{i=1: n} x_{i} \sum_{i=1: n} y_{i}}{n \sum_{i=1: n} y_{i}^{2}-\left(\sum_{i=1: n} y_{i}\right)^{2}}=\frac{s_{x y}}{s_{y y}}
$$


The correlation coefficient $r^{2}$ is then defined by

$$
r=\sqrt{b b^{\prime}}=\frac{n \sum_{i=1: n} x_{i} y_{i}-\sum_{i=1: n} x_{i} \sum_{i=1: n} y_{i}}{\sqrt{\left(n \sum_{i=1: n} x_{i}^{2}-\left(\sum_{i=1: n} x_{i}\right)^{2}\right)\left(n \sum_{i=1: n} y_{i}^{2}-\left(\sum_{i=1: n} y_{i}\right)^{2}\right)}}
$$

\section{A.2 Derivation of mean and variance of the Weibull distribution}

The definition of mean value and variance are

$$
\begin{gathered}
\bar{v}=\int_{0}^{\infty} v f_{V}(v) d v \\
\sigma^{2}=\int_{0}^{\infty}(v-\bar{v})^{2} f_{V}(v) d v
\end{gathered}
$$

The probability density function of the Weibull distribution is defined as follows:

$$
f_{V}(v)=\frac{\beta}{\alpha}\left(\frac{v}{\alpha}\right)^{\beta-1} e^{-\left(\frac{v}{\alpha}\right)^{\beta}} \text { for } v \geq 0
$$

Substituting (A.9) to (A.7):

$$
\begin{aligned}
\bar{v} & =\int_{0}^{\infty} v \frac{\beta}{\alpha}\left(\frac{v}{\alpha}\right)^{\beta-1} e^{-\left(\frac{v}{\alpha}\right)^{\beta}} d v \\
& =\left\{\left(\frac{v}{\alpha}\right)^{\beta}=t, v=\alpha t^{\frac{1}{\beta}}, d v=\frac{\alpha}{\beta} t^{\frac{1}{\beta}-1} d t\right\} \\
& =\int_{0}^{\infty} \alpha t^{\frac{1}{\beta}} \frac{\beta}{\alpha}\left(\frac{\alpha t^{\frac{1}{\beta}}}{\alpha}\right)^{\beta-1} e^{-\left(\frac{\alpha t^{\frac{1}{\beta}}}{\alpha}\right)^{\beta}} \frac{\alpha}{\beta} t^{\frac{1}{\beta}-1} d t \\
& =\alpha \int_{0}^{\infty} e^{-t} t^{\left(\frac{1+\beta}{\beta}-1\right)} d t
\end{aligned}
$$

Definition of gamma function is:

$$
\Gamma(x)=\int_{0}^{\infty} e^{-t} t^{x-1} d t
$$


Thus (A.10) is simplified as follows:

$$
\bar{v}=\alpha \Gamma\left(1+\frac{1}{\beta}\right)
$$

Similarly,

$$
\begin{aligned}
\sigma^{2} & =\int_{0}^{\infty}(v-\bar{v})^{2} \frac{\beta}{\alpha}\left(\frac{v}{\alpha}\right)^{\beta-1} e^{-\left(\frac{v}{\alpha}\right)^{\beta}} d v \\
& =\alpha^{2} \int_{0}^{\infty} e^{-t} t^{\frac{\beta+2}{\beta}-1} d t-2 \bar{v} \int_{0}^{\infty} e^{-t} t^{\frac{\beta+1}{\beta}-1} d t+\bar{v} \int_{0}^{\infty} e^{-t} t^{\frac{\beta}{\beta}-1} d t \\
& =\alpha^{2} \Gamma\left(1+\frac{2}{\beta}\right)-\bar{v}^{2}
\end{aligned}
$$


